\title{
Materials and Fuels Complex FY-21 - FY-25 Five-Year Mission Strategy
}




\section{DISCLAIMER}

This information was prepared as an account of work sponsored by an agency of the U.S. Government. Neither the U.S. Government nor any agency thereof, nor any of their employees, makes any warranty, expressed or implied, or assumes any legal liability or responsibility for the accuracy, completeness, or usefulness, of any information, apparatus, product, or process disclosed, or represents that its use would not infringe privately owned rights. References herein to any specific commercial product, process, or service by trade name, trade mark, manufacturer, or otherwise, does not necessarily constitute or imply its endorsement, recommendation, or favoring by the U.S. Government or any agency thereof. The views and opinions of authors expressed herein do not necessarily state or reflect those of the U.S. Government or any agency thereof. 
INL/EXT-21-61296

Revision 1

\section{Materials and Fuels Complex FY-21 - FY-25 \\ Five-Year Mission Strategy}

June 2021

Idaho National Laboratory Idaho Falls, Idaho 83415

http://www.inl.gov

Prepared for the

U.S. Department of Energy

Office of Nuclear Energy

Under DOE Idaho Operations Office

Contract DE-AC07-05ID14517 
MFC FIVE-YEAR MISSION STRATEGY

Page intentionally left blank 


\section{EXECUTIVE SUMMARY}

The Idaho National Laboratory (INL), through its designated mission of advancing innovative nuclear energy solutions, is actively engaged in the research, development, demonstration and deployment of advanced nuclear technology, as well as in fostering private-public partnership for technology development. Key to the success of INL's mission is the Materials and Fuels Complex (MFC), the only complex in the U.S. that hosts a world-class assemblage of facilities, capabilities and instruments for handling, testing, and characterizing radioactive materials. Driven by its mission/vision of "Engineering and Experiments that Drive the World's Nuclear Energy Future," MFC is at the center of INL's - and indeed the Department of Energy's advanced nuclear technology development initiatives, providing essential capabilities such as engineering-scale high-assay low-enriched uranium (HALEU) fuel production, reactor demonstration facilities, post-irradiation examination, and transient irradiation testing. Furthermore, MFC provides an ideal environment for test beds that are utilized for research, development and demonstration (RD\&D) activities on used fuel treatment, nuclear nonproliferation, forensics, and nuclear power sources used for space exploration missions conducted by the National Aeronautics and Space Administration (NASA).

To accomplish the strategic objectives of the INL mission and prepare for upcoming RD\&D needs, MFC will focus on delivering the following critical-tosuccess outcomes during the FY-21 - FY-25 timeframe:

1. Enable and accelerate the demonstration, testing, and operational deployment of advanced reactors, working in close collaboration with the National Reactor Innovation Center (NRIC), NASA and private partners

2. Fabricate and supply innovative nuclear fuels for demonstration and test reactors, and advance technologies and processes for the treatment of used fuel

3. Perform irradiation, analysis and testing of fuel and materials benefiting nuclear applications ranging from improved performance of operating reactors to radioisotope production

4. Provide components and/or technology to meet NASA objectives for radioisotope power generation

5. Fulfill environmental stewardship commitments.

These outcomes will be achieved through a strategy of:

- Striving for operational excellence and best-in-class safety performance via the execution of the MFC Operations Management Improvement strategy

- Continuing to develop the scientific and engineering expertise that underpins the MFC core competencies

- Executing the 5-Year Investment plan, including the construction of a new reactor fuels research laboratory

- Continuing to implement the MFC User Facility model

- Collaborating actively with other INL directorates, government agencies, private industry partners, other national laboratories, and academia to 
grow the MFC user base.

There are some significant challenges that must be overcome to successfully deliver on these commitments in the next five years. For example, progress must continue on drastically cutting the development time for transitioning innovative concepts from the laboratory to deployment, securing the investment needed for maintaining and upgrading aging facilities as well as adding new facilities, and attracting and retaining the talent needed for mission performance. Furthermore, the MFC organization must execute infrastructure projects flawlessly, responsibly manage legacy materials, and continuously improve how MFC operations are conducted.

MFC has made progress in addressing these risks in recent years, as reflected in the significant increases observed from FY-16 to FY-20 in the areas of MFC infrastructure utilization, number of RD\&D capabilities, and investment in research infrastructure. Pursuing the MFC strategy and delivering on the critical outcomes outlined above will enable MFC to build on those successes, and play a pivotal role in supplying the world with safe, affordable, clean and reliable energy, combating climate change, and regaining U.S. leadership in advanced reactor technology. 


\section{CONTENTS}

EXECUTIVE SUMMARY ……………………………………………………………

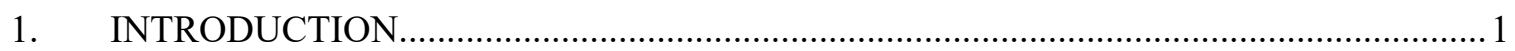

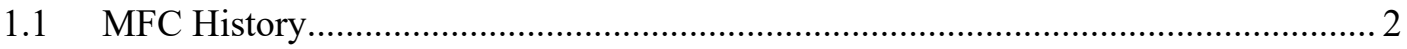

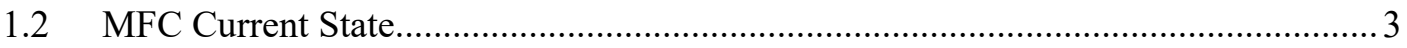

$1.3 \quad$ Purpose

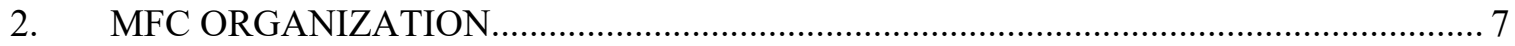

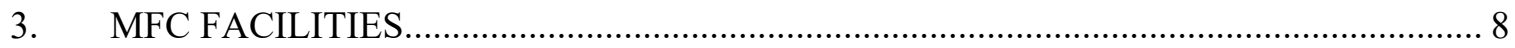

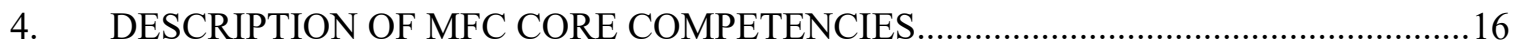

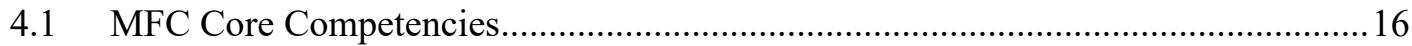

4.1.1 Nuclear Fuels Fabrication.......................................................................... 16

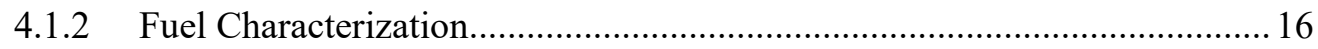

4.1.3 Characterization of Radiation Damage in Cladding and In-Core Structural

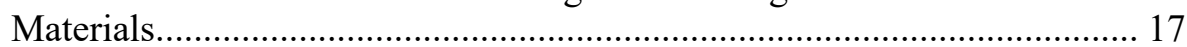

4.1.4 Fuel Recycling and Nuclear Material Management................................... 17

4.1.5 Transient Irradiation Testing.....................................................................17

4.1.6 Nuclear Nonproliferation and Nuclear Forensics..................................... 18

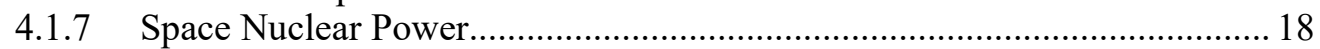

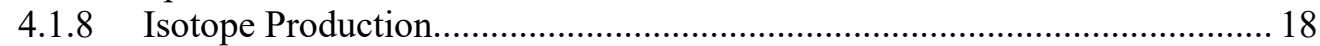

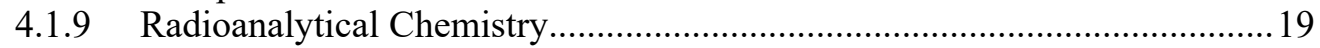

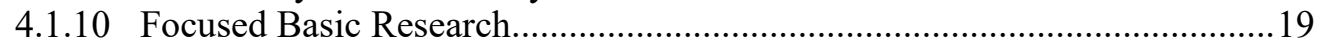

4.2 Alignment of MFC Competencies with INL Core Capabilities............................... 19

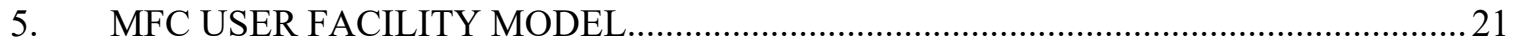

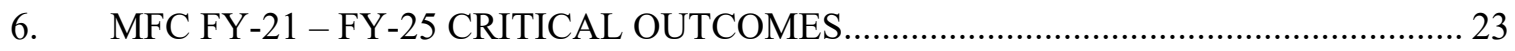

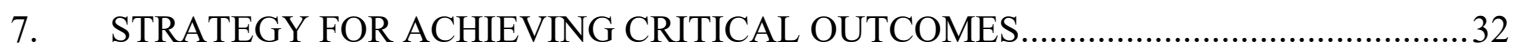

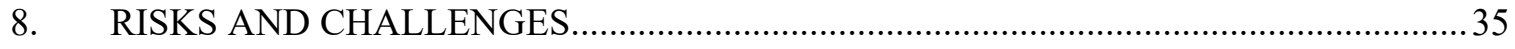

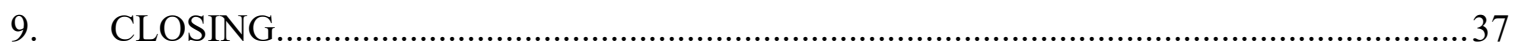

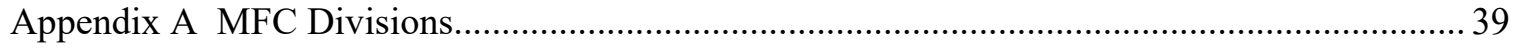

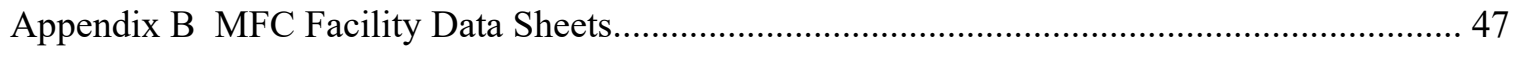

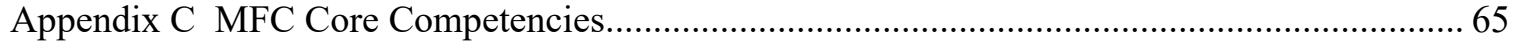

Appendix D Flow Down of INL Strategic Objectives to MFC Critical Outcomes..................... 102

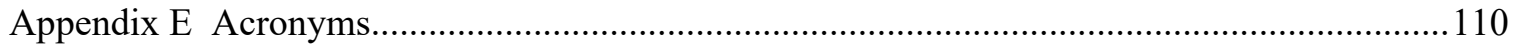




\section{FIGURES}

Figure 1. Vision for INL contributions to advanced reactor development and deployment............ 2

Figure 2. Photograph of the INL Materials and Fuels Complex (top) and MFC map showing key

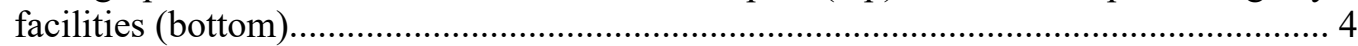

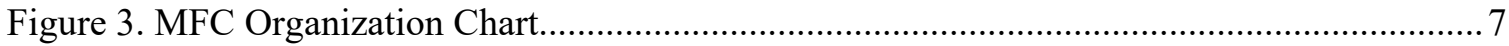

Figure 4a. Existing nuclear RD\&D capabilities at MFC: Fabrication...........................................

Figure 4b. Existing nuclear RD\&D capabilities at MFC: Irradiation........................................... 10

Figure 4c. Existing nuclear RD\&D capabilities at MFC: Characterization...................................11

Figure 4d. Existing nuclear RD\&D capabilities at MFC: PIE at HFEF/NRAD.............................12

Figure 4e. Existing nuclear RD\&D capabilities at MFC: PIE at FCF, SPL (planned), and EML.

Figure 4f. Existing nuclear RD\&D capabilities at MFC: PIE at AL, FASB, IMCL, and CAES... 14

Figure 4g. Existing nuclear RD\&D capabilities at MFC: SSPSF, EDL, and INTEC .................... 15

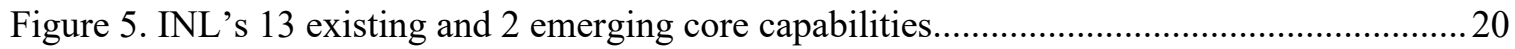

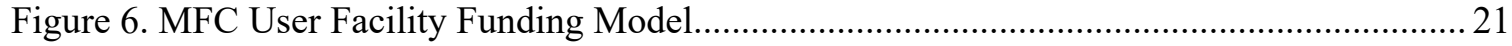

Figure 7. When completed, the MFC Sample Preparation Laboratory (SPL) will provide INL with a central point for collaborations with universities, industry partners, and other DOE user facilities on research involving irradiated structural and cladding materials......... 37

Figure C-1. Sintered high-density $\mathrm{U}_{3} \mathrm{Si}_{2}$ pellets (left) and $\mathrm{U}_{3} \mathrm{Si}_{2}$ microstructure (right)...............68

Figure C-2. Comparison of the effect of the oxygen-to-metal ratio (i.e., $\mathrm{O} / \mathrm{M}$ ) in minor actinide mixed oxide fuel. A lower oxygen-to-metal ratio results in reduced fuel-cladding chemical interaction.

Figure C-3. Next-generation nuclear reactor fuels are designed to be more efficient and resistant to accident conditions. TRISO fuel contains a layer of silicon carbide that serves as the primary containment for radioactive material (center). Researchers have subjected TRISO fuel to extreme temperatures well above postulated accident conditions and found that most fission products remained inside the fuel particles.

Figure C-4. An optical micrograph of an irradiated low-enriched uranium monolithic fuel plate showing laminated fuel structure (top) and fuel microstructure (bottom) after irradiation to a fission density in excess of $4.1 \times 10^{21}$ fissions $/ \mathrm{cm}^{3}$, showing fission-gas bubbles within recrystallized regions, remnants of original grains, and precipitates.

Figure C-5. Fabrication process modeling can be used to determine optimum casting mold geometry and thermal conditions, reducing time for development of advanced fuel fabrication technology....

Figure C-6. Laser additive manufacturing is being developed and applied for use in the manufacturing of advanced materials, for example, turbine engine components. The method will be applied to the development of advanced nuclear fuels at MFC............ 75

Figure C-7. Transmission electron microscopy images of an ordered array of fission gas bubbles in U-Mo fuel at high burnup. The ordered array of high-pressure gas bubbles provides a stable and efficient mechanism for storing fission gas (INL/EXT-10-20466)...

Figure C-8. Thermal conductivity measurements of $\mathrm{U}_{3} \mathrm{Si}_{2}$ using several methods comparing different length scales and a wide range of temperatures. (a) Scanning electron 
microscopy image of an $\mathrm{U}_{3} \mathrm{Si}_{2}$ sample, (b) reconstructed microstructure and mesh in MOOSE for MARMOT calculations, and (c) thermal conductivity of $\mathrm{U}_{3} \mathrm{Si}_{2}$ as a function of temperature. The solids symbols are experimental measurements from literature and INL. TCM (i.e., thermal conductivity microscope) and PPMS (i.e., physical property measurement system) results are shown as the solid triangles. The MARMOT results, based on the reconstructed mesh, are represented by the open triangles.

Figure C-9. Silver transport through the silicon carbide layer in TRISO fuel has been a known issue for more than four decades, but has not been understood. Analysis using advanced PIE in HFEF, AL, and ORNL, coupled with high-resolution transmission electron microscopy is now helping to identify transport paths and understand the mechanism.

Figure C-10. Focused ion beam sample preparation at MFC allows INL staff to conduct fuel experiments at other national user faculties. An irradiated U-Mo fuel sample was prepared for characterization at the Advanced Photon Source at Argonne National Laboratory. Access to Advanced Photon Source beam lines provides a combination of three-dimensional data on fuel behavior that is not otherwise available, such as threedimensional phase analysis, three-dimensional grain size analysis, grain orientation, lattice parameters, microstrain, dislocation density, and pores, cracks, and bubbles.....80

Figure C-11. Thin-walled tubing is being developed as an alternative to zircaloy cladding for use in LWRs..

Figure C-12. IASCC test rigs for high-activity materials.

Figure C-13. Irradiated X-750 nickel alloy specimens (left) were prepared by focused ion beam (right) for Atomic Energy Canada Limited. This joint work helps to address the root cause of a material performance issue in CANDU reactors and define improved material specifications.

Figure C-14. Cutaway sketch of the TREAT reactor illustrating core configuration and accessibility to the core for emplacement of experiment vehicles..

Figure C-15. INL researchers have demonstrated a new sample preparation technique that makes it easier to examine irradiated fuel at the nanoscale. The new technique uses an ion beam to mill material sections that are just tens of nanometers thick. A platinum layer (i.e., the blue square) protects the surface and an Omniprobe needle (i.e., gray) is used to lift the tiny sample. After preparation, the sample has low radiological activity and can be used for a variety of characterization activities that probe fundamental properties

Figure C-16. Examination using transmission electron microscopy shows that the unusual fission gas bubble superlattice that forms in U-Mo fuel during irradiation and is retained to ultra-high burnup...

Figure C-17. Physical Property Measurement System (DynaCool-9, currently installed at the INL Idaho Research Center). Availability of this capability in IMCL will result in unique capability for understanding the fundamental properties of the actinides and actinidebearing ceramics and alloys. 


\section{TABLES}

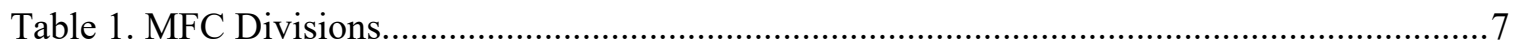

Table 2. Principal MFC facilities (website links are listed when available)...................................8

Table 3. FY-21 - FY-25 Activities: Enable and accelerate the demonstration, testing, and

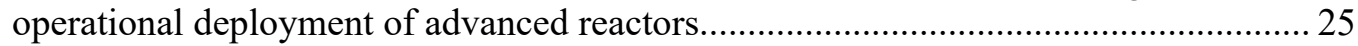

Table 4. FY-21 - FY-25 Activities: Fabricate and supply innovative nuclear fuels for demonstration and test reactors, and advance technologies and processes for treatment

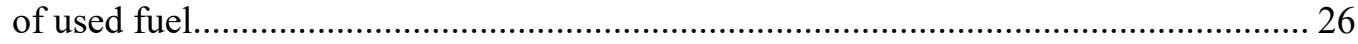

Table 5. FY-21 - FY-25 Activities: Perform irradiation, analysis and testing of fuel and materials

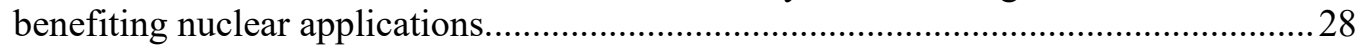

Table 6. FY-21 - FY-25 Activities: Provide components and/or technology to meet NASA

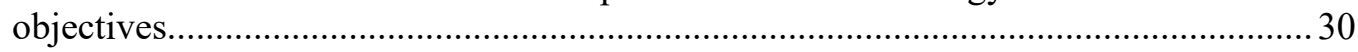

Table 7. FY-21 - FY-25 Activities: Fulfill environmental stewardship commitments.................. 31

Table 8. FY-21 - FY-25 Activities: Strategy for achieving critical outcomes................................ 33

Table D-1. INL Strategic Objectives Supported by MFC and Flow down to MFC Critical Outcomes. 


\section{INTRODUCTION}

The Materials and Fuels Complex (MFC) is home to expert personnel and a unique infrastructure that serve the mission of the Idaho National Laboratory (INL). INL is a multi-program Department of Energy (DOE) laboratory. It is tasked by the DOE Office of Nuclear Energy (DOE-NE) with the core responsibility for leading and conducting nuclear energy research, development, and demonstration (RD\&D) in support of DOE-NE's mission to advance nuclear energy science and technology to meet U.S. energy, environmental, and economic needs ${ }^{\mathrm{a}}$. INL also contributes significantly to the advancement of national and homeland security-related technologies as well as technologies for non-nuclear energy generation. These responsibilities are all reflected in the mission and vision statements of INL:

- Vision: INL will change the world's energy future and secure our nation's critical infrastructure

- Mission: Discover, demonstrate, and secure innovative nuclear energy solutions, other clean energy options, and critical infrastructure.

The nuclear energy responsibility of the INL mission has gained prominence due to increasing agreement in the U.S. that the reduction needed in greenhouse gas emissions to combat climate change can be achieved only by expanding the use of nuclear energy. Furthermore, there is mounting concern over the very real risk to national security posed by ceding U.S. leadership in nuclear technology development to countries such as Russia and China. Together, these drivers have led to extensive bipartisan support for federal investment in a public-private partnership aimed at maintaining the viability of the existing commercial nuclear reactor fleet in the U.S., and accelerating the deployment of advanced reactor designs that produce energy cost-competitively while continuing to subscribe to strong nonproliferation, safety, and security standards. In parallel, the emergence of new companies - often backed by significant private capital - proposing innovative reactor concepts as well as renewed interest and investment by traditional nuclear suppliers in advancing new designs have accelerated progress in USbased reactor technology development.

These trends have resulted in some notable recent developments, namely:

- The National Reactor Innovation Center (NRIC), an INL-led national program authorized by the 2018 Nuclear Energy Innovation Capabilities Act, was created to further innovative nuclear energy solutions by providing resources to test, demonstrate, and assess performance of new nuclear technologies in preparation for commercial deployment.

- The U.S. Department of Defense (DOD) has launched Project Pele, with the goal of demonstrating a mobile microreactor by 2024 .

- DOE-NE announced in October 2020 that two advanced reactor designers have been awarded $\$ 160 \mathrm{M}$ for demonstration through the Advanced Reactor Development Program (ARDP). An additional $\$ 30 \mathrm{M}$ was awarded in December 2020 to five other designers to use for risk reduction in preparation for future demonstrations. Also in December 2020, DOE-NE announced \$20M in awards to three teams under the ARDP's Advanced Reactor Concepts-20 (ARC-20) program.

- The Versatile Test Reactor (VTR) project received DOE approval for Critical Decision 1 in September 2020, thus moving to the engineering design phase.

- NASA has announced plans to develop nuclear propulsion systems for space exploration, and to operate surface fission reactors on the moon and possibly other planets.

- Uses of nuclear technology for applications other than electricity generation are being actively assessed, as evidenced by a recent DOE award to Xcel Energy - owner/operator of two nuclear power plants - to work with INL to test a high-temperature electrolysis process for hydrogen production.

a. DOE Office of Nuclear Energy: Strategic Vision (January 2021). 
As the designated nuclear energy laboratory for the DOE, INL is heavily engaged in these activities which will not only reestablish the U.S. as the leader in nuclear technology but also provide other countries $^{b}$ looking to reduce their carbon footprint with a clean, affordable, and safe energy choice. An illustration of the INL vision for advanced reactor development is shown in Figure 1.

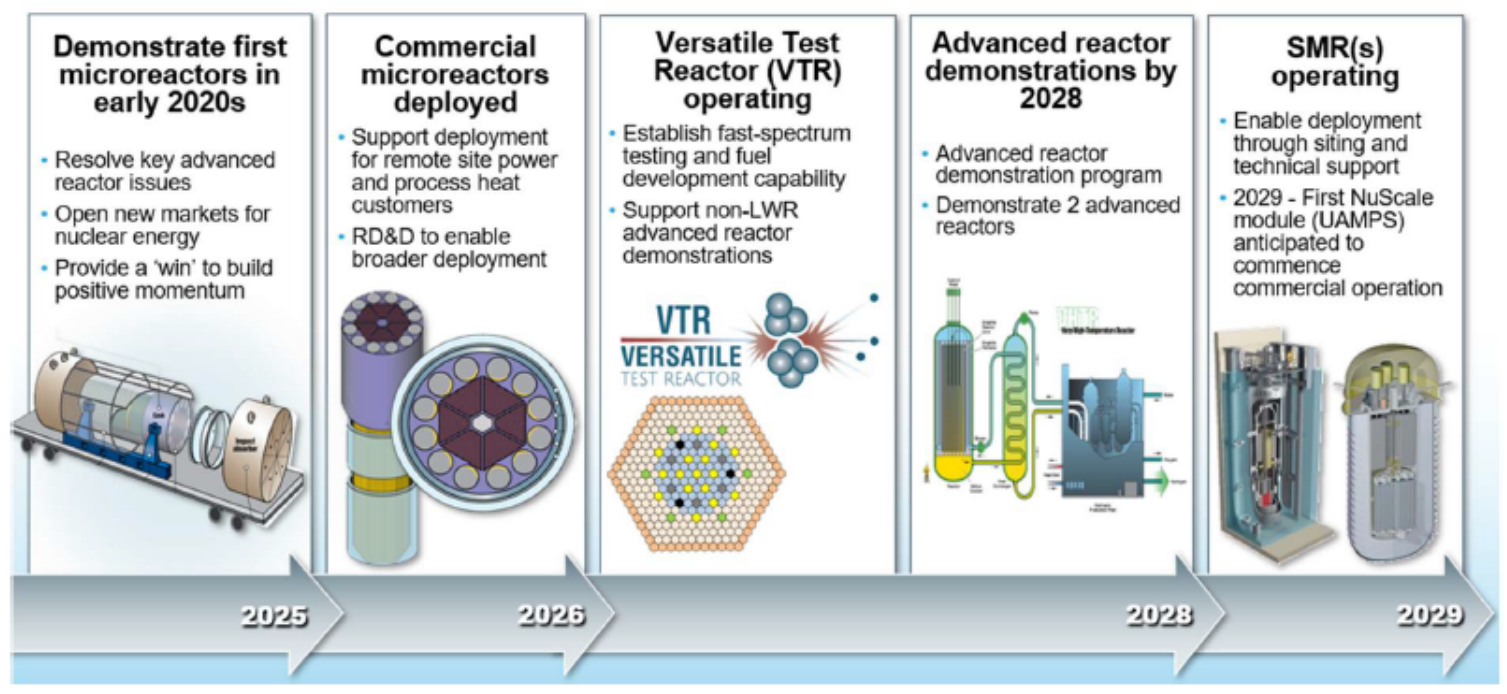

Figure 1. Vision for INL contributions to advanced reactor development and deployment.

As a source of expertise, facilities, and test beds related to the nuclear fuel cycle and nuclear materials development, MFC has an instrumental role in those INL activities involving nuclear energy RD\&D. The capabilities available at MFC today have evolved from MFC's historical mission, and that context is summarized here.

\subsection{MFC History}

When the National Reactor Test Station was established in Idaho in 1949 to be a remote location for the testing of reactors, Argonne National Laboratory built and operated the Experimental Breeder Reactor, later known as Experimental Breeder Reactor I or EBR-I, there. Argonne established an Idaho Division and located other higher-risk facilities at the EBR-I site (rather than in the more populated Argonne location in Chicago suburbs). When the Atomic Energy Commission and Argonne agreed EBR-II would be built, the EBR-II site was selected to be closer to Idaho Falls, and Argonne had new facilities built there as well, such as the Transient Reactor Test Facility (TREAT) and the Analytical Laboratory. EBR-II and the associated Fuel Cycle Facility were built to demonstrate reprocessing of fast reactor spent fuel into new fuel recycled back into the reactor and to demonstrate reliable power generation from a fast reactor. That initial mission was accomplished during 1965-1969, after which the EBR-II mission evolved to irradiation testing, operational testing, and safety testing. ${ }^{\mathrm{c}}$ The desire to reduce EBR-II's operating cost as an irradiation facility led to new technology developments that are now central to many fast reactor concepts being proposed by private developers. Specifically, the burnup capability of metal fuel was improved to match that of mixed oxide fast reactor fuel initially as a means to reduce EBR-II fuel cost, and the advantages of a metal-fueled, sodium-cooled fast reactor with a pool-type primary system were demonstrated from a program initially intended to determine how to economically

b. Internationally, new nuclear plants are being actively explored in countries throughout Europe, the Middle East, and Africa.

c. For additional information on the history of EBR-II and the Fuel Cycle Facility see Leonard J. Koch, Experimental Breeder Reactor-II (EBR-II): An Integrated Experimental Fast Reactor Nuclear Power Station (Argonne, IL; Argonne National Laboratory, n.d.), 1-1; Catherine Westfall, Civilian Nuclear Power on the Drawing Board: The Development of Experimental Breeder Reactor-II, Argonne National Laboratory report ANL/HISST-1-03/6 (Argonne, IL; Argonne National Laboratory, n.d.), 18; Charles E. Stevenson, The EBR-II Fuel Cycle Story (La Grange Park, IL; American Nuclear Society, 1987), 13. 
ensure EBR-II's operating safety.

Additional facilities were built at the EBR-II site, which became known as Argonne National Laboratory - West (ANL-W), most directly supporting the EBR-II irradiation testing mission, such as the Hot Fuel Examination Facility (HFEF), the Fuel Assembly and Storage Building (FASB), and the Fuel Manufacturing Facility (FMF). Other facilities otherwise supporting U.S. fast reactor development were placed there, such as the Zero Power Plutonium Reactor. After the shutdown of EBR-II, TREAT, and the Zero Power Plutonium Reactor in 1994, the ANL-W site served varied purposes, primarily nuclear materials stabilization but also some smaller research programs that reached beyond the historic fast reactor development mission and used site facilities for new purposes. During that period, the Space and Security Systems Power Facility (SSPSF) was built for assembly of Pu-238 radioisotope power sources, again broadening the programmatic capability of the site. With the establishment of INL in 2005, the newly renamed Materials and Fuels Complex benefitted from a mission focused again on nuclear energy RD\&D but addressing a broad range of nuclear energy technologies. INL continued and expanded the effort to transition and re-equip legacy facilities for broader capabilities. The need for the Irradiated Materials Characterization Laboratory (IMCL) was articulated and the facility built in 2016. TREAT was restarted in 2017 with the mission to support fuel safety testing for a variety of reactor types. Through these transitions over 20 years, MFC expanded on a set of core capabilities and facilities that include fuel manufacturing, post-irradiation examination of fuel and structural materials, fuel reprocessing and waste disposal. ${ }^{\mathrm{d}}$ The investment in MFC by DOE-NE and INL accelerated in the 2017 - 2020 timeframe in expectation of MFC's enabling role in the RD\&D of next-generation reactor technologies scheduled for deployment in the 2020s and 2030s. A recent photograph of the MFC site along with a map showing the location of key facilities are shown in Figure 2.

\subsection{MFC Current State}

The historical infrastructure of MFC combined with more recent upgrades and installations have resulted in a world-class assemblage of facilities, capabilities, and instruments for handling, testing, and characterizing radioactive materials such as nuclear reactor fuels, components, and structural materials. The principal source of investment in MFC is DOE-NE, as MFC primarily serves the nuclear energy science and technology advancement mission of DOE-NE. Users from other DOE and national security programs, NASA, private industry and academia also make use of the capabilities and radioactive materials available at MFC.

The mission/vision of MFC, "Engineering and Experiments that Drive the World's Nuclear Energy Future," is served by resources such as:

- The largest inert-atmosphere hot cell facilities in the U.S.

- A uniquely capable transient neutron-irradiation test reactor (TREAT)

- Capability to fabricate at bench-scale nearly all fuel types of interest to reactor designers and developers

- Facilities and equipment to produce high-assay low-enriched uranium (HALEU) fuel forms on an engineering scale (Fuels and Applied Science Building [FASB], Fuel Manufacturing Facility [FMF])

- Facilities for treatment, recycling and disposal of used fuel

- World class characterization capabilities at the Irradiated Materials Characterization Laboratory (IMCL), Electron Microscopy Laboratory (EML) and Analytical Research Laboratories

d. The Fuel Conditioning Facility at MFC was selected as an American Nuclear Society Historic Landmark on September 3, 2020, for its Historic Work Recycling EBR-II Used Nuclear Fuel. 

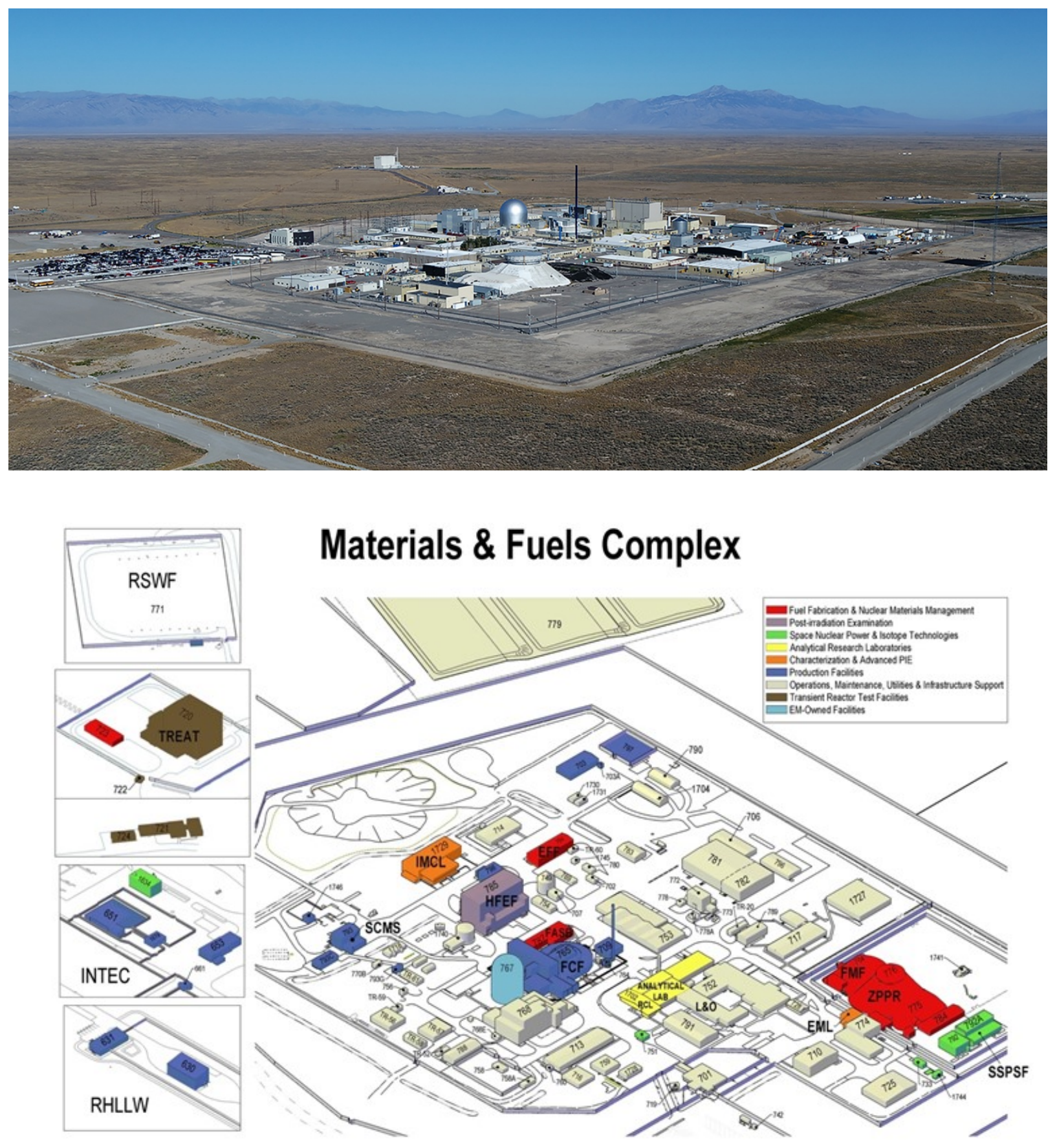

Figure 2. Photograph of the INL Materials and Fuels Complex (top) and MFC map showing key facilities (bottom). 
- Extensive suite of gloveboxes for handling transuranic and ceramic fuel, special nuclear materials and radioisotope power systems assembly

- Multiple furnaces with temperature capability up to $2,000^{\circ} \mathrm{C}$ in vacuum, argon, air, hydrogen, and nitrogen atmospheres (Experimental Fuels Facility)

- NRAD, a 250-kW TRIGA reactor optimized for neutron radiography

- $\quad$ The EBR-II dome and Zero Power Physics Reactor (ZPPR) cell that are being repurposed for hosting private-sector reactor demonstration projects.

These MFC capabilities, supported by a dedicated staff of research and operations personnel, provide a platform for conducting RD\&D activities related to nuclear energy technology. Examples of ongoing and planned activities include the following:

- Advanced reactor demonstration and testing

- Fuel fabrication for advanced reactors

- Irradiation, analysis and testing of fuel and structural reactor materials

- Radioisotope power systems for space missions

- Treatment of used fuel for recycling and disposal.

To further illustrate the MFC capabilities, here are some of the major milestones achieved during the preceding year (FY-20):

- Delivered a Multi Mission Radioisotope Thermoelectric Generator (MMRTG) to NASA, and supporting nuclear thermal propulsion technology development

- Met major objectives supporting advanced fuel R\&D such as Fission Accelerated Steady-state Test (FAST), transient tests, and accident-tolerant fuel cladding testing

- Supported DOE efforts to meet environmental obligations of the Idaho Settlement Agreement, including the commitment to have all used fuel removed from wet storage by the end of Calendar 2023

- Met objective for annual treatment amount of sodium-bonded Experimental Breeder Reactor-II (EBR-II) Driver Fuel for DOE-Idaho Operations Office in support of the 2019 Supplemental Agreement of the 1995 Settlement Agreement for generation of HALEU from sodium-bonded EBR-II Driver Fuel

- Commenced construction of the Sample Preparation Laboratory (SPL) which, when completed, will provide a central point for collaborations with universities, industry partners, and other DOE user facilities on research involving irradiated structural and cladding materials

- Invested in facility reliability and research infrastructure, such as enhancement of the R\&D capabilities of the neutron radiography reactor (NRAD)

- Focused resources on RD\&D program support as usage of facilities increased.

\subsection{Purpose}

The purpose of this Mission Strategy plan is to identify the critical-to-success outcomes required from MFC during the FY-21 - FY-25 timeframe in support of the INL and DOE missions, as well as the mission/vision of MFC, namely "Engineering and Experiments that Drive the World's Nuclear Energy Future." The plan also describes the underlying strategic activities needed to accomplish these critical outcomes and includes a section on the risks and challenges related to mission execution. 
The MFC Five-Year Mission Strategy plan is complementary to the MFC Operations Management Improvement (OMI) Strategy and the MFC Five-Year Investment Strategy. The Mission Strategy plan also references the INL Lab Agenda and the INL Lab Plan. The relationships between these documents can be summarized as follows:

- The MFC Five-Year Mission Strategy defines the MFC outcomes and strategies required to meet DOE and INL Laboratory objectives identified in the INL Lab Agenda and DOE-NE programs.

- The MFC Five-Year Investment Strategy defines infrastructure needs, cost, and timeline necessary to meet the MFC mission strategy.

- The OMI Strategy identifies barriers to MFC success in terms of people, processes, and additional equipment needs not identified in the investment strategy. The OMI Strategy defines actions and timelines to remove those barriers.

Last, annual budget development is done through the Integrated Resource Planning Tool which identifies and allocates resources and funding required to meet mission objectives. 


\section{MFC ORGANIZATION}

A current version of the MFC organization chart is shown in Figure 3. The MFC divisions, led by the Associate Laboratory Director (ALD), are grouped into two categories: Research and Production and Engineering, Operations, and Maintenance. The science mission of MFC is carried out primarily by the Research and Production Divisions. The Engineering/Operations/Maintenance Divisions ensure that MFC facilities are properly operated, maintained and upgraded to fulfill their respective mission functions in a manner that complies fully with applicable safety and environmental regulations. Table 1 shows the breakdown of the MFC divisions according to these two categories. Brief descriptions of the divisions are provided in Appendix A.

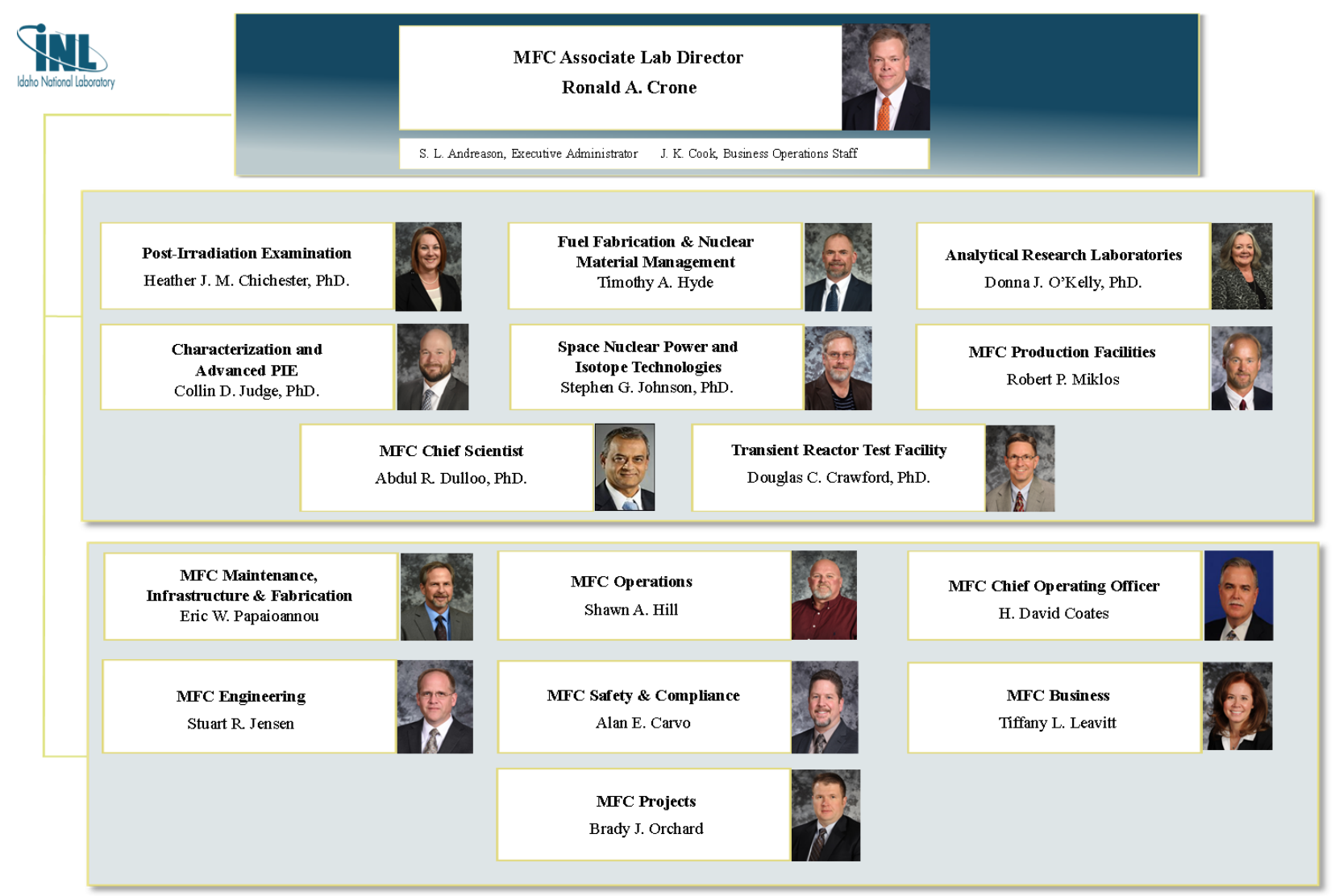

Figure 3. MFC Organization Chart

Table 1. MFC Divisions.

\begin{tabular}{|c|c|}
\hline Engineering/Operations/Maintenance ${ }^{\mathrm{a}}$ & Research/Production ${ }^{\mathrm{b}}$ \\
\hline MFC Business & Analytical Research Laboratories \\
\hline MFC Engineering & Characterization and Advanced PIE \\
\hline MFC Maintenance, Infrastructure \& Fabrication & Fuel Fabrication \& Nuclear Material Management \\
\hline MFC Operations & MFC Production Facilities \\
\hline MFC Projects & Post-Irradiation Examination \\
\hline MFC Safety \& Compliance & Space Nuclear Power and Isotope Technologies \\
\hline & Transient Reactor Test Facility (TREAT) \\
\hline
\end{tabular}




\section{MFC FACILITIES}

As discussed in Section 1, MFC's facilities and infrastructure support a comprehensive range of experiments and testing related to nuclear technology RD\&D. Information on several MFC facilities is provided in Appendix B. Descriptions of some facilities are also available on the web, and the applicable website links are listed in Table 2. Figure 4 shows how the extensive MFC capabilities are mapped to individual facilities.

Table 2. Principal MFC facilities (website links are listed when available).

\begin{tabular}{|c|c|}
\hline Research/Production Division & Facilities \\
\hline $\begin{array}{l}\text { Analytical Research } \\
\text { Laboratories }\end{array}$ & $\begin{array}{l}\text { Analytical Laboratory: } \\
\text { https://mfc.inl.gov/SitePages/Analytical\%20Laboratory.aspx\#mfc- } \\
\text { instruments } \\
\text { Radiochemistry Laboratory }\end{array}$ \\
\hline $\begin{array}{l}\text { Characterization and Advanced } \\
\text { PIE }\end{array}$ & $\begin{array}{l}\text { Electron Microscopy Laboratory: } \\
\text { https://mfc.inl.gov/SitePages/Electron\%20Microscopy\%20Laboratory.aspx } \\
\text { Irradiated Materials Characterization Laboratory: } \\
\text { https://mfc.inl.gov/SitePages/Irradiated\%20Materials\%20Characterization\%2 } \\
\text { 0Laboratory.aspx } \\
\text { Sample Preparation Laboratory (under construction): } \\
\text { https://mfc.inl.gov/SitePages/Sample\%20Preparation\%20Laboratory.aspx }\end{array}$ \\
\hline $\begin{array}{l}\text { Fuel Fabrication \& Nuclear } \\
\text { Material Management }\end{array}$ & $\begin{array}{l}\text { Advanced Fuels Facility (AFF) } \\
\text { Experimental Fuels Facility: } \\
\text { https://mfc.inl.gov/SitePages/Experimental\%20Fuels\%20Facility.aspx } \\
\text { Fuel Manufacturing Facility: } \\
\text { https://mfc.inl.gov/SitePages/Fuel\%20Manufacturing\%20Facility.aspx } \\
\text { Fuels and Applied Science Building: } \\
\text { https://mfc.inl.gov/SitePages/Fuels\%20and\%20Applied\%20Science\%20Buil } \\
\text { ding.aspx } \\
\text { Zero Power Physics Reactor: } \\
\text { https://mfc.inl.gov/SitePages/Zero\%20Power\%20Physics\%20Reactor.aspx }\end{array}$ \\
\hline MFC Production Facilities & $\begin{array}{l}\text { Fuel Conditioning Facility: } \\
\text { https://mfc.inl.gov/SitePages/Fuel\%20Conditioning\%20Facility.aspx } \\
\text { Sodium Components Maintenance Shop (SCMS) } \\
\text { Radioactive Scrap and Waste Facility (RSWF) } \\
\text { Remote Handled Low Level Waste (RHLLW) Facility }\end{array}$ \\
\hline Post-Irradiation Examination & $\begin{array}{l}\text { Hot Fuel Examination Facility: } \\
\text { https://mfc.inl.gov/SitePages/Hot\%20Fuel\%20Examination\%20Facility.aspx }\end{array}$ \\
\hline $\begin{array}{l}\text { Space Nuclear Power and } \\
\text { Isotope Technologies }\end{array}$ & $\begin{array}{l}\text { Space and Security Power Systems Facility: } \\
\text { https://inl.gov/research-program/space-power-systems/ }\end{array}$ \\
\hline Transient Reactor Test Facility & $\begin{array}{l}\text { Transient Reactor Test Facility (TREAT): } \\
\text { https://mfc.inl.gov/SitePages/Transient } \% 20 \text { Reactor } \% 20 \text { Test } \% 20 \text { Facility.aspx } \\
\text { https://transient.inl.gov/SitePages/Home.aspx }\end{array}$ \\
\hline
\end{tabular}




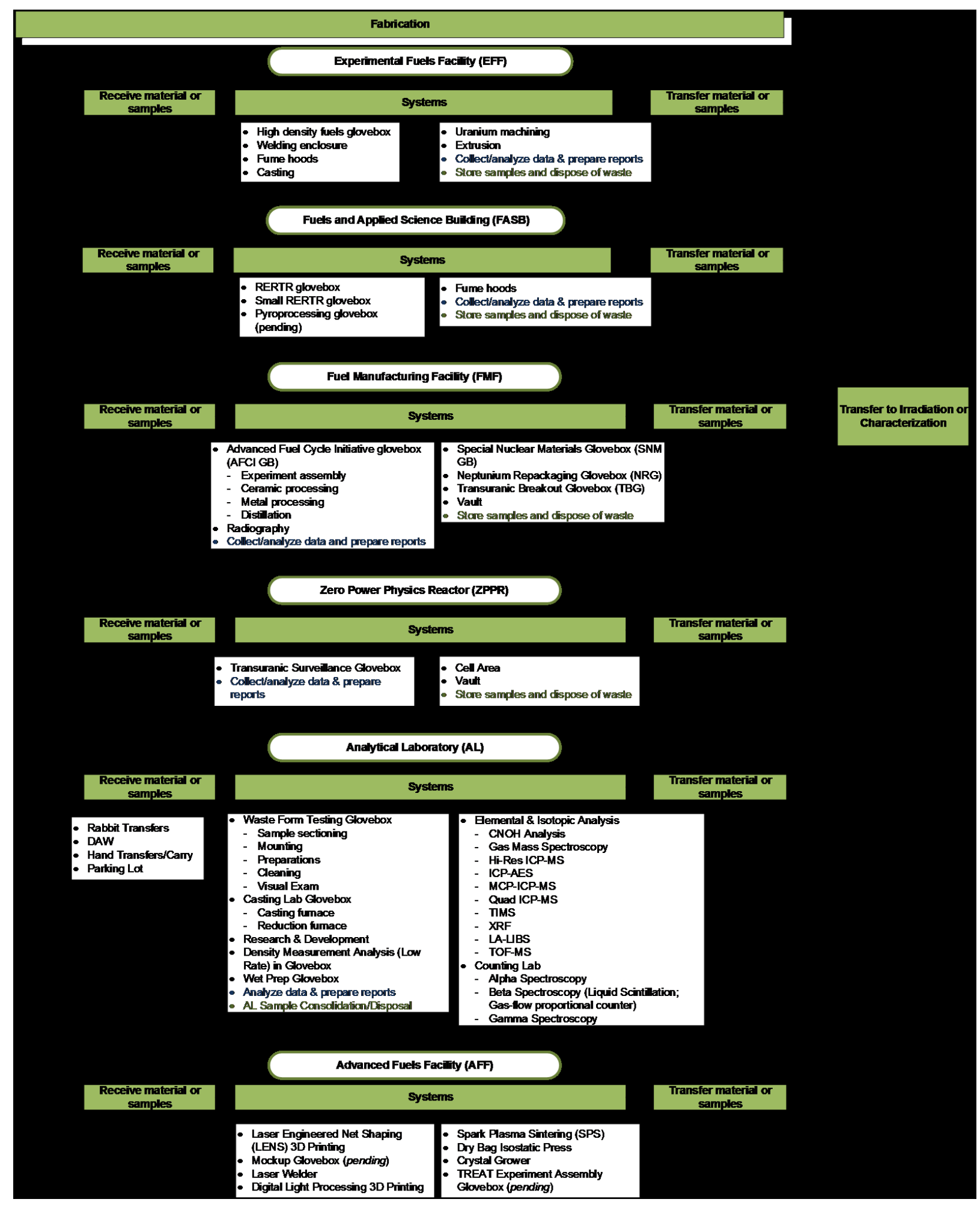

Figure 4a. Existing nuclear RD\&D capabilities at MFC: Fabrication. 


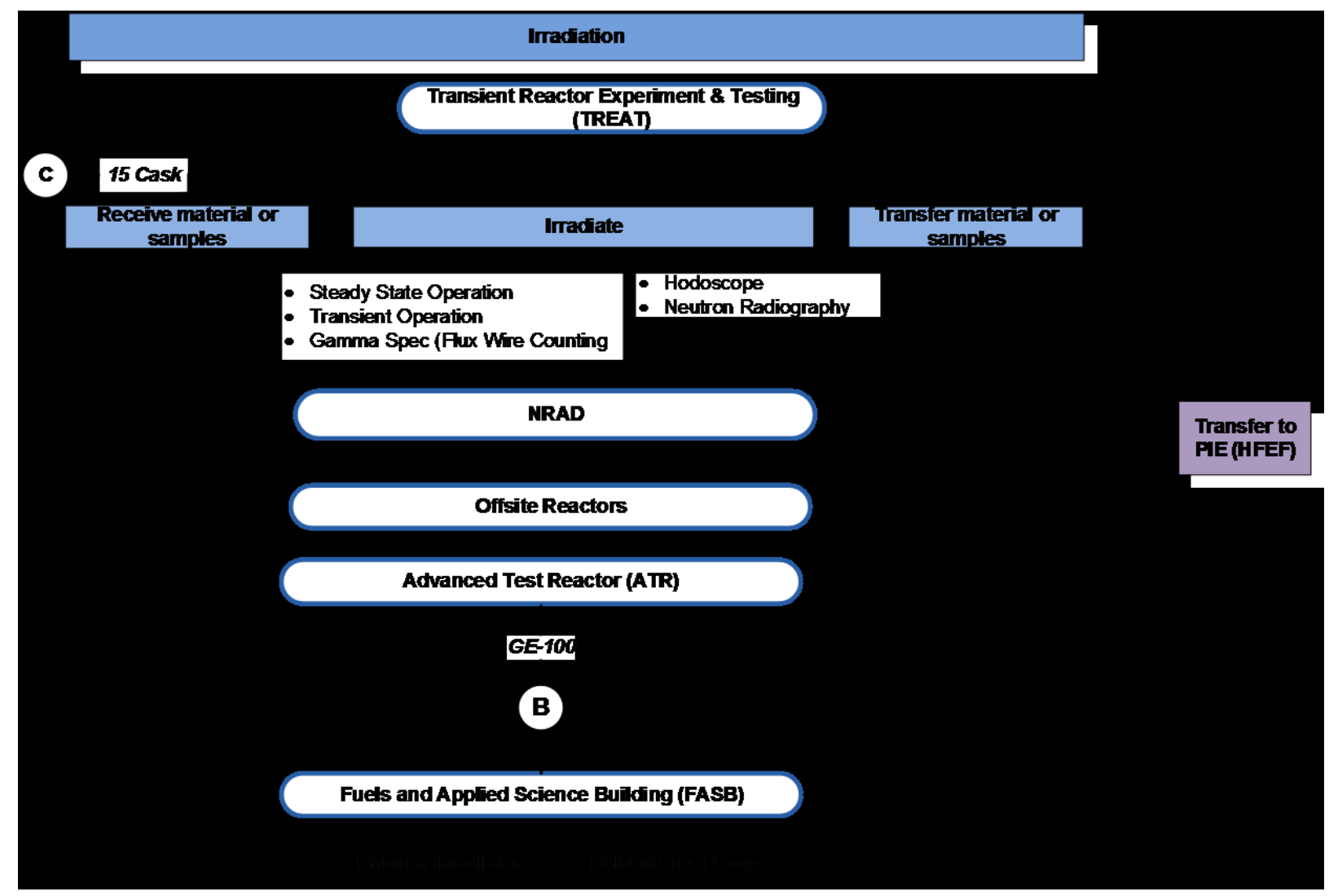

Figure 4b. Existing nuclear RD\&D capabilities at MFC: Irradiation. 


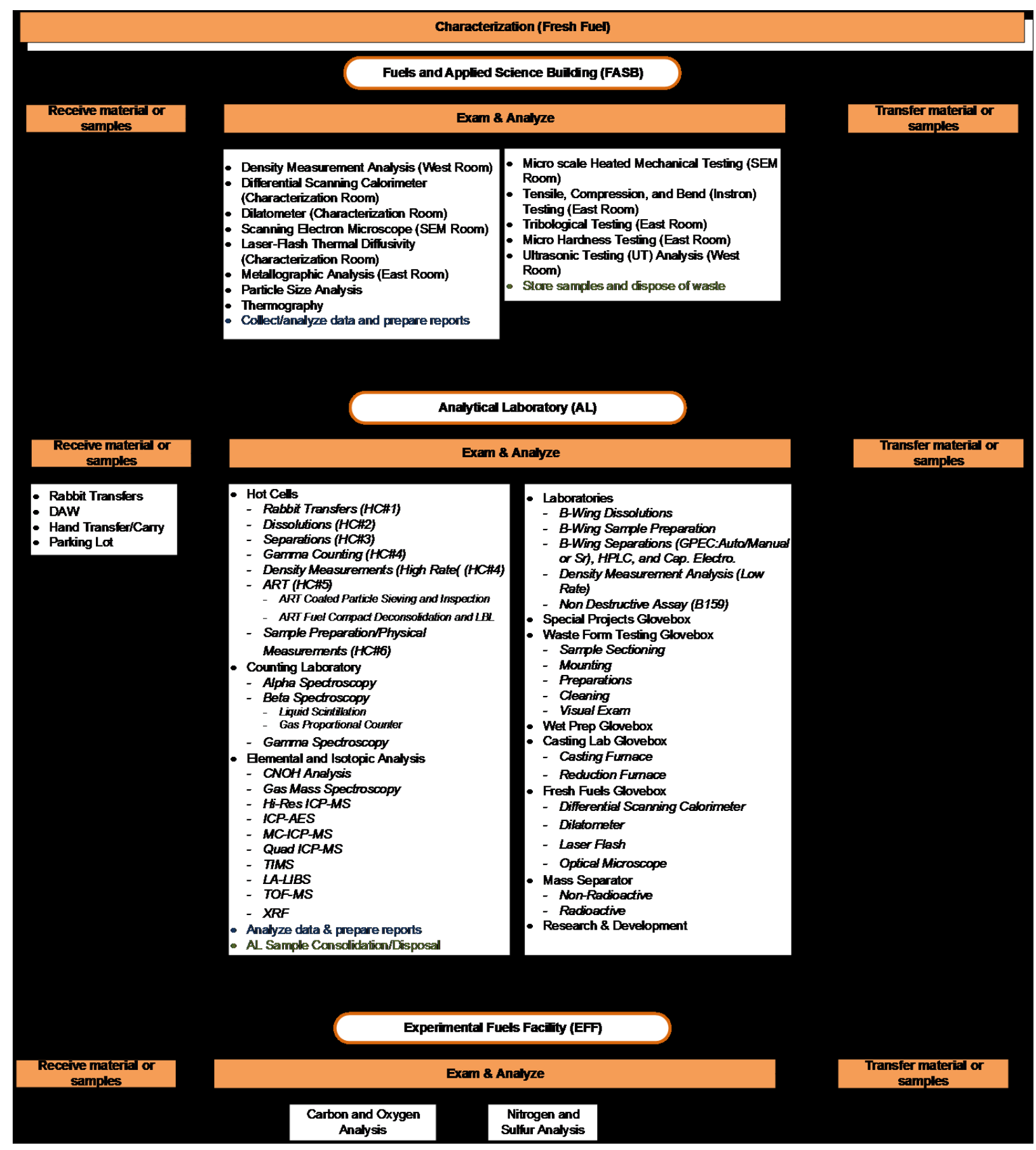

Figure 4c. Existing nuclear RD\&D capabilities at MFC: $\underline{\text { Characterization. }}$ 


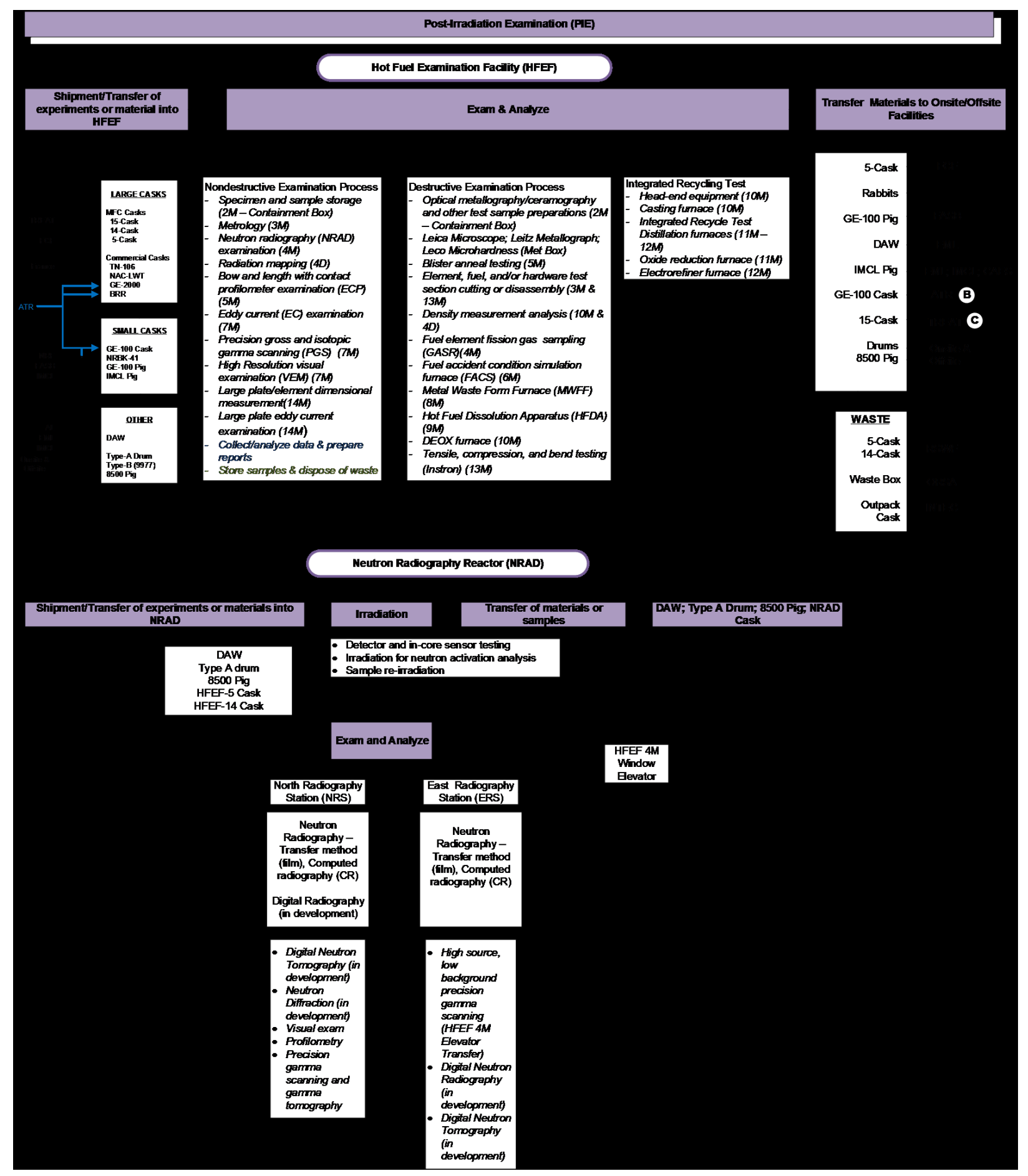

Figure 4d. Existing nuclear RD\&D capabilities at MFC: $\underline{\text { PIE at HFEF/NRAD. }}$ 


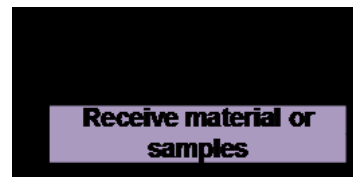

\section{Fuel Conditioning Facitity (FCF)}

Syste
- Prepare \& size
- Vertical Assembler/ Dismantier
(VAD)
- Vaculum inspection station/
bottle cutting
- Production element chopper
- Blankef element chopper
- Collectlanalyze data \& prepare
reparts
Stcre samnles \& dispose of waste

\section{Systems}

Transfer materi? or samples

Fuel Cycle

Laboratory-R\&D

of pyrochemical-

based fuel cycles

\section{- Bectrochemical separations sodium neutralization \\ experimentation/ treatment \\ - Mk-IV Electrorefiner \\ - Mk-V Electrorefiner \\ - Cathode processor \\ - Casting fumace \\ Waste form development \\ - Mk-N Electrorefiner \\ - Mk-V Electrorefiner \\ - Cathode processor \\ - Casting fumace}

\section{Sample Preparalion Laboratory"} (in Conkepturall Phase)
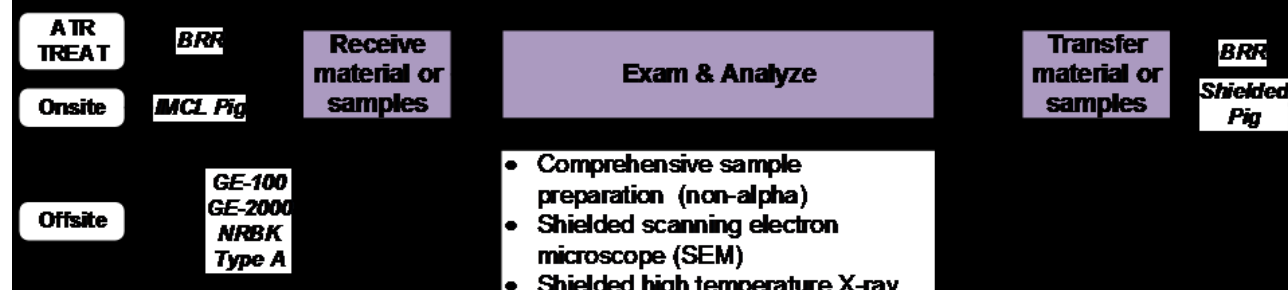

- Comprehensive sample

preparation (non-alpha)

- Shielded scamning electron

microscope (SEM)

- Shielded high temperature X-ray

difraction (XRD) analysis

- Surface science

- Metrology

- Shielded mechanical testing

- Collectlanalyze data \& prepare reparts

- Stare sanndes \& dispose of waste

Receive material or samples

\section{Bectron Microscopy Laboratory (EML)}

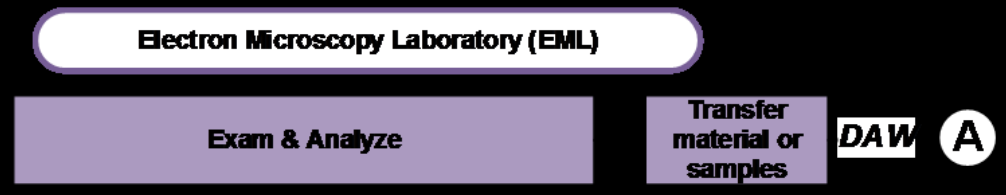

- Dual beam focused ion
beam (FB) with SEM, EDS,
and EBSD (134B SEM
Lab)
- Micro hardhess testing
(134)
- Hysitron PI 88 SEM
nanocindenter (In-Situ
Nanomechanical Test
Instrument)
- Custom analysis
- Optical microscopy
- Collectanalyze data \&
prepare reports
- Sare samples \& dispose $a$
waste

- Sample preparation (134)

- Transmission electron microscope (TEM)

Talos (Chemistry, EELS ASTAR) dynamic 3D imaging, 1200 Cheated stage (134C TEM Lab)

- Laser cutting \& etching

- Micro X-ray difraction $(\mu-X R D)$ analysis

Figure 4e. Existing nuclear RD\&D capabilities at MFC: PIE at FCF, SPL (planned), and EML. 


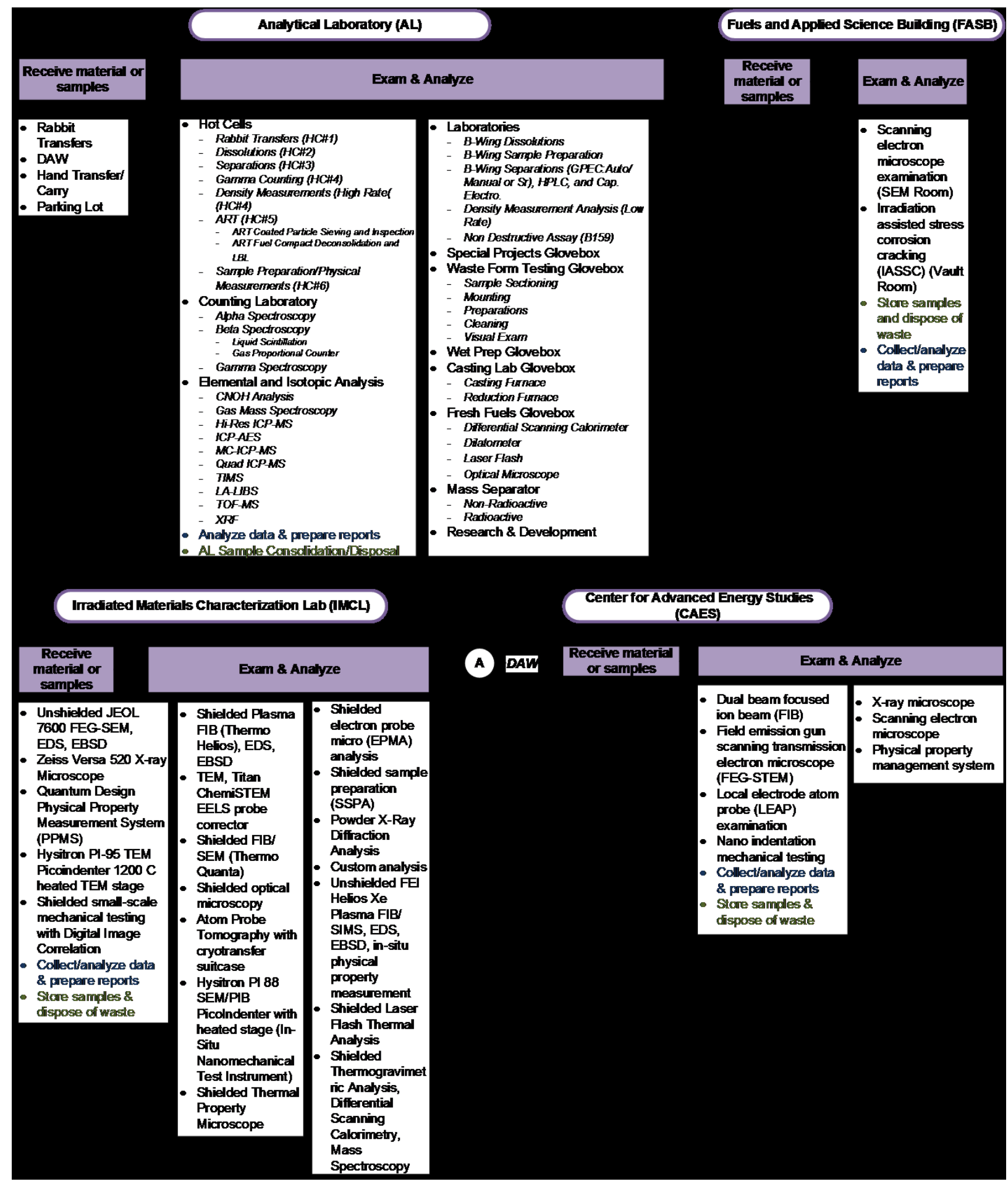

Figure 4f. Existing nuclear RD\&D capabilities at MFC: PIE at AL, FASB, IMCL, and CAES. 


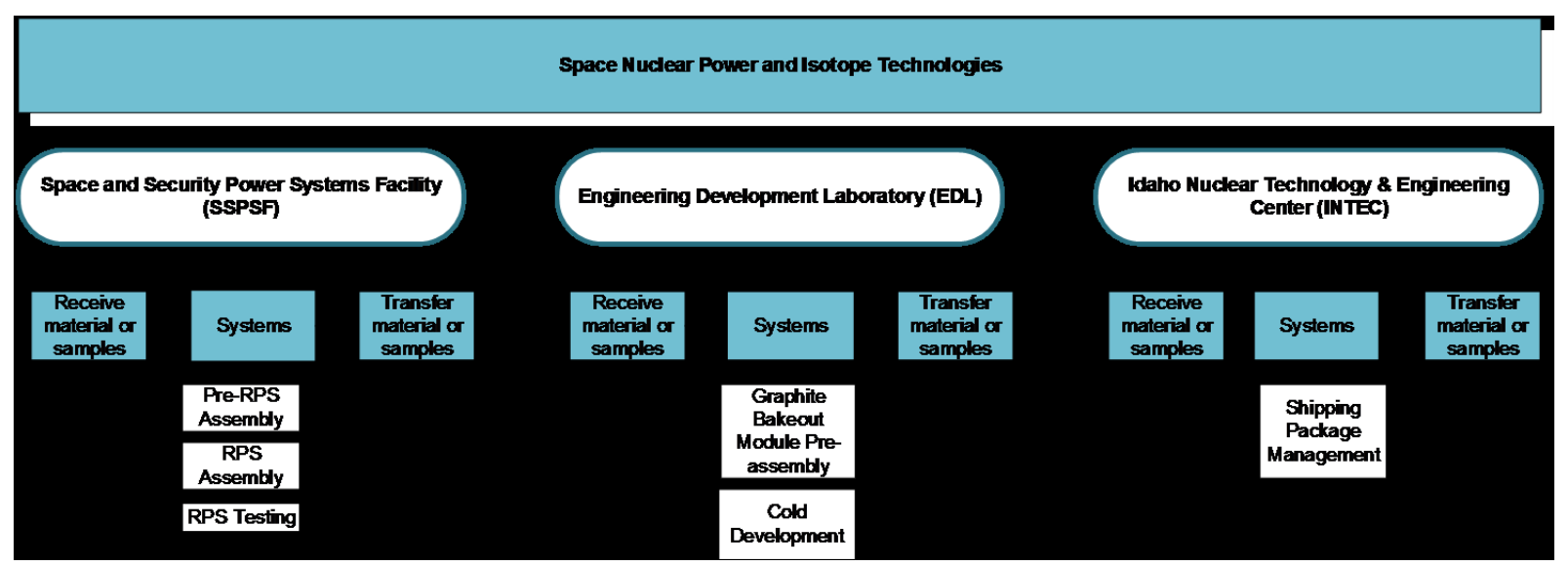

Figure 4g. Existing nuclear RD\&D capabilities at MFC: $\underline{\text { SSPSF, EDL, and INTEC. }}$ 


\section{DESCRIPTION OF MFC CORE COMPETENCIES}

MFC offers the following core competencies:

- Nuclear fuels fabrication

- Fuel characterization

- Characterization of radiation damage in cladding and in-core structural materials

- Fuel recycling and nuclear material management

- Transient irradiation testing

- Nuclear nonproliferation and nuclear forensics

- Space nuclear power

- Isotope production

- Radioanalytical chemistry

- Focused basic research.

A short description of each of these competencies is provided in this section. Additional information is provided in Appendix $\mathrm{C}$, including proposed areas of research to advance the knowledge base of the competencies. It should be noted that new competencies can be added to the current core over time as needed to support the mission of MFC. This section concludes with a discussion on the connection between the MFC core competencies and the INL core capabilities.

\subsection{MFC Core Competencies}

\subsubsection{Nuclear Fuels Fabrication}

Fuel fabrication facilities at MFC allow fabrication process development for nearly any nuclear fuel form of interest today, including production of fuel test samples to be incorporated into ATR and TREAT irradiation tests. Also available are facilities, instrumentation and personnel to perform both pre- and postradiation characterization of fuel material. MFC has previously operated engineering-scale fuel production capabilities (i.e., FMF) in support of EBR-II. These capabilities support continuing advances in light water reactor (LWR) fuel technology that have been critical to increasing performance of the current fleet and improving tolerance to severe accidents. They also support development of advanced nuclear fuels central to deploying advanced nuclear systems that have significant advantages over LWRs in terms of efficiency, waste generation, safety, increased residence and coping time, and proliferation resistance. Many fuel development needs associated with advanced reactors include adaptation of fast reactor fuel technology to new reactor concepts. MFC is also researching and demonstrating advanced manufacturing techniques for fuel fabrication and experimentation.

\subsubsection{Fuel Characterization}

MFC hosts facilities, instrumentation and expertise to perform both pre- and post-irradiation characterization of fuel material. The Hot Fuel Examination Facility (HFEF) is equipped to receive radioactive materials and irradiated components in a range of sizes, and provides shielded space and equipment for disassembly, nondestructive examination, size reduction, and destructive examination. The Irradiated Materials Characterization Laboratory (IMCL) is specially designed to apply state-of-the-art instrumentation for microstructural and thermal characterization of irradiated fuel. The facilities of the Analytical Research Laboratories receive a wide variety of samples from across INL and from outside entities, including irradiated and unirradiated fuels and materials. Last, fresh fuel characterization can be performed in the FASB and EFF. 


\subsubsection{Characterization of Radiation Damage in Cladding and In-Core Structural Materials}

The life-limiting factors in both fuel and reactor operating lifetime are cladding and structural materials. Understanding and overcoming the effects of high radiation damage levels is therefore instrumental in maintaining the current fleet and developing advanced reactors. MFC capabilities for sample characterization on the nano and atomic scales, as well as sample preparation and storage, are key to this research. Also important are the availability of materials for study by the nuclear energy research community, the ability to fabricate standard test samples from irradiated materials mined from current reactors, and the ability to transport materials to and from NSUF partner facilities as appropriate.

\subsubsection{Fuel Recycling and Nuclear Material Management}

Nuclear fuel cycles that increase uranium resource utilization and reduce nuclear waste are required to reduce long-term waste disposition risk, induce a greater level of public acceptance of nuclear power, and support a more economical closed fuel cycle. MFC capabilities and expertise include engineeringscale capabilities for pyroprocessing, bench-scale capability for development of aqueous processes, and potential to expand the Fuel Conditioning Facility (FCF) mission for fuel cycle demonstrations if appropriate. Laboratory space in FASB and FCF supports fuel processing and treatment R\&D. FCF hot cells are used for processing and treatment of used nuclear fuel, resulting in waste materials suitable for disposal in a deep geologic repository.

The Fuel Fabrication and Nuclear Material Management (FFNMM) Division manages a substantial inventory of contact-handled accountable nuclear material at MFC. The major quantities of contacthandled nuclear material are associated with ZPPR fuel, unirradiated fast reactor fuel and associated fabrication scrap, and feedstock materials. The overarching nuclear material management goal is to maintain and enhance the capability to efficiently support excess material disposition and programmatic missions while minimizing the number of facilities and locations that are required to manage significant quantities of special nuclear material. To this end, FFNMM continues to support programmatic planning efforts to ensure nuclear material is available to meet anticipated needs while minimizing the inventory of excess nuclear material stored at MFC. Prior efforts have resulted in tons of excess special nuclear material and approximately $170 \mathrm{MT}$ of excess source nuclear material being removed from MFC. Current excess material management efforts focus on monitored safe storage of the existing material inventory, along with continued processing and shipment of legacy highly enriched uranium (HEU) scrap materials. These efforts facilitate transition of the HEU to beneficial reuse where practical, produce a more stable and better characterized material form, free up vault storage space to support new RD\&D missions, and demonstrate progress towards responsible removal of excess nuclear material from the state of Idaho. Future efforts will focus on developing new equipment capabilities needed to process and disposition the legacy plutonium-bearing scrap materials.

\subsubsection{Transient Irradiation Testing}

Transient testing of nuclear fuels is needed to develop and prove the safety basis for advanced reactors and new fuel designs for operating reactors. With resumption of operations at the TREAT facility, state-of-the-art transient irradiation capabilities along with the requisite operational expertise have been re-established for development of advanced nuclear fuel systems, the study of high intensity neutron interactions with materials, and the testing of nuclear instrumentation under reactor transient conditions. TREAT is capable of neutron irradiation of a variety of experiment configurations at time scales and neutron-flux pulses not attainable in reactor facilities such as the Advanced Test Reactor (ATR). The co-location of TREAT at MFC greatly facilitates efficiencies in assembly of experimental modules, pre- and post-irradiation characterization, and access to other essential support services. The TREAT facility is a significant asset for carrying out important programs ranging from accident-tolerant fuel qualification to startup of one or more DOE-authorized demonstration reactors by 2025 . 


\subsubsection{Nuclear Nonproliferation and Nuclear Forensics}

Critical initiatives that support national security programs include preparation of measurement standards that support verification measurements for nuclear detection for the Comprehensive Test Ban Treaty Organization, performing research that addresses the detection of nuclear proliferation threats from rogue organizations and governments, support for nuclear forensics, materials protection, and control and accountability for protecting current and future reactors and nuclear fuel cycle facilities world-wide. MFC's inventory of strategic materials is used to conduct R\&D on detection and characterization for DOE-NE, NNSA, DOD, and the Department of Homeland Security (DHS). This capability can be extended to develop and demonstrate safeguards technology appropriate for inclusion in the design of new facilities.

\subsubsection{Space Nuclear Power}

Production of radioisotope power sources (RPSs) has been an ongoing endeavor for DOE and its predecessor agencies for the past five decades. The overall mission of the RPS Program is to develop, demonstrate, and deliver compact, safe nuclear power systems and related technologies for use in remote, harsh environments (such as space), where it is impractical to provide the fuel and maintenance that more conventional electrical power sources require. MFC facilities are an important link in the RPS supply chain, which also includes Oak Ridge National Laboratory and Los Alamos National Laboratory. Specifically, INL fuels, performs acceptance testing (vibrational testing, mass properties, magnetic field testing and thermal vacuum testing), delivers to NASA and provides ground support at NASA site for radioisotope power systems. The ground support includes efforts such as safety basis work for ground facilities and launch safety, hurricane plans, security plans and upset condition planning. The NASA facilities are essentially made into DOE nuclear facilities during the stay of the RPS at the NASA facilities. Long-term planning working with DOE and NASA is a featured activity to provide for a clear understanding on which NASA missions can be supported with nuclear power capabilities and the interconnectedness.

INL also actively supports NASA's efforts in two space-related reactor development projects. The first is a surface fission power demonstration for a lunar application slated for 2027. This is a reactor for unmanned demonstration in the $10 \mathrm{kWe}$ range. The second project is a reactor for space propulsion which would be necessary for future travel to locations such as Mars. This would be a fission-based system that would be in the $\sim 100 \mathrm{MWth}$ range and provide for the generation of a very hot hydrogen stream for propulsion. An actual system is likely a 2030's application goal.

Development of advanced radioisotope power systems is an ongoing effort with activities in the advanced thermo-electric and dynamic conversion systems underway. These activities are joint ones with NASA-Glen Research Center. The goal of the dynamic power conversion system is a lunar demonstration mission in the mid-2020s. The systems under consideration are Stirling and Brayton based. The advanced thermo-electric systems are working towards a goal of a qualification unit by 2028 to support a mission by 2030 .

\subsubsection{Isotope Production}

There are two customers for the Isotope production side of the business, the Office of Science (DOE-SC) and DOE-NE. The production of the medical isotope, Co-60, is for the DOE-SC and takes place in the Advanced Test Reactor (ATR). Other isotopes are under investigation for future production for DOE-SC. Pu-238 is also produced in ATR for DOE-NE on the behalf of NASA for use in radioisotope power systems (see previous section). 


\subsubsection{Radioanalytical Chemistry}

Building on MFC's experience for applied and developmental research in radiochemical separations for the nuclear fuel cycle, MFC has developed significant expertise and measurement capabilities in analytical chemistry in support of programs that include advanced nuclear fuel design, nuclear waste management, and nuclear nonproliferation. MFC can provide modern instrumentation and subject-matter expertise for analyses in the areas of radionuclide separations, mass spectrometry, elemental analysis, and radio-analytical measurement (alpha, beta and gamma counting).

\subsubsection{Focused Basic Research}

Focused basic research sets the stage for advances in technology through revolutionary advances in the fundamental understanding of the underlying physics and chemistry of material behavior in the nuclear environment. MFC occupies a unique position for performing this type of basic research through the availability of facilities with state-of-the-art instrumentation and expert instrument scientists, relevant materials, and scientists who are experts in the behavior of materials in the nuclear environment. MFC is particularly adept at conducting basic research on radioactive materials that require remote handling. In addition to performing basic research using its own assets, MFC can also enable research by other national laboratories and universities by providing samples with low levels of contamination that fit within the acceptable radioactive permit limits of these entities.

\subsection{Alignment of MFC Competencies with INL Core Capabilities}

It is worthwhile noting how the MFC core competencies map against the designated INL core capabilities that enable the Laboratory's mission ${ }^{\mathrm{e}}$. Of the twenty-four DOE-designated core capabilities shared across DOE's science and applied energy laboratories, INL focuses on thirteen core capabilities and two emerging core capabilities shown on Figure 5. Seven of those INL core capabilities are supported by MFC's competencies and facilities:

- Applied materials science and engineering

- Chemical engineering

- Condensed matter physics and materials science (emerging)

- Large-scale user facilities/R\&D facilities/advanced instrumentation

- Mechanical design and engineering

- Nuclear and radiochemistry

- Nuclear engineering.

Additional information on the INL core capabilities can be found in the INL Annual Laboratory Plan.

e. Annual Laboratory Plan 2020. 


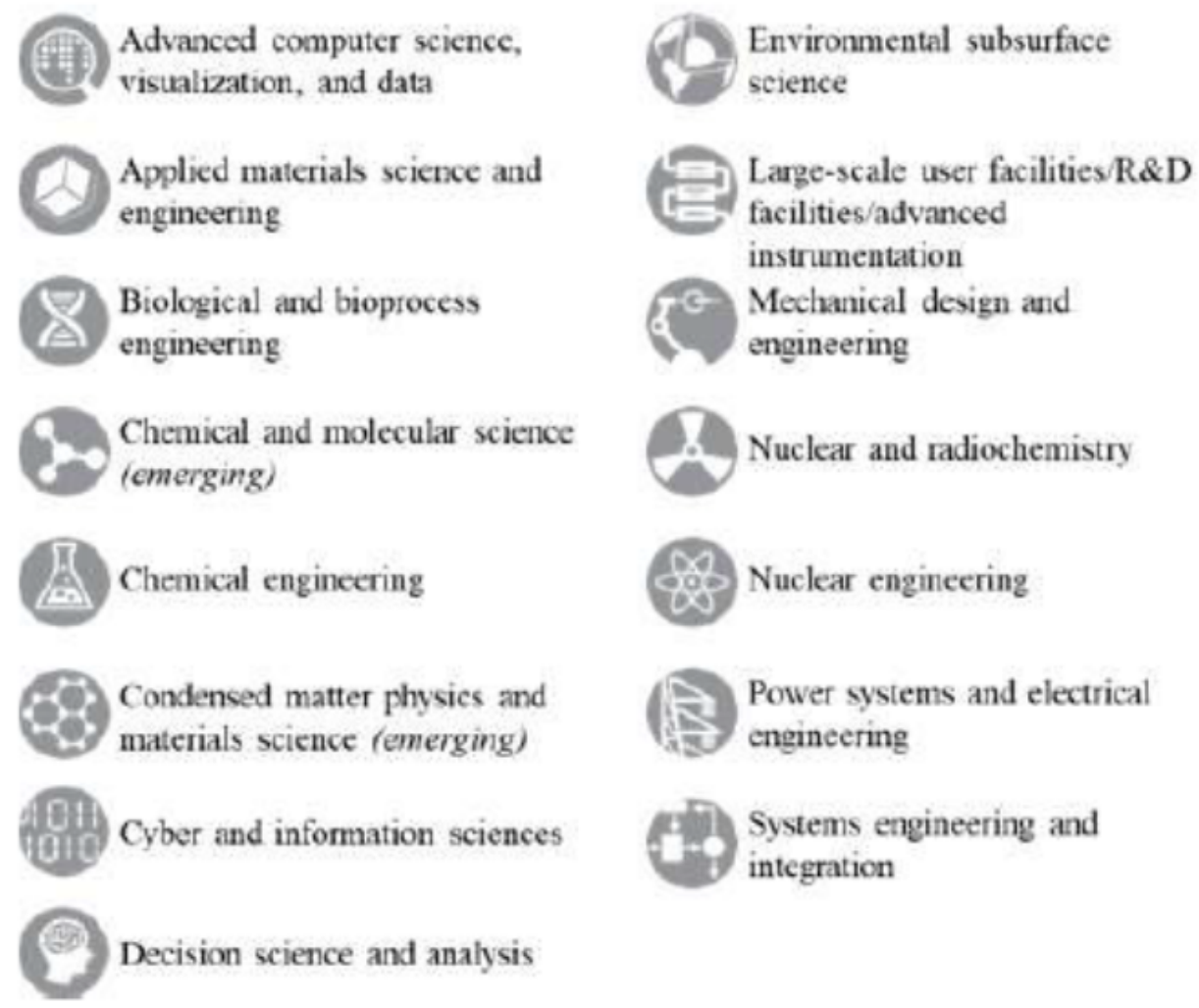

Figure 5. INL's 13 existing and 2 emerging core capabilities. 


\section{MFC USER FACILITY MODEL}

Given the wide range of R\&D performed at MFC and the multiple users of MFC facilities and instrumentation, a MFC user facility model is being implemented to ensure that adequate and reliable base funding is available for compliant nuclear facility operations and scientific infrastructure sustainment. The funding, coming on a continual annual basis from a single fund source (Idaho Facilities Management) establishes a base level of funding that ensures personnel expertise is available to operate and maintain both operations and scientific infrastructure and be available to support RD\&D activities at MFC. As illustrated in Figure 6, the user facility model is intended to build and maintain the DOE-NE RD\&D capability required for the test bed concept, which is especially relevant to MFC's role in NRIC. The user facility model provides the foundation for a comprehensive, reliable, and sustained research capability and also supports a stable environment for acquiring, training, and improving the expertise of the scientific and support work force. It implements and continually improves capabilities that support the nuclear RD\&D test bed, and increases cost-effectiveness and reliability of operations. Building on this foundation will increase the output of technological information critical to bridging the barriers to innovation that currently limit deployment of advanced nuclear technology. (Note that the user facility model is not directly applicable to the demonstration platform function at MFC, which would entail funding arrangements with private commercial organizations and DOE.)

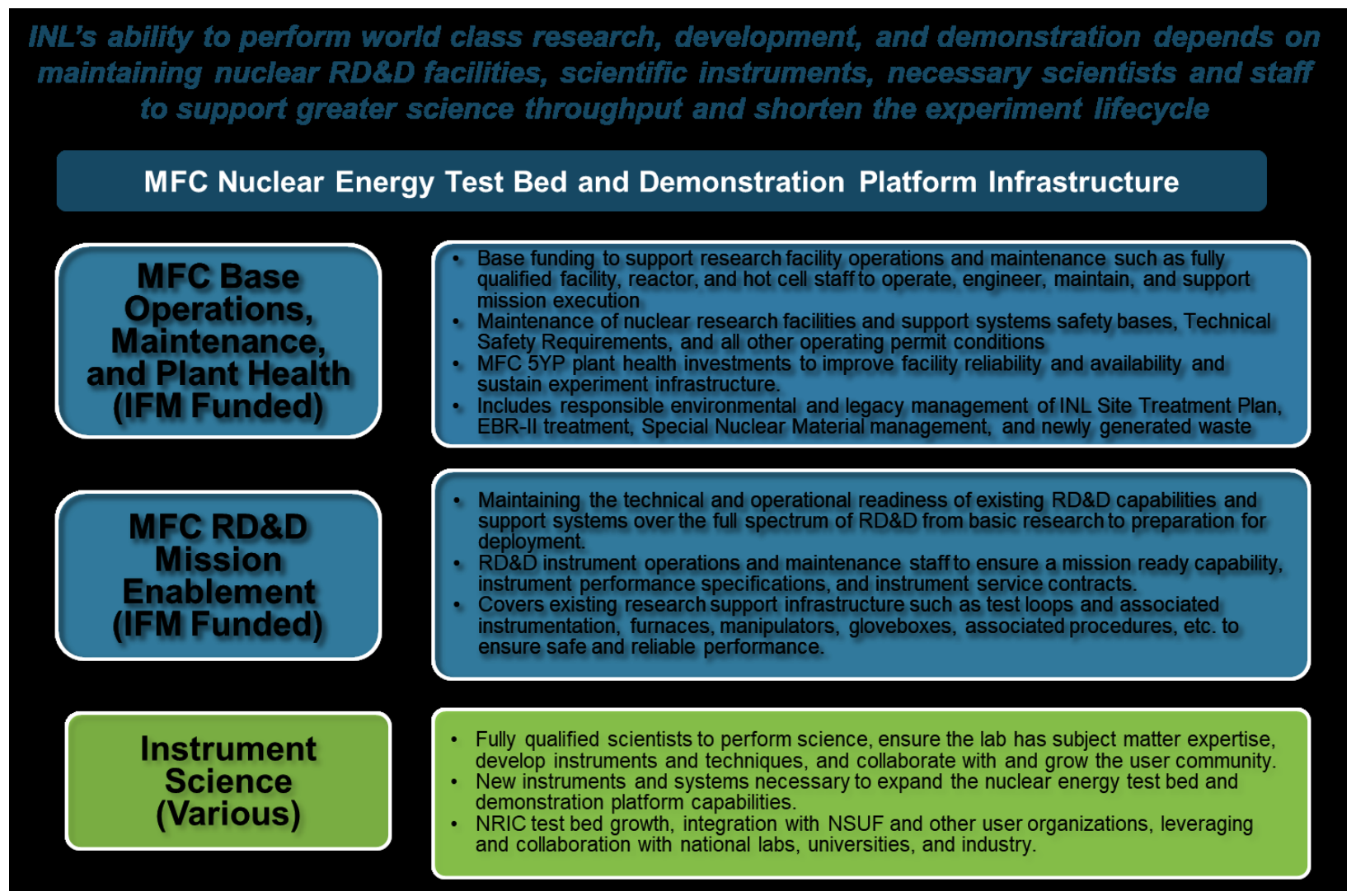

Figure 6. MFC User Facility Funding Model. 
The user facility model uses a consistent and simplified approach to funding (see Figure 6) that aligns with the operation of MFC as an RD\&D test bed. It draws from the funding models used for successful operation of other national user facilities. The proposed model accounts for three key lines of asset funding: (1) MFC Base Operations, Maintenance and Plant Health, (2) MFC RD\&D Mission Enablement, and (3) Instrument Science.

- $\quad$ MFC Base Operations, Maintenance, and Plant Health provides compliance-level support to operate and maintain MFC nuclear and radiological facilities in a safe, stable, and compliant state of readiness to accept work. It includes funding for staff to operate, engineer, maintain, and support mission execution in reactors and hot cells. Plant health refers to additional investment beyond basic preventative and corrective maintenance that addresses revitalization and refurbishment activities focused on improving facility reliability and accelerating research throughput. This supports DOE-NE programmatic objectives by maintaining and improving existing test bed infrastructure and constructing new support infrastructure, as needed, to ensure the safe operation of MFC.

- $\quad$ MFC RD\&D Mission Enablement provides predictable and reliable funding to support a core team of expert RD\&D support staff and critical RD\&D test bed systems and infrastructure (including instruments), thus ensuring qualified personnel and systems are ready to support important research missions. Activities funded under Mission Enablement include instrument performance specifications and service contracts; and maintaining existing support infrastructure such as test loops, manipulators, and associated equipment and instrumentation. These are distinct from Base Operations activities, which focus on systems and infrastructure associated with building operations (heating, ventilating, and air conditioning [HVAC], electrical, safety systems, building roofs and shells, etc.) and maintain facility safety bases and compliance requirements.

- Instrument Science supports a staff of fully qualified scientists, engineers and technicians to perform $R \& D$ and ensures the laboratory has subject matter expertise to develop instruments and techniques, and collaborate with and grow the user community. Activities include collaborating with the Nuclear Scientific Users Facility, INL Nuclear Science and Technology (NS\&T) programs, National Homeland Security (NHS) programs, NRIC, and others to prioritize and pursue funding for construction or enhancement of future or current capabilities where national gaps exist. This can also include indirect laboratory investment in scientific capabilities.

Details of proposed investments in facility and instrument infrastructure are available in the companion document "Materials and Fuels Complex FY-21 - FY-25 Five-Year Investment Strategy" (INL/EXT-21-61529).

f. This document is scheduled to be issued during Q2 of FY 2021. 


\section{MFC FY-21 - FY-25 CRITICAL OUTCOMES}

As mentioned earlier, MFC supports the INL mission to discover, demonstrate, and secure innovative nuclear energy solutions, other clean energy options, and critical infrastructure. Details on the strategy to accomplish this mission are described in the INL Lab Agenda. ${ }^{g}$ The latter identifies the strategic initiatives and near-term RD\&D and mission-support activities necessary to accomplish INL strategic objectives for DOE-NE, other DOE programs and federal agencies, and deliver on INL's commitment to simultaneous excellence in science and technology (S\&T), operations, and community service. Each INL Directorate - including MFC - in turn maintains a 5-year strategy for supporting the INL mission based on the respective Directorate's mission responsibilities and capabilities. These strategies are documented in Directorate-level strategic or mission plans and are updated annually.

Because of the RD\&D assets and capabilities available within the MFC complex, the MFC Directorate contributes to the accomplishment of the INL mission both directly and by supporting the mission of other INL Directorates, especially the NS\&T and N\&HS Directorates ${ }^{\mathrm{h}}$. MFC also supports important research for NASA. Hence, the needs of these Directorates and programs are a significant input to the MFC mission plan. In order to effectively serve the INL mission and support the entities just described, MFC must achieve the following critical-to-success outcomes during the FY-21 - FY-25 5-year term:

1. Enable and accelerate the demonstration, testing, and operational deployment of advanced reactors, working in close collaboration with NRIC, NASA and private partners

2. Fabricate and supply innovative nuclear fuels for demonstration and test reactors, and advance technologies and processes for treatment of used fuel

3. Perform irradiation, analysis and testing of fuel and materials benefiting nuclear applications ranging from improved performance of operating reactors to radioisotope production

4. Provide components and/or technology to meet NASA objectives for radioisotope power generation

5. Fulfill environmental stewardship commitments.

Accomplishments of these critical outcomes while excelling in safety and operational performance will advance the following three of the four mission-enabling INL strategic objectives documented in the INL Lab Agenda:

- Sustained and expanded nuclear energy leadership to advance a low-carbon energy future and increase the contribution of nuclear energy to the nation's energy mix (Science \& Technical Excellence)

- Increased performance and economic competitiveness of materials for extreme environments, including advanced energy-generation and management systems, and space and defense systems (Science \& Technical Excellence)

- Achieve excellence in Laboratory operations and enable modern science by transforming INL infrastructure, capabilities, systems, and processes (Operational Excellence)

Additional information on how these three INL strategic objectives flow down to the MFC critical outcomes is provided in Appendix D. The rest of this section describes the MFC critical outcomes in more detail.

\section{Enable and Accelerate the Demonstration, Testing, and Operational Deployment of Advanced Reactors, Working in Close Collaboration With NRIC, NASA and Private Partners}

g. FY 2020 Detailed Lab Agenda Mid-Year Update

h. Information on the NS\&T and N\&HS strategies can be found in the 2020-2025 NS\&T Strategic Plan and Implementing Framework and the 2018-2023 N\&HS Strategic Plan, respectively. 
MFC's unique expertise, experience and facilities make it the premier location in the US for enabling the demonstration of advanced reactors planned within the next decade. Specific strategic initiatives include

- $\quad$ NRIC Support - MFC plays a crucial role in the success of a key component of the NRIC strategy to provide a network of test beds and sites that can accommodate a wide variety of demonstration reactors with a Congressionally-mandated objective of demonstrating advanced reactor concepts by 2025.

- Project Pele - MFC capabilities are also well-suited to assist the Strategic Capabilities Office (SCO) of the DOD in achieving the objective of Project Pele to perform power testing of a microreactor by the end of 2023.

- Versatile Test Reactor (VTR) - With the selection of INL as the preferred alternative for the siting of the VTR, MFC must continue to support VTR planning and design, starting with serving as a reference site for VTR scoping studies. The VTR is a sodium-cooled fast test reactor being developed with support from DOE-NE to provide accelerated irradiation testing capabilities in the U.S. and is scheduled to reach criticality as early as 2026 .

- NASA Surface Fission Power - This is a collaborative effort with NASA and soon private firms for a demonstration mission to the lunar surface. The goal is an autonomous reactor of approximately $10 \mathrm{kWe}$ size to operate for several years.

- NASA Nuclear Thermal Propulsion - This is a collaborative effort with NASA and private industry to provide for a system that can allow human travel to Mars. The system will likely be complete in the 2030s and consist of a $\sim 100$ MWth reactor capable of supplying a stream of very hot hydrogen gas to provide thrust for a spacecraft.

The success of these and other demonstration initiatives will rely on an efficient collaboration framework between MFC, NRIC, DOD-SCO, private advanced reactor developers, and other national laboratories.

Key Stakeholder(s): DOE-NE, DOD-SCO, NS\&T, NRIC, NASA, advanced reactor developers MFC Divisions with Applicable Facilities: Fuel Fabrication and Nuclear Material Management (FFNMM); Transient Reactor Test (TREAT) facility; Space Nuclear Power \& Isotope Technologies; MFC Production Facilities, including the Fuel Conditioning Facility (FCF)

Applicable MFC Competencies: Nuclear fuels fabrication and characterization; Fuel recycling and nuclear material management; Space nuclear power

i. FY 2021 INL Performance Evaluation and Measurement Plan (PEMP) 
Table 3. FY-21 - FY-25 Activities: Enable and accelerate the demonstration, testing, and operational deployment of advanced reactors.

\begin{tabular}{|c|c|c|c|}
\hline Activity & Sub-Task (if applicable) & $\begin{array}{c}\text { Related FY-21 } \\
\text { PEMP/Notable } \\
\text { Outcome }^{\mathbf{i}}\end{array}$ & $\begin{array}{l}\text { Related FY-20 Lab } \\
\text { Agenda Initiative }\end{array}$ \\
\hline \multirow{4}{*}{$\begin{array}{l}\text { Continue to support the } \\
\text { NRIC mission }\end{array}$} & $\begin{array}{l}\text { Complete preparation of the Experimental } \\
\text { Breeder Reactor-II Test Bed and the Zero } \\
\text { Power Physics Reactor Test Bed in time } \\
\text { to host a microreactor demonstration by } \\
2023\end{array}$ & & $\begin{array}{l}\text { Nuclear reactor } \\
\text { sustainment and } \\
\text { expanded } \\
\text { deployment }\end{array}$ \\
\hline & $\begin{array}{l}\text { Support N\&ST in the design of the } \\
\text { Molten Salt Thermophysical Examination } \\
\text { Capability (MSTEC) and in related } \\
\text { procurement activities, and prepare for } \\
\text { potential installation in FCF }\end{array}$ & & \\
\hline & $\begin{array}{l}\text { Prepare TREAT for hosting the } \\
\text { Microreactor Applications Research, } \\
\text { Validation and Evaluation (MARVEL) } \\
\text { reactor, including establishment of an } \\
\text { integrated electrically heated test system } \\
\text { in FY-21 }\end{array}$ & $\begin{array}{l}\text { Notable } \\
\text { Outcome 1.1.D } \\
\text { - Microreactors }\end{array}$ & $\begin{array}{l}\text { Nuclear reactor } \\
\text { sustainment and } \\
\text { expanded } \\
\text { deployment }\end{array}$ \\
\hline & $\begin{array}{l}\text { Support as needed private companies } \\
\text { awarded funding under the Advanced } \\
\text { Reactor Demonstration Program }\end{array}$ & & \\
\hline $\begin{array}{l}\text { Contribute to the design } \\
\text { and approval of the VTR }\end{array}$ & $\begin{array}{l}\text { Continue to support siting efforts at MFC } \\
\text { for the VTR }\end{array}$ & & $\begin{array}{l}\text { Nuclear reactor } \\
\text { sustainment and } \\
\text { expanded } \\
\text { deployment }\end{array}$ \\
\hline $\begin{array}{l}\text { Support Project Pele } \\
\text { microreactor } \\
\text { demonstration }\end{array}$ & $\begin{array}{l}\text { Complete preparation of the Experimental } \\
\text { Breeder Reactor-II Test Bed for } \\
\text { microreactor demonstration }\end{array}$ & & $\begin{array}{l}\text { Nuclear reactor } \\
\text { sustainment and } \\
\text { expanded } \\
\text { deployment }\end{array}$ \\
\hline \multirow{2}{*}{$\begin{array}{l}\text { Support NASA fuel- } \\
\text { development plan for } \\
\text { ceramic-metallic and } \\
\text { ceramic-ceramic fuel for a } \\
\text { nuclear thermal } \\
\text { propulsion system }\end{array}$} & $\begin{array}{l}\text { Complete the Sirius } 2 \mathrm{~b} \text { irradiation cycle } \\
\text { in TREAT during FY- } 21\end{array}$ & \multirow{2}{*}{$\begin{array}{l}\text { Notable } \\
\text { Outcome 1.4.B } \\
\text { - NASA } \\
\text { Programs }\end{array}$} & \multirow{2}{*}{$\begin{array}{l}\text { Nuclear reactor } \\
\text { sustainment and } \\
\text { expanded } \\
\text { deployment } \\
\text { Advanced materials } \\
\text { and manufacturing } \\
\text { for extreme } \\
\text { environments }\end{array}$} \\
\hline & $\begin{array}{l}\text { Perform full-element fuel and moderator } \\
\text { tests at TREAT using flowing hydrogen }\end{array}$ & & \\
\hline $\begin{array}{l}\text { Support design and } \\
\text { testing efforts for a fission } \\
\text { surface power system } \\
\text { planned for late } 2020 \mathrm{~s} \\
\text { launch }\end{array}$ & & $\begin{array}{l}\text { Notable } \\
\text { Outcome 1.4.B } \\
\text { - NASA } \\
\text { Programs }\end{array}$ & \\
\hline $\begin{array}{l}\text { Support development of } \\
\text { waste management } \\
\text { strategies, interim storage, } \\
\text { funding strategies and } \\
\text { disposition }\end{array}$ & & & \\
\hline
\end{tabular}

i. $\quad$ FY 2021 INL Performance Evaluation and Measurement Plan (PEMP) 


\begin{tabular}{|l|l|l|l|}
\hline \multicolumn{1}{|c|}{ Activity } & Sub-Task (if applicable) & $\begin{array}{c}\text { Related FY-21 } \\
\text { PEMP/Notable } \\
\text { Outcome }\end{array}$ & $\begin{array}{l}\text { Related FY-20 Lab } \\
\text { Agenda Initiative }\end{array}$ \\
\hline $\begin{array}{l}\text { Prepare the MFC } \\
\text { organization to } \\
\text { accommodate training } \\
\text { and qualification of } \\
\text { reactor operators for } \\
\text { testing and demonstration } \\
\text { reactors }\end{array}$ & & $\begin{array}{l}\text { Nuclear reactor } \\
\text { sustainment and } \\
\text { expanded } \\
\text { deployment }\end{array}$ \\
\hline $\begin{array}{l}\text { Engage with private } \\
\text { entities planning to use }\end{array}$ & $\begin{array}{l}\text { MFC facilities and test } \\
\text { beds to ensure mutual } \\
\text { understanding of } \\
\text { capabilities and } \\
\text { requirements }\end{array}$ & & $\begin{array}{l}\text { Nuclear reactor } \\
\text { sustainment and } \\
\text { expanded } \\
\text { deployment }\end{array}$ \\
\hline
\end{tabular}

\section{Fabricate and Supply Innovative Nuclear Fuels for Demonstration and Test Reactors, and Advance Technologies and Processes for Treatment of Used Fuel}

Several of the promising advanced reactor and microreactor designs employ high-assay low-enriched uranium (HALEU) fuel. There is currently no commercial supply chain for HALEU fuel in the U.S., and one is not expected in time to support the fueling of demonstration reactors scheduled within the 2023-2025 period. MFC will leverage its expertise and facilities to address this gap by developing and implementing more efficient engineering-scale processes for downblending existing high-enriched uranium inventory into an interim HALEU supply for advanced reactor developers.

MFC expertise and assets will also support R \& D for the secure transportation, storage, and disposition of radiological materials generated by these advanced reactor technologies, including used fuel. Furthermore, MFC will assist in developing an integrated civilian nuclear fuel cycle test bed capability that includes the ability to process both $\mathrm{U}$ and $\mathrm{Pu}$ as well as testing of new nonproliferation technologies.

Key Stakeholder(s): DOE-NE, DOE-NNSA, NS\&T, N\&HS, advanced reactor developers

MFC Divisions with Applicable Facilities: MFC Production Facilities; Fuel Fabrication and Nuclear Material Management (FFNMM); Hot Fuel Examination Facility; Characterization and Advanced Post Irradiation Examination (CAPIE); Analytical Research Laboratories

Applicable MFC Competencies: Nuclear fuels fabrication and characterization; Fuel recycling and nuclear material management; Nuclear nonproliferation and nuclear forensics; Radioanalytical chemistry; Focused basic research

Table 4. FY-21 - FY-25 Activities: Fabricate and supply innovative nuclear fuels for demonstration and test reactors, and advance technologies and processes for treatment of used fuel.

j. $\quad$ PLN-6098 Revision 1, "Treatment Plan for Irradiated Sodium-Bonded Driver Fuel and the Production of High-Assay LowEnriched Uranium,” November 2020 


\begin{tabular}{|c|c|c|c|}
\hline Activity & Sub-Task (if applicable) & $\begin{array}{l}\text { Related FY-21 } \\
\text { PEMP/Notable } \\
\text { Outcome }\end{array}$ & $\begin{array}{l}\text { Related FY-20 Lab } \\
\text { Agenda Initiative }\end{array}$ \\
\hline $\begin{array}{l}\text { Produce an interim supply } \\
\text { of HALEU from } \\
\text { treatment of EBR-II spent } \\
\text { fuel in the Fuel } \\
\text { Conditioning Facility } \\
\text { (FCF) and recasting in } \\
\text { regulus form in HFEF }\end{array}$ & $\begin{array}{l}\text { Continue processing and process } \\
\text { enhancement as defined in PLN-6098 }\end{array}$ & $\begin{array}{l}\text { Notable } \\
\text { Outcome 2.3.C } \\
\text { - Maximize } \\
\text { EBR-II driver } \\
\text { SNF processing } \\
\text { and EBR-II } \\
\text { blanket SNF } \\
\text { treatment } \\
\text { alternative } \\
\text { research (within } \\
\text { available } \\
\text { funding) }\end{array}$ & \multirow[t]{3}{*}{$\begin{array}{l}\text { Integrated fuel cycle } \\
\text { solutions }\end{array}$} \\
\hline \multirow{2}{*}{$\begin{array}{l}\text { Prepare MFC buildings } \\
\text { for installation of fuel } \\
\text { fabrication and } \\
\text { production equipment for } \\
\text { campaign-style, } \\
\text { engineering-scale fuel } \\
\text { production }\end{array}$} & $\begin{array}{l}\text { Develop and demonstrate cutting-edge, } \\
\text { fabrication techniques and processes, } \\
\text { including the development of Advanced } \\
\text { Manufacturing techniques for nuclear fuel }\end{array}$ & & \\
\hline & $\begin{array}{l}\text { Continue planning for the Reactor Fuels } \\
\text { Research Laboratory that will provide a } \\
\text { flexible and reconfigurable Hazard } \\
\text { Category } 2 \text { fuel fabrication facility (see } \\
\text { Appendix C) }\end{array}$ & & \\
\hline \multirow{2}{*}{$\begin{array}{l}\text { Contribute to the design } \\
\text { and approval of the VTR }\end{array}$} & $\begin{array}{l}\text { Ensure the INL alternative for MFC siting } \\
\text { of VTR fuel production is sufficiently } \\
\text { elaborated to enable successful VTR site } \\
\text { selection }\end{array}$ & $\begin{array}{l}\text { Notable } \\
\text { Outcome 1.1.A } \\
\text { - Versatile Test } \\
\text { Reactor (VTR) }\end{array}$ & \multirow{3}{*}{$\begin{array}{l}\text { Nuclear reactor } \\
\text { sustainment and } \\
\text { expanded } \\
\text { deployment }\end{array}$} \\
\hline & $\begin{array}{l}\text { Evaluate the production of U/Pu metallic } \\
\text { fuel for the VTR, evaluating options to } \\
\text { use existing space within the ZPPR Test } \\
\text { Bed facility or adding more Safeguard } \\
\text { Category I space }\end{array}$ & & \\
\hline \multicolumn{3}{|l|}{$\begin{array}{l}\text { Provide fuel elements for } \\
\text { the MARVEL reactor }\end{array}$} & \\
\hline $\begin{array}{l}\text { Complete the Joint Fuel } \\
\text { Cycle Study (JFCS), an } \\
\text { international } \\
\text { collaboration between the } \\
\text { U.S. and the Republic of } \\
\text { Korea to demonstrate } \\
\text { recycling of LWR fuel } \\
\text { with pyrochemical } \\
\text { techniques }\end{array}$ & & $\begin{array}{l}\text { Notable } \\
\text { Outcome 1.1.C } \\
\text { - Fuel Cycle }\end{array}$ & \multirow{3}{*}{$\begin{array}{l}\text { Integrated fuel cycle } \\
\text { solutions }\end{array}$} \\
\hline $\begin{array}{l}\text { Continue to develop and } \\
\text { demonstrate capabilities } \\
\text { for nuclear fuel-related } \\
\text { basic and applied science } \\
\text { research }\end{array}$ & $\begin{array}{l}\text { Support research on nuclear fuel } \\
\text { processing that results in increased } \\
\text { energy extraction and less spent material } \\
\text { generation }\end{array}$ & & \\
\hline $\begin{array}{l}\text { Develop innovative } \\
\text { solutions for the } \\
\text { processing, storage, }\end{array}$ & $\begin{array}{l}\text { Continue testing on zirconium/aluminum- } \\
\text { cladding removal with a chloride } \\
\text { volatility process (Zircex) }\end{array}$ & & \\
\hline
\end{tabular}

j. $\quad$ PLN-6098 Revision 1, "Treatment Plan for Irradiated Sodium-Bonded Driver Fuel and the Production of High-Assay LowEnriched Uranium,” November 2020 


\begin{tabular}{|l|l|l|l|}
\hline \multicolumn{1}{|c|}{ Activity } & \multicolumn{1}{|c|}{ Sub-Task (if applicable) } & $\begin{array}{c}\text { Related FY-21 } \\
\text { PEMP/Notable } \\
\text { Outcome }\end{array}$ & $\begin{array}{c}\text { Related FY-20 Lab } \\
\text { Agenda Initiative }\end{array}$ \\
\hline $\begin{array}{l}\text { transportation, and } \\
\text { treatment of used fuel }\end{array}$ & $\begin{array}{l}\text { Develop U/Pu process test bed (Project } \\
\text { Beartooth) }\end{array}$ & \begin{tabular}{l} 
Integrated fuel cycle \\
Solutions \\
\cline { 2 - 4 } \\
Safety case for various HALEU forms. \\
Obuclear reactor \\
sustainment and \\
expanded \\
deployment
\end{tabular} \\
\hline $\begin{array}{l}\text { Support N\&HS Mission } \\
\text { to advance security } \\
\begin{array}{l}\text { solutions that prevent, } \\
\text { detect, and counter } \\
\text { nuclear and radiological } \\
\text { threats }\end{array}\end{array}$ & $\begin{array}{l}\text { Assist in fuels R\&D for proliferation } \\
\text { resistance }\end{array}$ & $\begin{array}{l}\text { Integrated fuel cycle } \\
\text { solutions }\end{array}$ \\
\hline
\end{tabular}

\section{Perform Irradiation, Analysis and Testing of Fuel and Materials Benefiting Nuclear Applications Ranging From Improved Performance of Operating Reactors to Radioisotope Production}

When combined with the thermal irradiation available at the ATR, MFC's TREAT reactor, hot cells, and analytical laboratories provide a comprehensive suite of capabilities that can foster the R\&D needed to deploy nuclear-reactor components and fuels with revolutionary performance improvements and cost competitiveness. These would benefit both operating reactors and advanced reactors, including the preand post-irradiation analysis of accident-tolerant fuel for commercial reactors and the evaluation of material properties of advanced-manufactured components subjected to the temperature and radiation environments expected in advanced or operating reactors. Several of these tests and evaluations are planned within the FY-21 - FY-25 period.

The MFC and ATR capabilities will also be utilized to assist with the mission of the DOE Office of Science (DOE-SC) for U.S.-based production of radioisotopes such as cobalt-60 that have important medical and industrial applications.

Key Stakeholder(s): DOE-NE; NS\&T; commercial reactor operators; advanced reactor developers; DOE-SC

MFC Divisions with Applicable Facilities: Hot Fuel Examination Facility; Characterization and Advanced Post Irradiation Examination (CAPIE); Analytical Research Laboratories; Transient Reactor Test (TREAT) facility; Space Nuclear Power \& Isotope Technologies; Fuel Fabrication and Nuclear Material Management (FFNMM)

Applicable MFC Competencies: Nuclear fuels fabrication and characterization; Transient irradiation testing; Assessing radiation damage in cladding and in-core structural materials; Radioanalytical chemistry; Space nuclear power and isotope technologies; Focused basic research

Table 5. FY-21 - FY-25 Activities: Perform irradiation, analysis and testing of fuel and materials benefiting nuclear applications.

\begin{tabular}{|l|l|l|l|}
\hline \multicolumn{1}{|c|}{ Activity } & \multicolumn{1}{|c|}{ Sub-Task (if applicable) } & $\begin{array}{l}\text { Related FY-21 } \\
\text { PEMP/Notable } \\
\text { Outcome }\end{array}$ & $\begin{array}{l}\text { Related FY-20 Lab } \\
\text { Agenda Initiative }\end{array}$ \\
\hline $\begin{array}{l}\text { Complete establishment } \\
\text { of new irradiation testing } \\
\text { and fabrication } \\
\text { capabilities at INL to }\end{array}$ & $\begin{array}{l}\text { Execute the TREAT test program to } \\
\text { provide results needed to evaluate and } \\
\text { demonstrate safety-related behavior of } \\
\text { nuclear fuel and nuclear reactor concepts }\end{array}$ & $\begin{array}{l}\text { Notable } \\
\text { Outcome 1.1.B } \\
\text { - Advanced } \\
\text { Fuel (ATF) }\end{array}$ & $\begin{array}{l}\text { Nuclear reactor } \\
\text { sustainment and } \\
\text { expanded } \\
\text { deployment }\end{array}$ \\
\hline
\end{tabular}




\begin{tabular}{|c|c|c|c|}
\hline Activity & Sub-Task (if applicable) & $\begin{array}{l}\text { Related FY-21 } \\
\text { PEMP/Notable } \\
\text { Outcome }\end{array}$ & $\begin{array}{l}\text { Related FY-20 Lab } \\
\text { Agenda Initiative }\end{array}$ \\
\hline $\begin{array}{l}\text { support Accident Tolerant } \\
\text { Fuel (ATF) deployment }\end{array}$ & $\begin{array}{l}\text { Complete the Experiment Preparation and } \\
\text { Inspection Cell (EPIC) to add capability } \\
\text { to install instrument sensors onto test rods } \\
\text { refabricated from shortened pre-irradiated } \\
\text { fuel rods }\end{array}$ & & \\
\hline $\begin{array}{l}\text { Characterize and test } \\
\text { advanced-manufactured } \\
\text { fuel and components }\end{array}$ & & & $\begin{array}{l}\text { Advanced materials } \\
\text { and manufacturing } \\
\text { for extreme } \\
\text { environments }\end{array}$ \\
\hline $\begin{array}{l}\text { Continue examination of } \\
\text { TRISO fuel }\end{array}$ & $\begin{array}{l}\text { Support TRISO R\&D for microreactor } \\
\text { designs and high-temperature gas reactors }\end{array}$ & & $\begin{array}{l}\text { Nuclear reactor } \\
\text { sustainment and } \\
\text { expanded } \\
\text { deployment }\end{array}$ \\
\hline \multirow{5}{*}{$\begin{array}{l}\text { Reduce the time required } \\
\text { for engineering-scale post } \\
\text { irradiation examination } \\
\text { by a factor of ten or more }\end{array}$} & $\begin{array}{l}\text { Collaborate with N\&ST Directorate to } \\
\text { demonstrate effective coupling of } \\
\text { modeling and simulation with experiment }\end{array}$ & & \multirow{6}{*}{$\begin{array}{l}\text { Nuclear reactor } \\
\text { sustainment and } \\
\text { expanded } \\
\text { deployment }\end{array}$} \\
\hline & $\begin{array}{l}\text { Expand the use of online instrumentation } \\
\text { to accelerate the analysis of irradiation } \\
\text { experiments }\end{array}$ & & \\
\hline & $\begin{array}{l}\text { Re-evaluate post irradiation examination } \\
\text { instruments and workflow for } \\
\text { optimization }\end{array}$ & & \\
\hline & $\begin{array}{l}\text { Explore the application of Artificial } \\
\text { Intelligence/Machine Learning to } \\
\text { accelerate data analysis }\end{array}$ & & \\
\hline & $\begin{array}{l}\text { Expand the use of robotics to automate } \\
\text { and accelerate the examination of } \\
\text { irradiated materials }\end{array}$ & & \\
\hline \multicolumn{3}{|l|}{$\begin{array}{l}\text { Leverage TREAT to } \\
\text { address some of the } \\
\text { capability gaps resulting } \\
\text { from the closure of the } \\
\text { Halden research reactor }\end{array}$} & \\
\hline $\begin{array}{l}\text { Support DOE-SC isotope } \\
\text { production strategy. }\end{array}$ & $\begin{array}{l}\text { Continue to support DOE-SC initiative on } \\
\text { cobalt- } 60\end{array}$ & & \\
\hline $\begin{array}{l}\text { Continue R \& D in } \\
\text { support of Naval Reactors } \\
\text { program }\end{array}$ & & & $\begin{array}{l}\text { Nuclear reactor } \\
\text { sustainment and } \\
\text { expanded } \\
\text { deployment } \\
\end{array}$ \\
\hline \multirow{2}{*}{$\begin{array}{l}\text { Attract external users } \\
\text { from industry and } \\
\text { academia through GAIN, } \\
\text { NEUP and NSUF } \\
\text { collaborations to perform } \\
\text { innovative R \& D related } \\
\text { to nuclear technology } \\
\text { applications }\end{array}$} & $\begin{array}{l}\text { Engage or re-engage with industry } \\
\text { partners to apply for GAIN vouchers }\end{array}$ & & $\begin{array}{l}\text { Nuclear reactor } \\
\text { sustainment and } \\
\text { expanded } \\
\text { deployment } \\
\end{array}$ \\
\hline & $\begin{array}{l}\text { Increase outreach to a broader set of } \\
\text { universities }\end{array}$ & & All \\
\hline
\end{tabular}

\section{Provide Components and/or Technology to Meet NASA Objectives for Radioisotope Power Generation}


Nuclear-sourced power - whether from radioisotopes or from fission reactors - is expected to play a vital role in NASA's upcoming missions such as the Dragonfly mission to explore Saturn's moon Titan and the establishment of human outposts, first on the moon and then on to other heavenly bodies, such as Mars. MFC's Space Nuclear Power \& Isotope Technologies division, in collaboration with the ATR and other national laboratories, will continue to lead DOE-NE activities to supply $\mathrm{Pu}-238$ for the radioisotope power systems used for NASA's deep-space exploration needs.

\section{Key Stakeholder(s): DOE-NE, NASA}

MFC Divisions with Applicable Facilities: Space Nuclear Power \& Isotope Technologies; Transient Reactor Test (TREAT) facility; Fuel Fabrication and Nuclear Material Management

Applicable MFC Competencies: Space nuclear power and isotope technologies; Nuclear fuels fabrication and characterization; Transient irradiation testing

Table 6. FY-21 - FY-25 Activities: Provide components and/or technology to meet NASA objectives.

\begin{tabular}{|c|c|c|c|}
\hline Activity & Sub-Task (if applicable) & $\begin{array}{c}\text { Related FY-21 } \\
\text { PEMP/Notable } \\
\text { Outcome }\end{array}$ & $\begin{array}{c}\text { Related FY-20 } \\
\text { Lab Agenda } \\
\text { Initiative }\end{array}$ \\
\hline $\begin{array}{l}\text { Initiate fabrication of Multi- } \\
\text { Mission Thermal Electric } \\
\text { Generators (MMRTGs) for } \\
\text { application to future NASA } \\
\text { missions }\end{array}$ & $\begin{array}{l}\text { Work on a customized MMRTG } \\
\text { version for the Dragonfly mission }\end{array}$ & $\begin{array}{l}\text { Notable } \\
\text { Outcome 1.4.B } \\
\text { - NASA } \\
\text { Programs }\end{array}$ & \\
\hline $\begin{array}{l}\text { Continue duties as National } \\
\text { Technical Director for Space } \\
\text { Nuclear Power }\end{array}$ & $\begin{array}{l}\text { Work with other national laboratories as } \\
\text { members of the Space Nuclear Power } \\
\text { Advisory Board to provide support for } \\
\text { DOE and NASA in several key areas: } \\
\text {-Replanning of launch safety planning } \\
\text {-Provide for better coordination and } \\
\text { vetting of alternative technologies for } \\
\text { space nuclear applications such as new } \\
\text { proposed power systems, power } \\
\text { conversion systems or radioisotopes. }\end{array}$ & $\begin{array}{l}\text { Notable } \\
\text { Outcome 1.4.B } \\
\text { - NASA } \\
\text { Programs }\end{array}$ & $\begin{array}{l}\text { Nuclear reactor } \\
\text { sustainment and } \\
\text { expanded } \\
\text { deployment }\end{array}$ \\
\hline
\end{tabular}




\section{Fulfill Environmental Stewardship Commitments}

INL shares the responsibility for the DOE's legacy nuclear waste and fuel on the INL site with the Idaho Cleanup Project (managed by Fluor Idaho). This responsibility involves the fulfillment of Regulatory Milestone Commitments to the State of Idaho as described in the Idaho Site Treatment Plan (STP), 1995 Settlement Agreement between the state of Idaho and the DOE, and in subsequent supplemental agreements signed in 2019 and 2020. MFC will play a key role in fulfilling several of these commitments, including the reprocessing of EBR-II fuel by 2028. INL and MFC plan to leverage capabilities and expertise in treatment and disposition of sodium and $\mathrm{NaK}$ components and the processing of sodium-bonded fuel to develop treatment technologies and disposition options for the legacy EBR-II fuel, as well as for the future inventory of used sodium-bonded fuel generated by advanced reactor technologies (see Subsection 3.2).

Key Stakeholder(s): DOE-NE Idaho Facilities Management, DOE Office of Environmental Management, DOE-NNSA, State of Idaho

MFC Divisions with Applicable Facilities: MFC Production Facilities, Fuel Fabrication and Nuclear Material Management, Analytical Research Laboratories

Applicable MFC Competencies: Fuel recycling and nuclear material management; Radioanalytical chemistry, sodium treatment capabilities and permitted storage capabilities

Table 7. FY-21 - FY-25 Activities: Fulfill environmental stewardship commitments.

\begin{tabular}{|c|c|c|c|}
\hline Activity & Sub-Task (if applicable) & $\begin{array}{l}\text { Related FY-21 } \\
\text { PEMP/Notable } \\
\text { Outcome }\end{array}$ & $\begin{array}{c}\text { Related FY-20 Lab } \\
\text { Agenda Initiative }\end{array}$ \\
\hline \multirow{3}{*}{$\begin{array}{l}\text { Develop treatment } \\
\text { technologies and } \\
\text { disposition options for } \\
\text { sodium-bonded fuels }\end{array}$} & $\begin{array}{l}\text { Maximize the number of treated } \\
\text { batches of sodium bonded } \\
\text { Experimental Breeder Reactor-II } \\
\text { Driver Fuel (EBR-II) in the Fuel } \\
\text { Conditioning Facility (FCF) Mark IV } \\
\text { electro-refiner }\end{array}$ & \multirow{3}{*}{$\begin{array}{l}\text { Notable Outcome } \\
\text { 2.3.B - Maximize } \\
\text { Experimental } \\
\text { Breeder Reactor- } \\
\text { II (EBR-II) driver } \\
\text { spent nuclear fuel } \\
\text { (SNF) receipts at } \\
\text { MFC in support } \\
\text { of the } 2019 \\
\text { Supplemental } \\
\text { Agreement } \\
\text { milestone. } \\
\text { Notable Outcome } \\
\text { 2.3.C - Maximize } \\
\text { EBR-II driver } \\
\text { SNF processing } \\
\text { and EBR-II } \\
\text { blanket SNF } \\
\text { treatment } \\
\text { alternative } \\
\text { research (within } \\
\text { available funding) }\end{array}$} & \multirow{4}{*}{$\begin{array}{l}\text { Operational } \\
\text { Excellence - } \\
\text { Advance INL's } \\
\text { stewardship of its } \\
\text { environmental } \\
\text { legacy } \\
\text { Integrated fuel cycle } \\
\text { solutions }\end{array}$} \\
\hline & $\begin{array}{l}\text { Within available funding, develop } \\
\text { alternate treatment methods for non- } \\
\text { candidate EBR-II driver SNF to } \\
\text { facilitate a successful outcome of the } \\
\text { December 31, 2028 Supplemental } \\
\text { Agreement milestone }\end{array}$ & & \\
\hline & $\begin{array}{l}\text { Continue alternative analysis, } R \& D \text { and } \\
\text { regulatory strategies for EBR II blanket } \\
\text { material within available funding }\end{array}$ & & \\
\hline $\begin{array}{l}\text { Continue active nuclear } \\
\text { material management \& } \\
\text { excess disposition of } \\
\text { MFC inventories }\end{array}$ & $\begin{array}{l}\text { Demonstrate disposal of legacy and } \\
\text { newly generated waste at commercial } \\
\text { facilities }\end{array}$ & $\begin{array}{l}\text { Notable Outcome } \\
\text { 1.1.C - Fuel } \\
\text { Cycle }\end{array}$ & \\
\hline
\end{tabular}




\section{STRATEGY FOR ACHIEVING CRITICAL OUTCOMES}

Achieving the outcomes described in the preceding section will rely on a strategy consisting of five principal elements:

- Maintaining operational excellence and best-in-class safety performance through the execution of the MFC OMI strategy

- Continuing to develop the scientific and engineering expertise that underpins the MFC core competencies

- Executing the 5-Year Investment plan, including the construction of a new reactor fuels research laboratory,

- Continuing to implement the MFC User Facility model, and

- Collaborating actively with other INL directorates, government agencies, private industry partners, other national laboratories, and academia to grow the MFC user base.

The actions contained in the OMI Strategy are intended to improve the effectiveness of MFC's facility operations and provide for overall improvement of the MFC organization. MFC will continue to implement an enhanced operations model focused on increasing facility reliability and shortening the experiment lifecycle. To this end, existing facilities will be modernized, and new infrastructure capability added. Furthermore, operations and maintenance processes such as engineering design approval, procurement, and equipment reliability will be continually assessed for simplification or upgrading, with the goals of improving reliability and, when appropriate, reducing administrative burden. Technologies that are already widely used in the non-nuclear industry such as robotics, artificial intelligence (AI), and augmented/virtual reality should be evaluated for their potential to improve efficiency at MFC. For example, MFC should actively leverage the INL Artificial Intelligence and Machine Learning Strategic Plan that is being developed by the NS\&T, N\&HS, and EES\&T Directorates.

INL works to embed safe conduct of research principles and human performance improvement (HPI) principles in its holistic culture of safety, based on the tenet that personnel and public safety is foundational to mission accomplishment ${ }^{\mathrm{k}}$. As a nuclear facility complex, MFC must address the unique characteristics and hazards associated with nuclear technology. In addition, MFC must handle the standard industrial hazards present in the systems, structures, and components which are utilized to perform work at MFC. Maintaining a healthy safety culture along with good processes and an environment that promotes continuous learning and improvement are therefore paramount to the ability of MFC to fulfill its mission.

A vibrant research culture is also an important enabler of the MFC mission. Efforts to improve the MFC research culture have already been initiated, mainly directed at encouraging R\&D staff to value RD\&D principles embodied in technical integrity, inquisitiveness, professional growth, and collaboration. These efforts will continue, and an updated set of metrics related to research performance is planned for rollout in FY-21. Furthermore, an MFC Mentor/Mentee program that focuses on personnel in science research roles will be initiated in FY-21.

k. Fundamental expectations relative to Nuclear Safety Culture, Human Performance Improvement, and Just Culture are codified in HBK-104, "MFC Human Performance and Nuclear Safety Culture Pocket Guide." 
Table 8. FY-21 - FY-25 Activities: Strategy for achieving critical outcomes.

\begin{tabular}{|c|c|c|c|}
\hline Activity & Sub-Task (if applicable) & $\begin{array}{l}\text { Related FY-21 } \\
\text { PEMP/Notable } \\
\text { Outcome }\end{array}$ & $\begin{array}{l}\text { Related FY-20 Lab } \\
\text { Agenda Initiative }\end{array}$ \\
\hline \multirow{2}{*}{$\begin{array}{l}\text { Maintain and execute the } \\
\text { MFC OMI Strategy }\end{array}$} & $\begin{array}{l}\text { Continually update and improve MFC } \\
\text { processes for greater safety, effectiveness, } \\
\text { and efficiency }\end{array}$ & & \multirow{16}{*}{$\begin{array}{l}\text { Operational } \\
\text { Excellence/ } \\
\text { Operations } \\
\text { Initiatives (various) }\end{array}$} \\
\hline & $\begin{array}{l}\text { Continue to fully leverage Asset Suite } \\
\text { capabilities }\end{array}$ & & \\
\hline \multirow{5}{*}{$\begin{array}{l}\text { Maintain and execute the } \\
\text { MFC Five-Year } \\
\text { Investment Strategy }\end{array}$} & Complete SPL construction & \multirow{5}{*}{$\begin{array}{l}\text { Notable } \\
\text { Outcome 2.3.A } \\
- \text { ATR and } \\
\text { MFC } \\
\text { Infrastructure } \\
\text { Investment for } \\
\text { reliability } \\
\text { Improvement }\end{array}$} & \\
\hline & $\begin{array}{l}\text { Initiate design and construction of the } \\
\text { reactor fuels research laboratory (see } \\
\text { Appendix C) }\end{array}$ & & \\
\hline & $\begin{array}{l}\text { Continue activities to provide offices, } \\
\text { shop space, and warehouse space capable } \\
\text { of supporting the increasing amount of } \\
\text { activities at MFC }\end{array}$ & & \\
\hline & $\begin{array}{l}\text { Update plan to ensure sufficient space } \\
\text { and facilities for Security Category I \& II } \\
\text { activities }\end{array}$ & & \\
\hline & Ensure facility reliability and availability & & \\
\hline \multirow{3}{*}{$\begin{array}{l}\text { Develop technical } \\
\text { expertise and capability }\end{array}$} & $\begin{array}{l}\text { Maintain current state-of-the art scientific } \\
\text { instruments and R\&D equipment }\end{array}$ & & \\
\hline & $\begin{array}{l}\text { Develop plans to hire and develop staff } \\
\text { with necessary skillset to use MFC } \\
\text { instruments and equipment }\end{array}$ & & \\
\hline & $\begin{array}{l}\text { Develop and apply new techniques and } \\
\text { processes that make new technology } \\
\text { increasingly available for nuclear R\&D }\end{array}$ & & \\
\hline \multirow{2}{*}{ Enhance research culture } & $\begin{array}{l}\text { Identify research metrics, and define and } \\
\text { implement a scheme or process for } \\
\text { tracking and reviewing metrics annually }\end{array}$ & & \\
\hline & $\begin{array}{l}\text { Develop an MFC Mentor/Mentee } \\
\text { program that focuses on personnel in } \\
\text { science research roles }\end{array}$ & & \\
\hline \multirow[b]{2}{*}{$\begin{array}{l}\text { Expand and improve the } \\
\text { implementation of the } \\
\text { MFC User Facility model }\end{array}$} & $\begin{array}{l}\text { Influence decision makers toward broader } \\
\text { funding of MFC as a user facility }\end{array}$ & & \\
\hline & $\begin{array}{l}\text { Deliver on commitments made to external } \\
\text { users, including those in the private } \\
\text { sector, other government agencies, and } \\
\text { universities }\end{array}$ & & \\
\hline \multirow{2}{*}{$\begin{array}{l}\text { Encourage a collaborative } \\
\text { culture among MFC R\&D } \\
\text { staff, facility operators } \\
\text { and support personnel, } \\
\text { and external users }\end{array}$} & $\begin{array}{l}\text { Broaden the implementation of the } \\
\text { instrument scientist concept across MFC } \\
\text { mission organizations }\end{array}$ & & \\
\hline & $\begin{array}{l}\text { Increase MFC engagement with the } \\
\text { Center for Advanced Energy Studies } \\
\text { (CAES) to assist with CAES mission } \\
\text { while building a pipeline of future talent }\end{array}$ & & \\
\hline
\end{tabular}

1. Information on CAES can be found at https://www.caesenergy.org/. 


\begin{tabular}{|l|l|l|l|}
\hline \multicolumn{1}{|c|}{ Activity } & \multicolumn{1}{|c|}{ Sub-Task (if applicable) } & $\begin{array}{c}\text { Related FY-21 } \\
\text { PEMP/Notable } \\
\text { Outcome }\end{array}$ & $\begin{array}{c}\text { Related FY-20 Lab } \\
\text { Agenda Initiative }\end{array}$ \\
\hline $\begin{array}{l}\text { Develop process to } \\
\text { prioritize and coordinate } \\
\text { demands for MFC } \\
\text { resources }\end{array}$ & $\begin{array}{l}\text { Develop in collaboration with NS\&T and } \\
\text { ATR Directorates an Irradiation Work } \\
\text { Acceptance Process for irradiation work } \\
\text { undertaken at INL }\end{array}$ & & \\
\hline $\begin{array}{l}\text { Develop risk management } \\
\text { plan to identify, rank, } \\
\text { track and address risks to } \\
\text { fulfilling critical } \\
\text { outcomes and to MFC } \\
\text { mission }\end{array}$ & $\begin{array}{l}\text { Leverage actions already captured in the } \\
\text { OMI Strategy that address major risk } \\
\text { categories, including tracking action } \\
\text { disposition }\end{array}$ & $\begin{array}{l}\text { Institute monthly Management Review } \\
\text { Meetings to identify and accurately } \\
\text { characterize significant MFC } \\
\text { performance gaps and risks to mission, } \\
\text { and apply appropriate emphasis and } \\
\text { methods to close the gaps }\end{array}$ & \\
\hline
\end{tabular}

1. Information on CAES can be found at https://www.caesenergy.org/. 


\section{RISKS AND CHALLENGES}

Accomplishing the outcomes described in Section 3 will require the mitigation, elimination and/or avoidance of challenges and risks. Some of the major risk/challenge categories expected during the next five years are

- Infrastructure

- Adequate planning and investment to maintain reliability of facilities is a concern.

- Lack of readily available large-area laboratory space and supporting technical staff for scale-up development and demonstration can lead to delays or even loss of opportunities.

- Limited space availability, especially in Security Category I and II and Hazard Category II facilities, can lead to conflicts between projects competing for the same space.

- MFC Funding and Investment

- A significant portion of the funding for activities planned at MFC is dependent on congressional budget allocations. The uncertainty in this funding source is well known, and presents substantial risks to program budget and schedule.

- Examples include funding to support advanced fuel fabrication and VTR

- Uncertainties exist in DOE-NE funding priorities for FY-21 and beyond that can negatively impact the ability of MFC to carry out needed maintenance and upgrades to aging facilities.

- Personnel

- Failure to successfully recruit, engage, develop and reward top talent presents a serious risk to mission accomplishment.

- Training and qualifying new researchers needed to replace current generation of subject matter experts approaching retirement requires careful planning and appropriate knowledge transfer processes.

- Safety

- Maintaining focus on industrial and radiological safety during times of high work activity can be challenging, leading to increased risks for personnel injury, environmental upsets, costly process and equipment failures, and impacted schedules.

- Work Execution

- Data management and analysis capabilities are lagging the ability to collect data.

- Increase in workload expected over the next five years may stretch the ability to deliver on commitments unless addressed through improved efficiency or personnel increase or combination thereof.

- Adoption of new technologies designed to increase efficiency can encounter resistance if not accompanied by well-crafted change management plans.

- External Stakeholder Commitments

- Loss of stakeholder confidence in INL's commitment to environmental stewardship can potentially impact INL future programs and mission, such as the ability to receive irradiated fuel for research purposes.

- Collaboration with Private-Industry and University Partners

- INL processes and procedures can be viewed as burdensome by external partners in industry and academia, which could hamper collaborative efforts with these entities. 
- Development Timescale for Nuclear Applications

- Nuclear technologies have inherent challenges related to the lengthy and expensive research, development, and demonstration process associated with bringing innovation to the nuclear industry, especially when regulatory approval is needed. While this is not an MFC-specific issue, MFC can contribute to its resolution by serving as a testbed for methods and processes to accelerate the transitioning of innovative concepts from the laboratory to the marketplace.

The risk categories mentioned above are not intended to be all-inclusive, but they represent some of the principal issues that MFC has faced or is facing. It should be noted that risks and challenges exist in most major endeavors, especially those that span multiple years. One of the most effective means to handle risk is through a living risk management plan that identifies risks and challenges early on, ranks and tracks their related mitigation/elimination/acceptance/avoidance activities, and is regularly updated throughout the period of performance. A corresponding activity to develop a risk management plan is captured in Table 8 of Section 7. 


\section{CLOSING}

Over the next five years, INL and MFC will be relied upon to help DOE-NE achieve its mission to advance nuclear energy science and technology to meet U.S. energy, environmental, and economic needs. MFC already has capabilities and infrastructure to support the R\&D efforts and demonstration test beds needed to underpin the next generation of nuclear technologies, and is in the process of adding new facilities such as the Sample Preparation Laboratory (Figure 7). Executing the strategy described in this document will ensure that MFC continues to maintain and expand upon these capabilities. It will also drive the accomplishment of the five critical outcomes that will position MFC to contribute to the success of the DOE-NE mission, and play a pivotal role in supplying the world with safe, affordable, clean and reliable energy, combating climate change, and regaining U.S. leadership in advanced reactor technology.

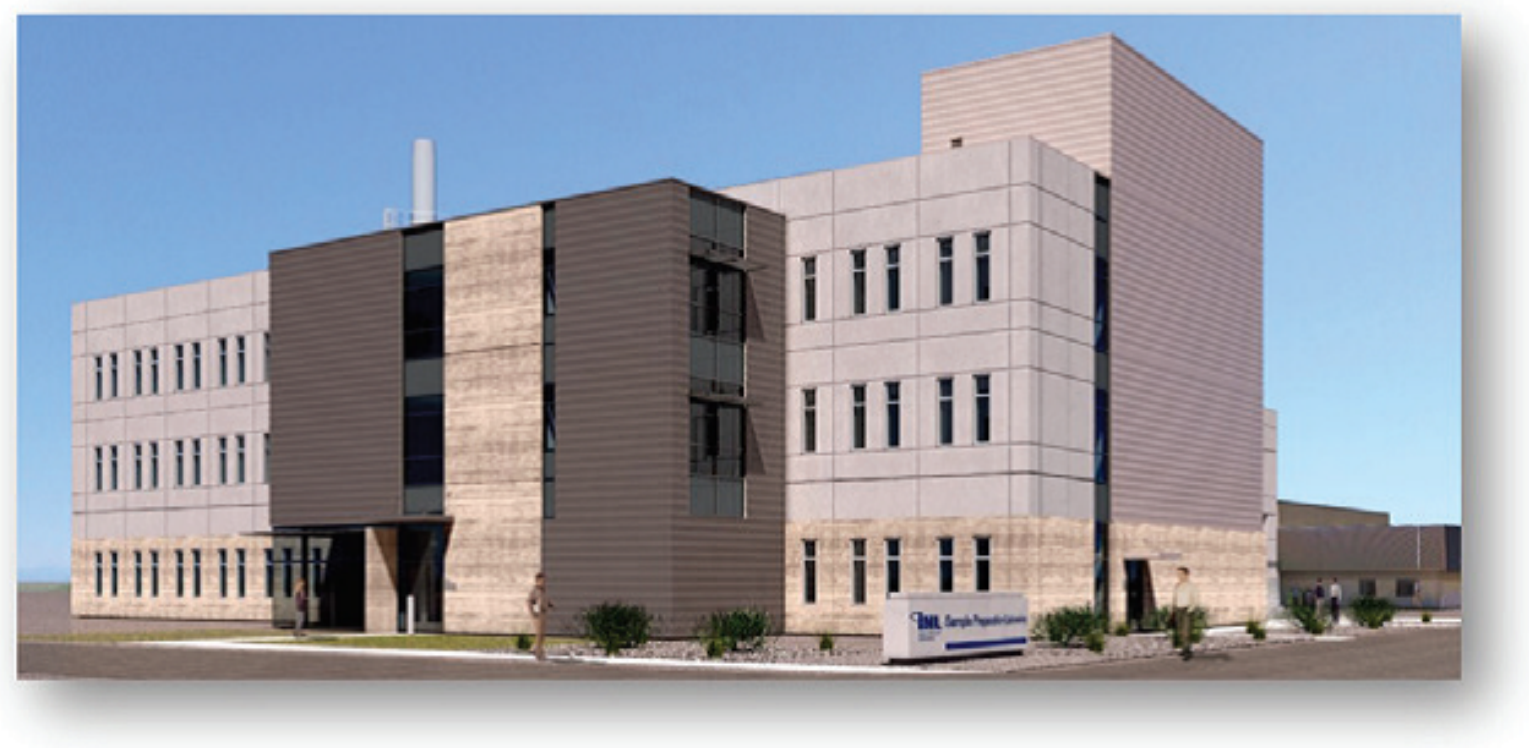

Figure 7. When completed, the MFC Sample Preparation Laboratory (SPL) will provide INL with a central point for collaborations with universities, industry partners, and other DOE user facilities on research involving irradiated structural and cladding materials. 
MFC FIVE-YEAR MISSION STRATEGY

Page intentionally left blank 
MFC FIVE-YEAR MISSION STRATEGY

Appendix A

MFC Divisions

\section{Appendix A}

\section{MFC Divisions}


MFC FIVE-YEAR MISSION STRATEGY

Appendix A

MFC Divisions

Page intentionally left blank 


\section{Appendix A}

\section{MFC Divisions}

The mission and key objectives for each of the thirteen MFC divisions are provided in this appendix.

\section{A-1. MFC BUSINESS}

Mission: Understand and respond to mission, program, and facility needs regarding processes and tools for performance analysis, training, document management, strategic planning, financial tracking, communications, and human resources.

\section{Key Responsibilities:}

- Provide metrics and analysis, assessment, issues management and causal analysis services

- Provide training design and delivery to improve employee knowledge, skills, and behaviors

- Use configuration management practices to create, revise, issue, and preserve MFC documents

- Develop strategy that identifies how MFC will support laboratory mission and vision; updates fiveyear plan annually

- Optimize funding sources to align resources to mission

- Provide timely information to MFC employees and provide general facts to those interested in MFC capabilities through tours, fact sheets, and on-line resources

- Recruit key talent and retain remarkable employees while fostering diversity and inclusion. Assist management team with performance management

- Provide technical troubleshooting for PCs, installation of standard software, remote access setup and support for travel, request access to accounts, and desktop backup

\section{A-2. MFC ENGINEERING}

Mission: The MFC Design Authority, responsible for the processes to design, create and secure modifications to MFC facilities and to ensure their sustained reliability. Develop unique equipment, processes, and systems to enable and protect research and experimentation. Maintain, control, and update MFC safety basis and design basis.

\section{Key Responsibilities:}

- Evaluate and resolve operational, maintenance, and programmatic engineering needs for systems, structures, and components at MFC facilities and ensure safety and defense-in-depth systems are reliable and meet design and safety analysis requirements

- Develop hot-cell operated systems and components in support of research experiments and processes and provide the technical interface between the nuclear facility and principal investigators responsible for the operation and maintenance of these systems

- Provide facility modification and new equipment design and drafting services based on best-practice engineering principles, codes, standards, and guidelines to support safe, efficient, quality research

- Provide safety analysis and nuclear safety regulatory processes to support safe, efficient, and compliant facility operations that enable quality research outcomes

- Procurement engineering, supplier management and oversight, ordering, tracking, kitting, and staging of materials for nuclear facilities 
- Provide instrumentation and control, network, cyber security, and software engineering/development for control, data acquisition, and research systems

\section{A-3. MFC MAINTENANCE, INFRASTRUCTURE \& FABRICATION}

Mission: Maximizing facility availability through reliability-centered maintenance of our facilities and support systems, fabricating one-of-a-kind components that support research outcomes, and operations and management of our support infrastructure.

\section{Key Responsibilities:}

- Nuclear and facility systems corrective and preventative maintenance

- Equipment Reliability Program: predictive maintenance

- Component machining and fabrication services

- Utility systems operation and infrastructure management

- Strategic Infrastructure Planning: space planning, infrastructure upgrades, and capability improvements

\section{A-4. MFC OPERATIONS}

Mission: MFC Operations Division provides safe and consistent operations ensuring successful implementation and delivery of preeminent research focused on nuclear energy, science, and technology.

\section{Key Responsibilities:}

- Provide leadership and technical oversight to ensure all MFC facilities are operating within their defined safety analysis (DSA)

- Provide strategic recommendations to MFC leadership team and operational personnel to ensure consistent management and compliance to Conduct of Operations (ConOps) in all Nuclear and Radiological facilities

- Provide mentoring and oversight to Nuclear Facility Manager (NFM), Facility Management (FM) and first-line management

- HPI Program implementation

- Lead event critiques and cause analysis

- Emergency management interface

- Safeguards \& Security interface

\section{A-5. MFC PROJECTS}

Mission: Successful completion of all projects and critical facility and mission activities using appropriate project management principles.

\section{Key Responsibilities:}

- Deliver line item capital construction projects that enhance Laboratory capabilities within approved budget and schedule

- Apply tailored project management principles in support of critical facility and mission activities

- Effectively complete construction projects that provide enhanced facility reliability and enable R\&D mission outcomes

- Establish and maintain a structured cask management program that ensures functionality and enables successful completion of mission outcomes 
- Implement a structured approach to management of projects that helps ensure successful project completion through effective planning, monitoring and control, and reporting

\section{A-6. MFC SAFETY \& COMPLIANCE}

Mission: Ensuring our workplace and our communities are safe; our workers are healthy and have a sense of well-being; and our environment is sustained for future generations.

\section{Key Responsibilities:}

- Provide mission-focused environmental, safety and health, quality, and radiological support services

- Provide the expertise needed to assist in the anticipation, recognition, evaluation, prevention, and control of those environmental factors or stresses arising in or from the workplace which may cause sickness, impaired health and wellbeing, or significant discomfort among workers

- Influence the regulatory climate to support specific mission and operation needs

- Provide radiation protection services to workers, facilities, and the public

- Implement NQA-1 requirements across MFC activities

- Evaluation of personnel injuries

\section{A-7. ANALYTICAL RESEARCH LABORATORIES}

Mission: Provide high quality analytical measurements, operate reliable nuclear facilities, conduct world class research, and provide unique educational experiences to INL, U.S. colleagues and our world-wide partners.

\section{Key Responsibilities:}

- Conduct analytical chemistry on nuclear fuels and materials in support of INL research programs and outside customers including advanced nuclear fuel design, nuclear waste management and nuclear nonproliferation

- Conduct analytical chemistry on environmental samples for regulatory compliance

- Provide data analyses on samples that meets or exceeds the requirements of the customer

- Develop cutting edge chemical methods to meet the growing analytical challenges of the nuclear fuels community

- Provide modern instrumentation and subject-matter expertise for analyses in the areas of radionuclide separations, mass spectrometry, elemental analysis, and radio-analytical measurement (counting)

- Foster development of scientific and operational talent

\section{A-8. CHARACTERIZATION AND ADVANCED PIE}

Mission: Data and analysis that drive innovation in nuclear fuels and materials.

\section{Key Responsibilities:}

- Provide the capabilities, data, and analysis of nuclear fuels and materials that shorten the development/deployment cycle for advanced nuclear energy systems

- Develop an active and diverse user community, inclusive of DOE laboratories, universities, industry, and international researchers

- Ensure that the quality of data produced meets or exceeds requirements for its intended purpose

- Publish knowledge gained in peer-reviewed journals 
- Drive improvements to PIE and characterization capabilities, methods, and facilities at INL, nationally, and internationally

- Collaborate to provide validation data for modeling and simulation

\section{A-9. FUEL FABRICATION \& NUCLEAR MATERIAL MANAGEMENT}

Mission: Support the advancement of nuclear energy by providing exceptional nuclear fuel fabrication, process development, experiment fabrication, feedstock development, instrument testing, and nuclear material management.

Key Responsibilities:

- Support the fabrication and development of improved fuels for LWRs, fast reactors, micro reactors and other advanced reactor concepts

- Develop advanced manufacturing capabilities for nuclear applications

- Plan, manage, and oversee the special nuclear material program

\section{A-10. MFC PRODUCTION FACILITIES}

Mission: Provide production environment that enables future R\&D capabilities and supports our environment commitments

Key Responsibilities:

- $\quad$ RD\&D advanced pyro chemical separations concepts

- Treatment of irradiated sodium bonded fuels and materials

- $\quad \mathrm{R} \& D$ for disposition alternatives for spent-fuel product

- Management, treatment, storage, and disposal of waste

- Ensures Site Treatment Plan compliance

\section{A-11. POST-IRRADIATION EXAMINATION}

Mission: The Hot Fuel Examination Facility and Neutron Radiography Reactor provide world-leading examination of experimental fuels and materials to support the world's nuclear energy future.

Key Responsibilities:

- Perform non-destructive and destructive post-irradiation examination of experimental fuels and materials for the advancement of nuclear energy

- Operate the Neutron Radiography Reactor to perform neutron imaging of irradiated fuels and materials, in-core irradiation of test samples, and provide neutron beams for advanced examination techniques

- Design, fabricate, and perform developmental testing of new instruments, fixtures, and tools to perform PIE

- Develop new remote examination techniques to support nuclear fuels and materials research

- Plan, manage, and execute key mission and infrastructure upgrades to support continued programmatic and facility availability and reliability

- Maintain and upgrade facility systems and equipment to support facility compliance and programmatic needs 


\section{A-12. SPACE NUCLEAR POWER AND ISOTOPE TECHNOLOGIES}

Mission: Develop the use of nuclear power in its various forms (heat, radioisotope, electric power, reactor driven) to provide energy needs (or nuclear power solutions) in remote or hostile environments for NASA or other U. S. governmental customers.

\section{Key Responsibilities:}

- Develop and enable nuclear power and isotope technologies for space and terrestrial applications

- Maintain knowledgeable and experienced staff to support radioisotope-power-system infrastructure and missions for fueling, testing, storing, transporting, and supporting ground operations at customer locations. This includes qualified staff in, for example, program and project management, engineering, material science, quality assurance, material control, fabrication, shipping-cask management, nuclear safety, and operations disciplines

- Provide leadership and coordination for INL's isotope production efforts for DOE-SC

- Support DOE-NE Nuclear Infrastructure Programs by staffing their Technical Integration Office to provide coordination among the DOE and other customer interfaces for:

- Mission planning capabilities (long-term and detailed, as needed)

- Technical issue resolution

- Scope, budget, and schedule integration among participants

\section{A-13. TRANSIENT REACTOR TEST FACILITY (TREAT)}

Mission: Provide state-of-the-art transient irradiation capabilities for development of advanced nuclear fuel systems and the study of high intensity neutron interactions with materials

Key Responsibilities:

- Develop and enable transient capabilities for advanced reactor fuels and materials testing.

- Provide state-of-the-art radiography capabilities for pre- and post-irradiation imaging of irradiated fuels and materials in support of transient testing.

- Provide cutting edge instrumentation development and integration to provide real time data during postulated nuclear accident scenarios in support of transient testing.

- Provide testing capabilities to qualify existing reactor fuel designs for baseload and load following operations. 
MFC FIVE-YEAR MISSION STRATEGY

Appendix A

MFC Divisions

Page intentionally left blank 
MFC FIVE-YEAR MISSION STRATEGY

Appendix B

MFC Facility Data Sheets

\section{Appendix B}

\section{MFC Facility Data Sheets}


MFC FIVE-YEAR MISSION STRATEGY

Appendix B

MFC Facility Data Sheets

Page intentionally left blank 


\title{
Appendix B
}

\section{MFC Facility Data Sheets}

\author{
MATERIALS AND FUELS COMPLEX
}

\section{Advanced Fuels Facility}

Fuel and Material Fabrication

\section{General Information:}

- he Advanced Fuels Facility (AFF) is a 4,920 square-foot facility located at Idaho National Laboratory's Materials and Fuels Complex (MFC). This less-than-hazard-category-3 radiological facility has been repurposed for nuclear fuel fabrication. AFF houses a wide range of material handling and fuel fabrication capabilities used for advanced manufacturing processes. Today, it supports INL's mission as lead nuclear energy lab for the nation.

The scope of operations in AFF involves research and development associated primarily with uranium-bearing fuels and associated surrogate materials in order to increase advanced fuel manufacturing capabilities at MFC.

Equipment and processes in AFF are used to support customers in the Department of Energy's Office of Nuclear Energy and private industry partners. AFF hosts a wide range of INL's new lab-scale capabilities for supporting the nation's need to develop advanced nuclear fuels.

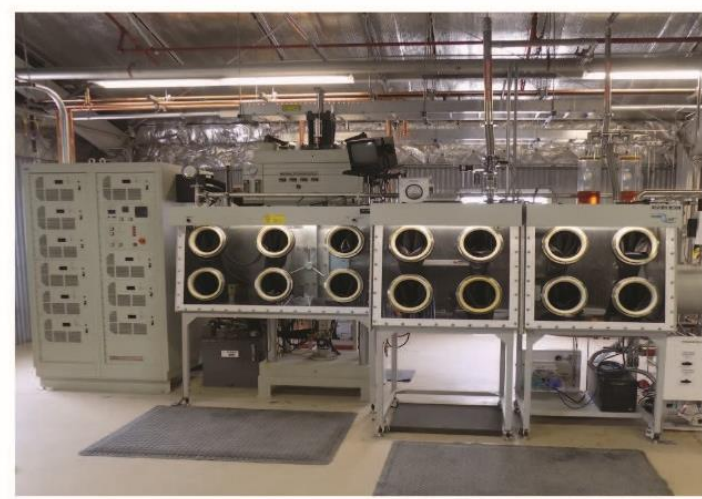

The SPS glovebox provides the capability to press radiological and nonradiological powder compacts while passing electric current through the material being compacted.

\section{Key Instruments:}

Basic uses of AFF will include research and development of uranium-bearing fuels associated with the following processes:

- Spark plasma sintering (SPS) furnace system to press radiological/nonradiological powder compacts while passing an electrical current through the material being compacted.

- Advanced manufacturing feedstock preparation in conjunction with an additive manufacturing 3D printer to fabricate material shapes from constituent powders blown across a laser fusion zone.

- Dry bag isostatic press system to manufacture unique material shapes from constituent powders using a high-pressure fluid.
- Crystal growing system to produce lab-sized crystals from a melt of source materials.

- Laser welding system to provide laser weld closures of fuel cladding and capsules.

- Admatec 3D printer to manufacture shapes by fusing additive layers of constituent powders.

\section{For more information}

\section{Timothy Hyde}

(208) 533-7509

timothy.hyde@inl.gov

www.inl.gov

A U.S. Department of Energy National Laboratory

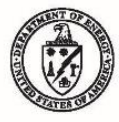




\section{Analytical Laboratory}

\section{Technical Information}

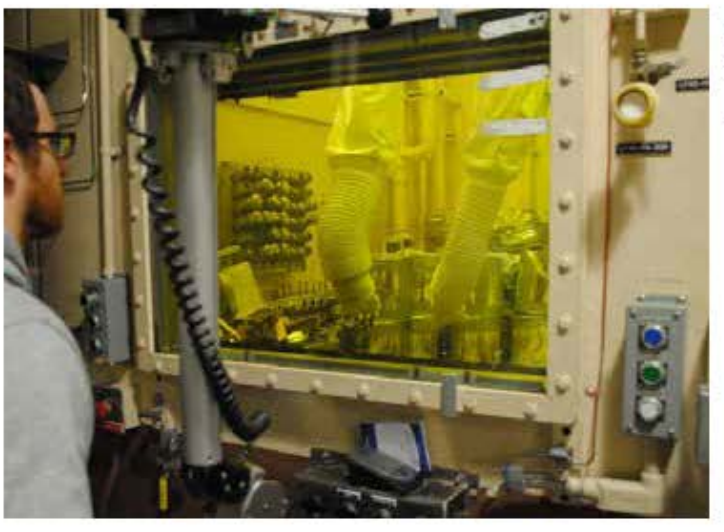

The ourrent mission of the Analytical Laboratory ( $\mathrm{AL}$ ) is to (a) perform chemical, radiochemical and physical mea surements; (b) provide nondestructive analysis measurements; and (c) conduct applied research and engineering development activities in support of advanced nuclear fuel design, waste management, environmental, and other programs conducted at the Materials and Fuels Complexand Idaho National Laboratory (INL). The mission is accomplished through a broad range of analytical chemistry capabilities.

As a result of this mission AL receives a wide variety of samples from across $\mathbb{N} \mathrm{NL}_{\text {, as }}$ aw ell as from other outside entities. Sample types include liquids, solids, and irradiated/unirradiated fuel related to activities such as research and development material accountability, radiation monitoring, process monitoring, and environmental monitoring. Engineering development activities, such as the preparation of samples for irradiation testing, are also supported by the AL.

\section{Basic Capabilities:}

- An alysis and characterization of as-built and post-irradiated nuclearfuels and reactor components mixed, or highly radioactive waste; other waste form; and samples

- Analytical chemistry support for nudear forensics

- Determinations of inorganic isotopic constituents and radionuclides

- Radioisotope separation

- Characterization of engineered materials

- Expertise in characterization of engineer ed materials and the nud ear fuel life cycle
- Analysis of hazardous
Key Instruments:

- Hot cells (six - interconnected)

- Gloveboxes

- Special form

- Radiochemistry

- Wasteform testing

- Casting lab

- Wet prep

- Fresh fuels

- Carbon nitrogen oxygen hydrogen

- Inductively coupled plasma - atomicemission (ICP-AES)

+ Fumehoods

- Counting laboratory

- Gamma

- Alpha spec

- Gas proportional counter

- Scintillation

- Gas mass spectrometer

- Mass spectrometers

- Inductively coupled pla sma (ICP-MS)

- ICP-AES

- Multi-collector - inductively coupled pla sma (MC-ICPMS)

- Thermal ionization

- Furnaces

- Glovebox advanced casting system (GACS) furnace

- Chemistrylaboratory

- Bridge crane (5-ton, overhead, loading dock) 


\section{Engineering Development Laboratory}

Fabrication, Assembly, and Testing of Research, Development, and Production Equipment

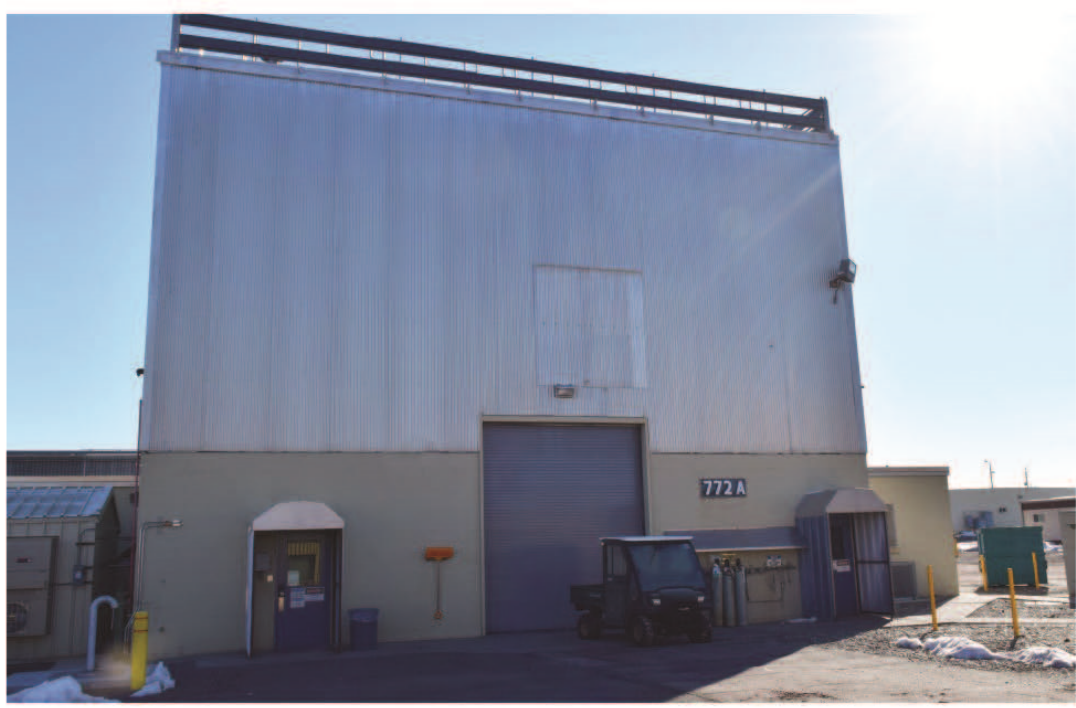

\section{Technical Information}

he Engineering Development Laboratory is used to

fabricate, assemble, mock up, and test various research, development and production equipment. The majority of work conducted in EDL is for the Space Nuclear Power \& Isotope Technologies Division. The EDL is a non-nuclear facility, managed as a laboratory space in accordance with Idaho National Laboratory work control requirements.

The EDL occupies most of Building 772 at the Materials and Fuels Complex (MFC). Two rooms within the building are used by the MFC Quality Assurance organization for nondestructive examinations, e.g., radiography and film pro- cessing. Two mezzanines, which constitute the second floor, can be moved to accommodate tall equipment ( 30 -foot floor-tocrane hook). The facility includes equipment and gloveboxes for welding, including an electronbeam welder; furnaces for bakeout of graphite components forming equipment for heat source hardware; and various machine tools.

Basic Capabilities:

- Fabrication

- Assembly

- Mock-up

- Testing

Key Instruments:

- Inert-atmosphere gloveboxes

- High-temperature bake-out furnaces
- Welding systems

- Forming equipment

- Pre-assembly operations for radioisotope power systems

\section{Formore information}

Kelly Lively

(208) $533-7388$

kelly.lively@inl.gov

www.inl.gov

A U.S. Department of Energy National Laboratory

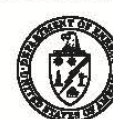




\section{Experimental Fuels Facility}

Technical Information

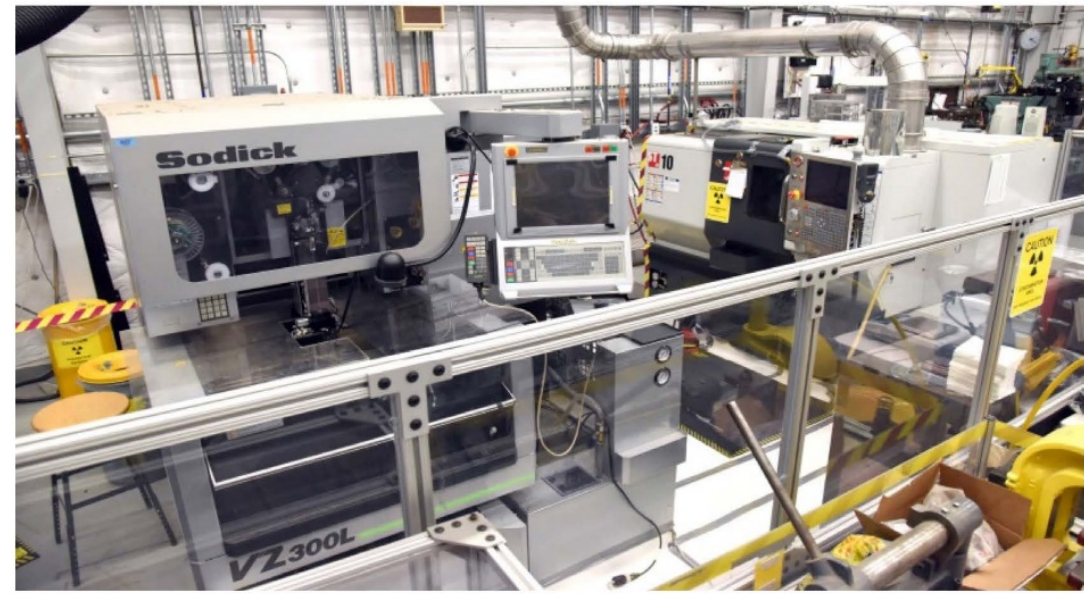
Facility (EFF) houses a tion capabilities, supporting customers in the Department of Energy's Office of Nuclear Energy and private industry partners through Idaho National Laboratory's cooperative research \& development program.

\section{Basic Capabilities:}

For more information

Timothy Hyde (208) 533-7509 timothy.hyde@inl.gov www.inl.gov

A U.S. Department of Energy National Laboratory

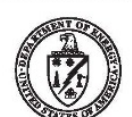

he Experimental Fuels wide range of fuel fabrica-

- Uranium and uranium-alloy casting

- Multiple furnaces with temperature capability up to $2,000^{\circ} \mathrm{C}$ in vacuum, argon, air, hydrogen and nitrogen atmospheres

- Nonradiological machine shop to support advanced fuel development

\section{Key Instruments:}

- Radiological fume hoods (4)

- Inert-atmosphere, radiological gloveboxes (3)

- Powder metallurgy process equipment

- Fuel experiment assembly equipment

Uranium machining equi ment capable of processing unalloyed and alloyed uranium metal and ceramics at all enrichments

- Inert-atmosphere uraniumprocessing glovebox line fo fabrication and handling of alloys and powders
- Annealing quench furnace

- Sodium glovebox

- Sodium-settling furnace

- Orbital capsule and cladding welding
- Uranium forming and machining

- Computer Numerical Contro (CNC) lathe

- Electrical discharge machine

- Centerless grinder

- Rolling mill

- Shears and punches

-150-ton extrusion press

- Hydraulic straightener/draw bench

- Gun drill

- High-temperature applications

- Arc-melting furnace

- Molten salt bath

- Billet-casting furnace

- High-temperature annealing furnace 


\section{Electron Microscopy Laboratory}

\section{Post-irradiation Examination}

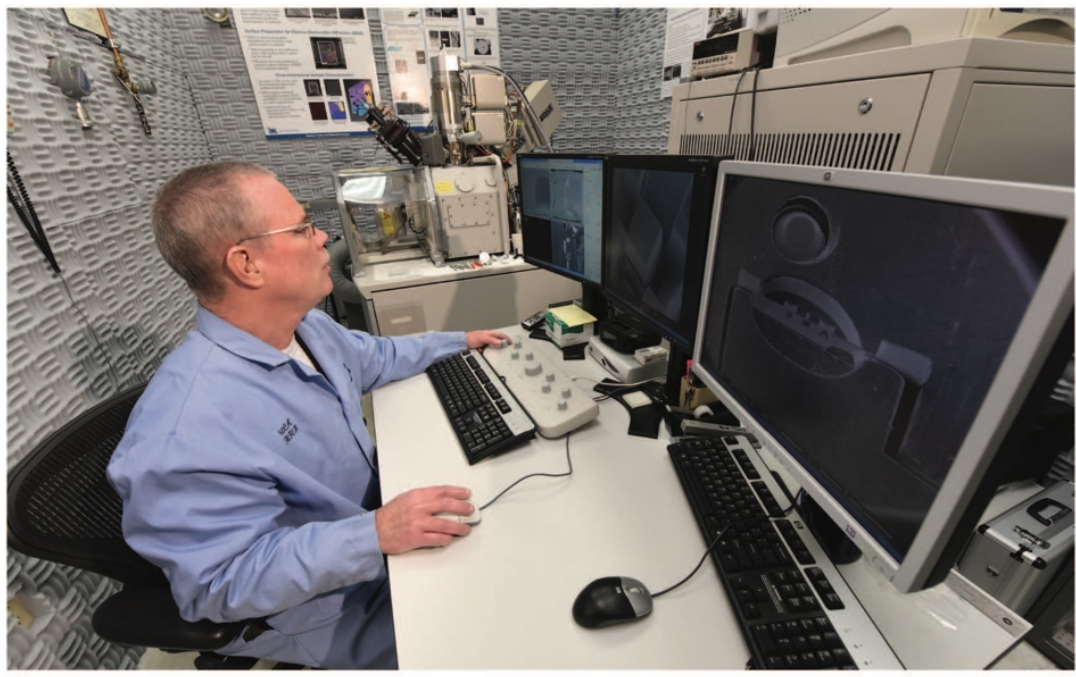

\section{Technical Information}

The Electron Microscopy Laboratory (EML) is a

user facility dedicated to materials characterization, using primarily electron and optical microscopy tools. Sample preparation capabilities for radioactive materials ensure that high-quality samples are available for characterization.

\section{Basic Capabilities:}

- Scanning electron microscopy (SEM) with microchemical analysis and grain-orientation imaging

- Dual-beam focused ion beam (FIB) with microchemical analysis and orientation imaging

- Transmission electron microscopy (TEM) with microchemical analysis

- Optical microscopy
- Microhardness testing

- Precision ion polishing and coating systems

- Sample preparation of irradiated metals, ceramics, and small quantities of irradiated fuel for examination in gloveboxes and chemical hoods

Key Instruments:

- FEI QUANTA 3G field emission gun (FEG) dual-beam focused ion beam with energy dispersive spectroscopy (EDS), wavelength dispersive spectroscopy (WDS), and electron backscatter diffraction (EBSD) detectors and omniprobe micromanipulator

- JEOL JSM-7000f SEM with EDS, WDS and EBSD detectors

- JEOL JEM 2010 scanning transmission electron micro- scope with LaB6 electron gun and EDS

- Gatan precision ion polishing systems (PIPS-2)

- Gatan precision etching and coating system (PECS)

For more information

Jan-Fong Jue

(208) 533-7491

jan-fong.jue@inl.gov

www.inl.gov

A U.S. Department of Energy National Laboratory

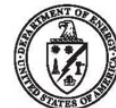


In addition to the Gamma Irradiation Test Loop shown here, FASB contains inert atmosphere gloveboxes used for fuel development, treating waste from other glovebox operations, and testing equipment that will be used in other facilities.

\section{For more information}

\section{Timothy Hyde} (208) 533-7509 timothy.hyde@inl.gov www.inl.gov

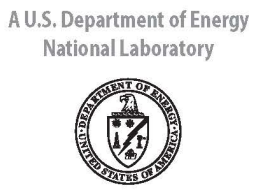

\section{Fuels and Applied Science Building}

\section{Technical Information}

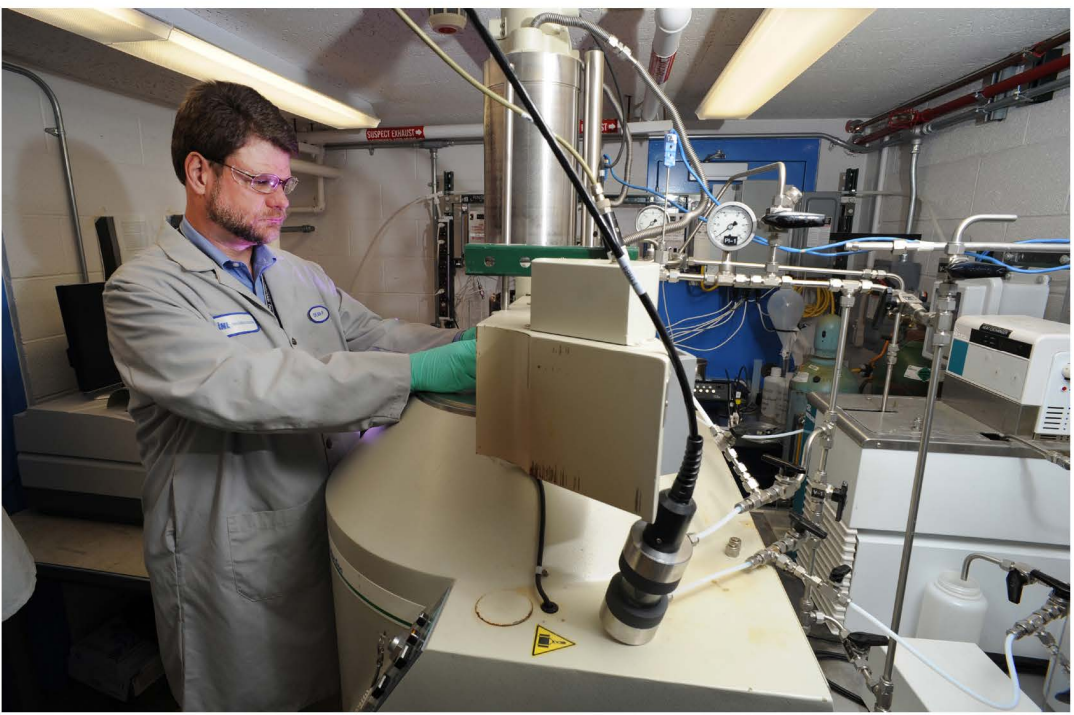

he Fuels and Applied Science Building (FASB) is a radiological facility that has broad capability in fuel fabrication and characterization in support of nuclear energy research and development.

The most recent addition to FASB is the irradiation assisted stress corrosion cracking (IASCC) hot cell. This addition supports several program customers through the Department of Energy's Nuclear Science User Facilities (NSUF) program to perform crack-growth-rate measurements on irradiated structural materials to support light water reactor life extension.

\section{Basic Capabilities:}

- Uranium fuel development at all enrichments

- Materials characterization
- IASCC testing of irradiated materials

- Multiple uranium gloveboxes to support fuel development

- Cobalt-60 gamma irradiator with a radiolysis/hydrolysis test loop

\section{Key Instruments:}

- Inert, radiological gloveboxes (4)

- Radiological fume hoods (4)

- Cobalt-60 gamma irradiator

- Solvent test loop

- Laboratory-scale molten salt electrorefiner

- Fabrication equipment

- Arc-melting furnace

- Induction furnace

- Hot isostatic press

- Hot rolling mill

- Powder metallurgy

- Atomizer

- Hydriding/nitriding apparatus

- Sieving
- Powder milling

- Particle-size analysis

- Pressing/sintering

- Characterization equipment

- Density measurement (helium pycnometer)

- Differential scanning calorimeter

- Dilatometer

- Laser-flash thermal diffusivity

- Scanning electron microscopy

- Optical microscopy

- Metallographic sample preparation

- Microhardness testing

- Positron-annihilation spectroscopy

- Tensile, compression and bend testing

- Ultrasonic testing

- Tribological testing

- High-temperature corrosion testing 


\section{Fuel Conditioning Facility}

\section{Technical Information}

FCF includes a mock-up shop where technicians can build and test new hot cell equipment before installing it into the hot cell.

\section{For more information}

\section{JC Price}

(208) 533-7211

jc.price@inl.gov

www.inl.gov

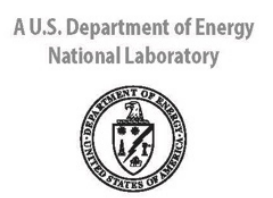

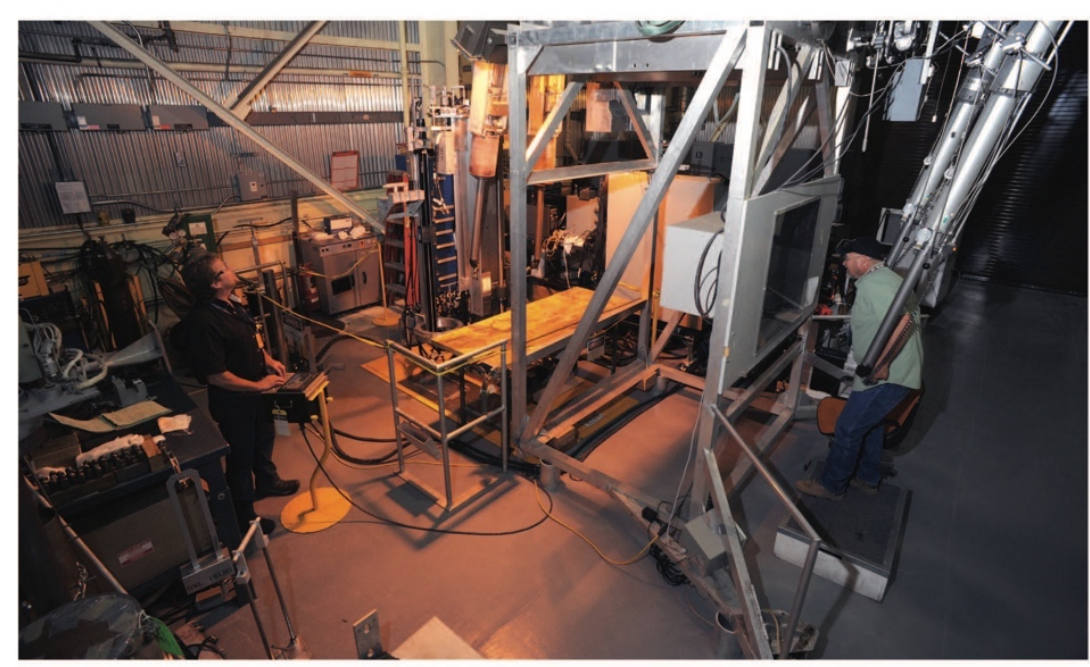

he Fuel Conditioning Facility (FCF) supports nuclear energy research and development for the U.S. Department of Energy (DOE) and other customers. Its unique capabilities make FCF an ideal facility for its primary mission to support treatment of DOEowned, sodium-bonded metal fuel.

In a secondary role, FCF also supports work to demonstrate the technical feasibility of pyroprocessing technology for treating used nuclear fuel for DOE's Fuel Cycle Research and Development Program. Pyroprocessing is a family of technologies involving high-temperature chemical and electrochemical methods for separation, purification and recovery of fissile elements from used nuclear fuel. FCF has an air- atmosphere cell where fuel assemblies are disassembled into individual fuel elements, an argon-atmosphere cell where the spent fuel elements are prepared and treated, and a hot repair area located in the basement where contaminated equipment can be washed and repaired.

\section{Basic Capabilities:}

- Engineering-scale equipment for treatment of sodiumbonded metallic fuel to deactivate the reactive sodium metal, recover fissionable uranium, and separate fission and activation products for incorporation into solid waste forms suitable for geologic disposal

- Systems to support handling heavily shielded shipping casks for fuel receipt and waste disposal

- Hot repair area equipped with remotely operated decontamination equipment, a specialized manipulator repair facility, and other maintenance and waste-handling equipment

\section{Key Instruments:}

- Electrochemical separations/ sodium neutralization experimentation/treatment

- Pneumatic rabbit transfer system

- Canister-cutting machine

- Remote uranium casting furnace

- Manipulator repair glovebox

- Vertical assembler/dismantler (VAD), vacuum inspection station/bottle cutting, production element chopper, blanket element chopper

- Hot cells

- Suited entry repair area

- Mock-up area 
Material processing in the special nuclear material (SNM) glovebox is part of an ongoing material disposition program that supports work at INL and other DOE labs.

\section{For more information}

\section{Randall Fielding}

(208) 533-7015

randall.fielding@inl.gov

www.inl.gov

A U.S. Department of Energy National Laboratory

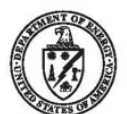

\section{Fuel Manufacturing Facility}

\section{Technical Information}

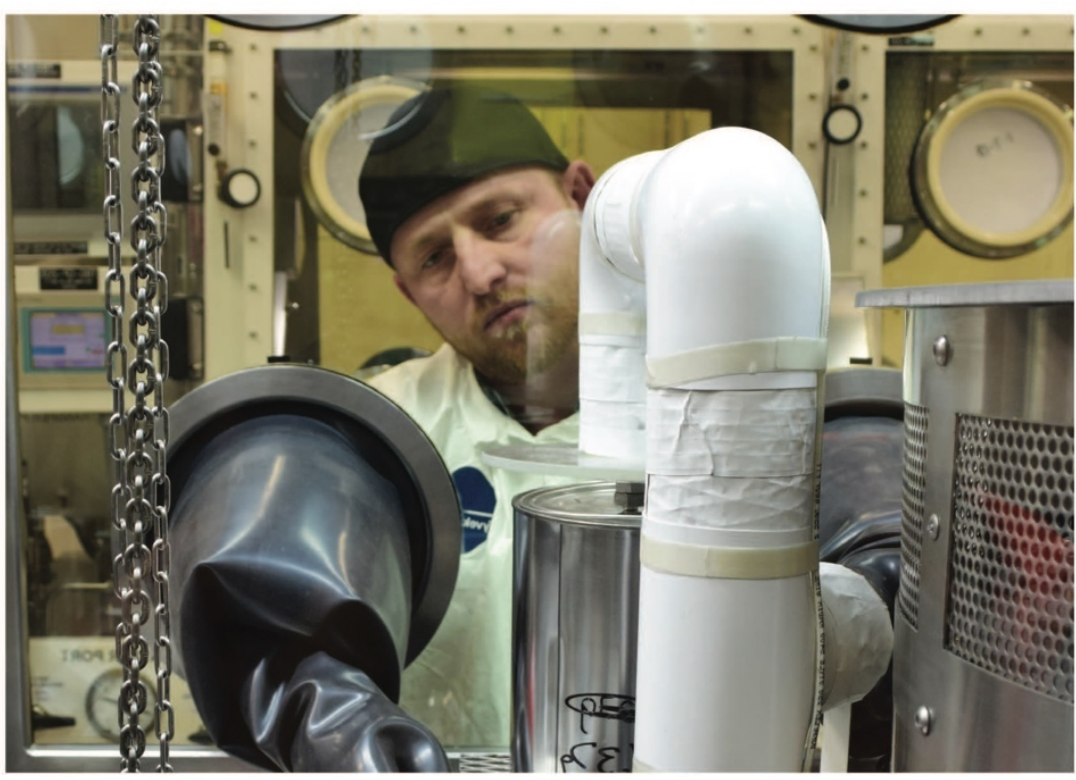

r Facility (FMF) is a hazard category 2 nuclear facility that consists of multiple workrooms and a material storage vault. The workrooms house the equipment utilized to support multiscale fuel development. The vault contains and supplies the feedstock materials used for numerous programs in multiple facilities at MFC.

\section{Basic Capabilities:}

- Transuranic metallic and ceramic fuels development

- Transuranic and enricheduranium materials storage

- Transuranic and enriched-uranium feedstock production, purification and breakouts

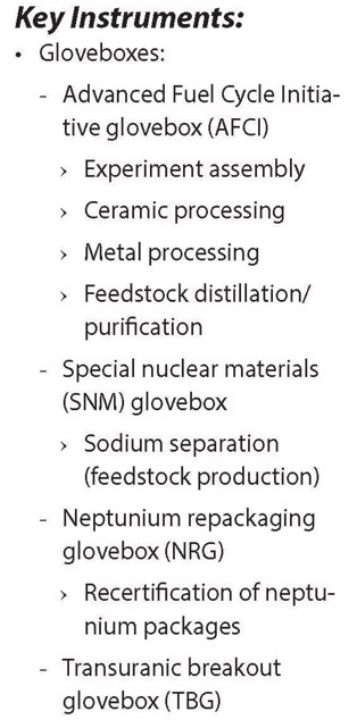

Key Instruments:

- Gloveboxes:

- Advanced Fuel Cycle Initiative glovebox (AFCl)

> Experiment assembly

> Ceramic processing

> Metal processing

> Feedstock distillation/ purification

- Special nuclear materials (SNM) glovebox

> Sodium separation (feedstock production)

- Neptunium repackaging glovebox (NRG)

> Recertification of neptunium packages

- Transuranic breakout glovebox (TBG) 


\section{Hot Fuel Examination Facility}

\section{Technical Information}

The HFEF TRIGA reactor, known as NRAD, enables neutronradiography irradiations to verify materials behaviors.

For more information

\section{David Sell}

(208) 533-7149

david.sell@inl.gov

www.inl.gov

AU.S. Department of Energy National Laboratory

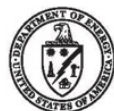

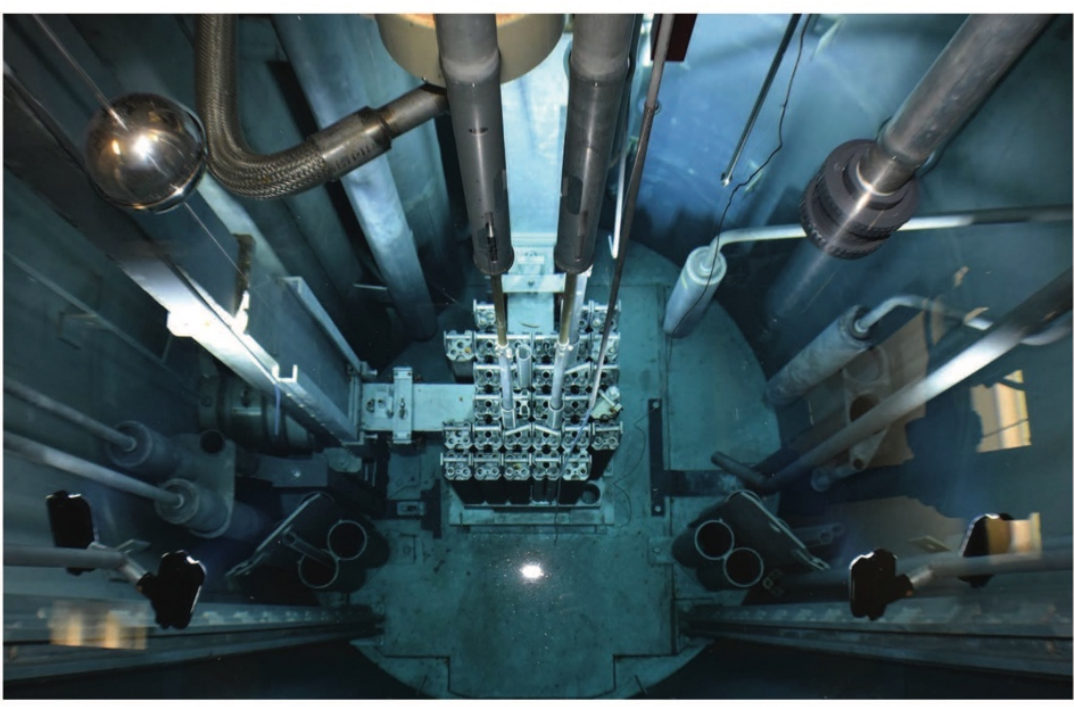

The Hot Fuel Examination

Facility (HFEF) is a

multi-program hot cell facility. There are two adjacent shielded hot cells (the main cell and decontamination cell), a shielded metallography box, an unshielded hot repair area, and a waste-characterization area. HFEF provides shielding and containment for remote examination, processing, and handling of highly radioactive and TRU-bearing materials in its argon-atmosphere hot cells, unshielded labs, support areas and special equipment for handling, examining, and testing of highly radioactive materials.

\section{Basic Capabilities:}

- Nondestructive and destructive post-irradiation examination of irradiated samples in two large heavily shielded hot cells
- Machining and disassembly ments

- Neutron radiography/neutron tomography

- Visual examination and dimensional examination

- Gamma scanning/gamma tomography

- Fission-gas-release measurement

- Sample preparation for metallography, chemical and isotopic analysis, and optical microscopy

- Mechanical testing of irradiated fuels and materials

- Bench-scale electrochemical separations research

- Handling and loading facilities capable of receiving large shipping casks and fuel assemblies up to 13 feet long
- Furnaces for simulating accident conditions at temperatures up to $2,000^{\circ} \mathrm{C}$ for extended periods of time

\section{Key Instruments:}

Nondestructive instruments include:

- 300 kW TRIGA Neutron Radiography Reactor (NRAD)

- Eddy Current probe for measurement of oxide thickness

- Precision gross and isotopic gamma spectrometer

- Element contact profilometer

Destructive instruments include:

- Laser puncture gas collection and analysis system

- Fuel Accident Condition Simulator (FACS) furnace

- Metal waste form furnace 


\section{Irradiated Materials Characterization Laboratory}

\section{Technical Information}

For more information

\section{Ling feng He}

(208) 533-725i

lingfeng.he@ini.gov

unwionligov

\footnotetext{
AU.S. Depar tment of Energy Mational Laboratory
}

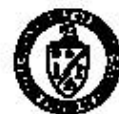

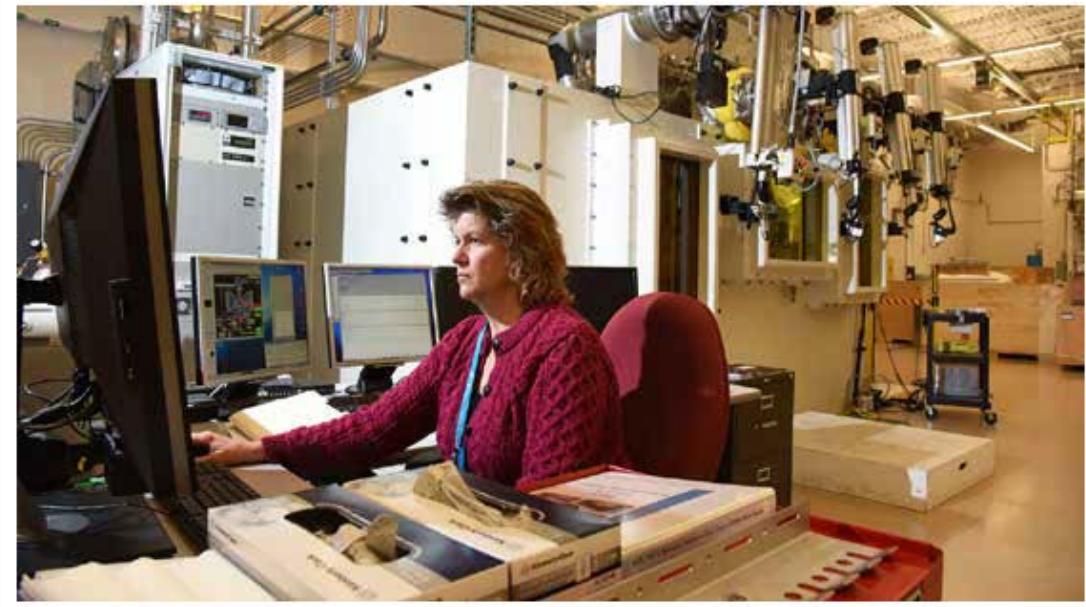

he Irradiated Materials

Characterization Laboratory

(IMCL) is a Hazard Category

2 nuclear facility that fou ses on microstructural, thermal, and mechanical characterization of irradiated nuclear fuels and materials. IMCL's unique design in corporates advanced characterization instruments that are sensitive to vibration, temperature, and electromagnetic interference into modular radiological shielding and confinement systems. The shielded instruments allow characteriza tion of highly radioactive fuels and materials at the micro, nano, and atomic levels, the scale at which irradiation damage processes occur. Enabled by its modular design, IMCL will continue to evolve and improve capability throughout its 40-year design life to meet the national and international user demand for high-end characterization instruments.

\section{Basic Capabilities:}

- Preparation of high-activity samples

+ Optical microscopy

- Electron probe microanalysis (EPMA)

- Dual-beam focused ion beam (FIB)

- Transmission electron microscopy (TEM)

- Scanning electron microscopy (SEM)

- Thermal property characterization

\section{Key Instruments:}

- Shielded Sample Preparation Area (SSPA hot cell)

+ Shielded Cameca SX100R EPMA

+ Shielded FEI QUANTA 3D field emission gun (FEG) dual-beam FIB

- FElTitan ChemiSTEM FEG-STEM

- Shield ed FEl Helios dual-beam SEM/plasma FIB

+ Shielded optical microscopy

- Space forfuture user-defined capability

- Shield ed thermal property measurement cell

- Laser-flash thermal diffusivity

- Differential scanning calorimetry

- Thermal conductivity migoscope 


\section{Idaho Nuclear Technology \& Engineering Center}

\section{Waste Forms and Separations}

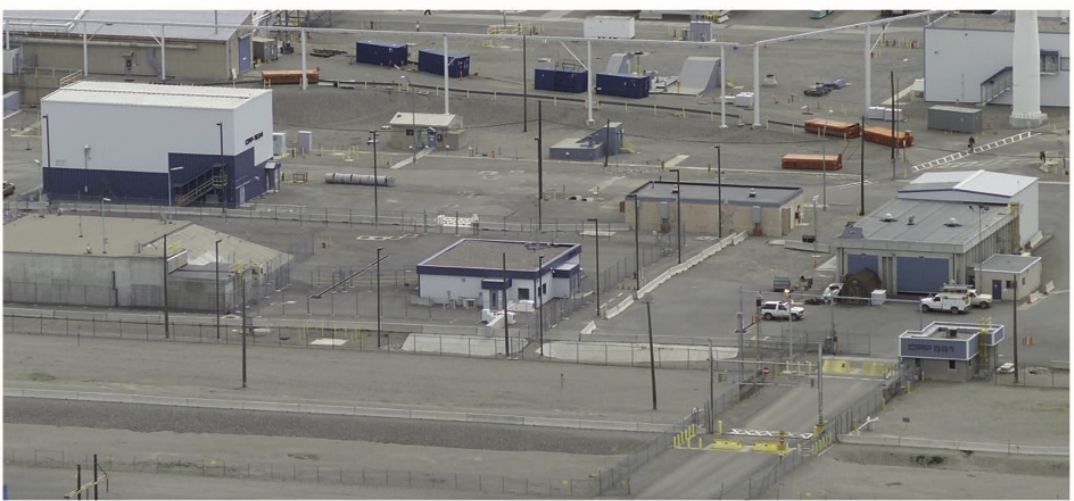

\section{Technical Information}

he Idaho Nuclear Technology and Engineering Center (INTEC) was established in the 1950s as the Idaho Chemical Processing Plant (ICPP) to recover usable uranium in spent nuclear fuel used in government reactors. In 1998, the plant was renamed INTEC. Expanded capabilities will be determined by the Department of Energy (DOE) funding and repurposing of existing facilities.

\section{Basic Capabilities:}

- Safe transfer of spent nuclear fuel from wet to dry storage and preparation for final disposal at an off-site repository or until the material is used for other purposes

- Radioactive material storage and repackaging capabilities

- Support Homeland Security in developing decontamination techniques

- Develop fuel cycle research capabilities

\section{Key Buildings:}

Material Security and Consolidation Facility (MSCF) - CPP-651

- MSCF provides storage for the Spent Fuel Treatment Program (SFTP) and unirradiated uranium in compliance with DOE safety, safeguards and security requirements. The primary mission of MSCF is to provide a storage location for SFTP until permanent storage is available or until the material is used for other purposes. MSCF also provides a storage location for unirradiated uranium (metals and oxides) awaiting program identification and readiness for subsequent shipment or transfer.

- CPP-653 - Fuel Cycle Research and Development

- The Material Recovery Project aims to design a material recovery fluidized bed system for scoping tests of the ZIRCEX process.
Support Homeland Security in developing decontamination techniques

Key Instruments:

- Hood in CPP-653

- Inductively coupled plasmamass spectroscopy (ICP-MS) in CPP-653

- Decontamination tent in CPP-653

- ZIRCEX process (under development)

For more information

\section{Pamela Crane}

(208) 533-7179

pamela.crane@inl.gov

www.inl.gov

A U.S. Department of Energy National Laboratory

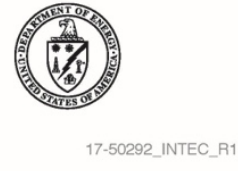




\section{Radiochemistry Laboratory Characterization, Post-irradiation Examination}

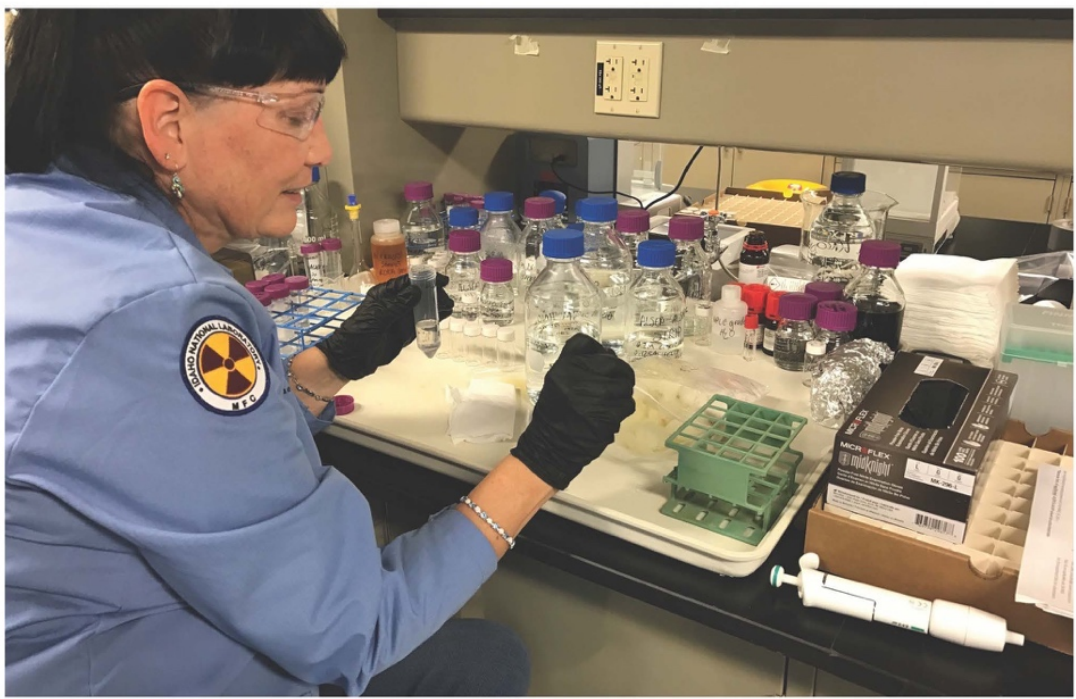

\section{Technical Information}

The Radiochemistry Laboratory (RCL) houses several laboratories for aqueous separations science and technology, actinide chemistry, radiochemistry research, and metals and isotopic analyses on radioactive materials. The RCL contains two radiochemistry laboratories, an instrumentation laboratory, a counting laboratory and a glovebox laboratory, as well as necessary chemical and source storage areas. $\mathrm{RCL}$ supports work from various outside entities and federal agencies, including the Department of Homeland Security and the Department of Energy.
Basic Capabilities:

- Analysis and characterization of nuclear fission products using aqueous chemistry

- Radioisotope separation

- Element dissolution of radioisotopes using advanced chemistry techniques

- Ability to create unique organic solvents for use in separations type work

\section{Key Instruments:}

- Counting Laboratory (gamma counters, liquid scintillation, nuclear magnetic resonance)

- Gas chromatograph/ion chromatograph

- Spectrometers (inductively coupled plasma-mass spectrometer and inductively coupled plasma-optical emission spectrometer)

- Spectrophotometer

- Argon separations glovebox

- Air separations gloveboxes

- Fume hoods

- Furnaces

For more information

\section{Dean Peterman}

(208) 533-7452

dean.peterman@inl.gov

www.inl.gov

A U.S. Department of Energy National Laboratory

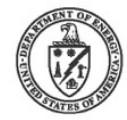




\section{Sample Preparation Laboratory}

\section{Post-irradiation Examination}

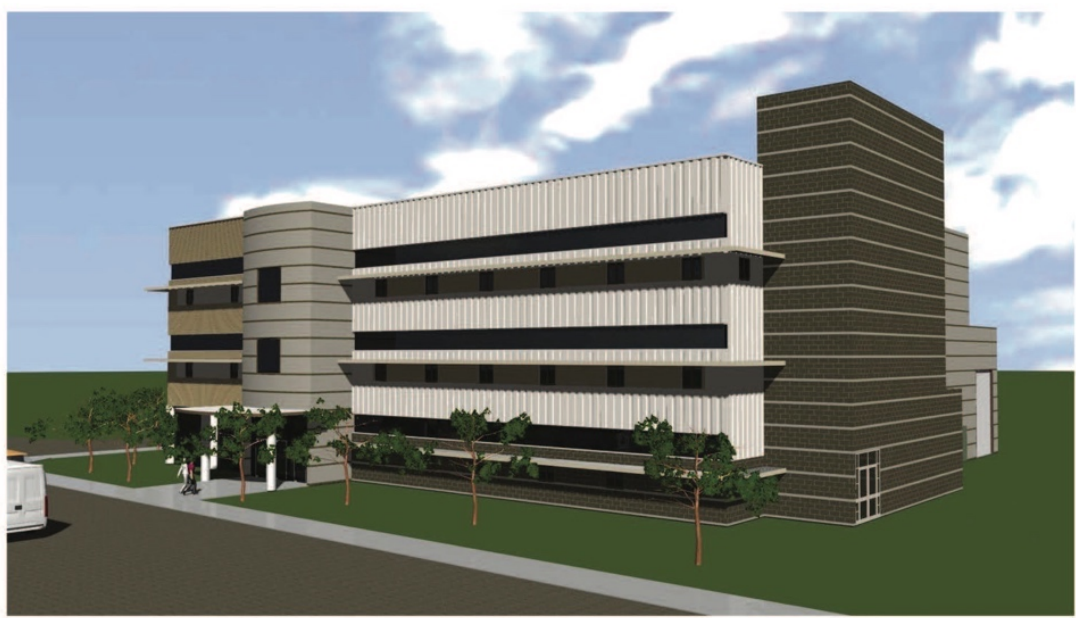

\section{Technical Information}

The Sample Preparation Laboratory (SPL) will, begin-

ning in 2022, provide for the needs of a growing nuclear energy research community.

\section{Basic Capabilities:}

SPL will provide instrumentation and capability not currently available for analysis of irradiated materials, including many for understanding materialaging issues, improving materials for use in advanced nuclear energy systems.

- Load frame and charpy testing machines, each with an environmental chamber to simulate a wide range of environments from cryogenic to high temperature

- Micro- and nanohardness testers to determine material properties such as modulus of elasticity, hardness, yield strength, and fracture toughness in a very small area of sample

- Scanning electron microscopy for fracture surface analysis, a critical component of materials research

- Surface science instruments such as secondary ion mass spectrometry and X-ray photoelectron spectroscopy for chemical characterization of oxide films and fracture surfaces

- X-ray diffraction for determination of crystal structure of phases and the phase array in a material, residual stress measurement, and texture measurement to evaluate the evolution of these traits during irradiation

\section{For more information}

Brandon Miller

(208) 533-7510

brandon.miller@inl.gov

www.inl.gov

A U.S. Department of Energy National Laboratory
Idaho National Laboratory 


\section{Transient Reactor Test Facility}

\section{Technical Information}

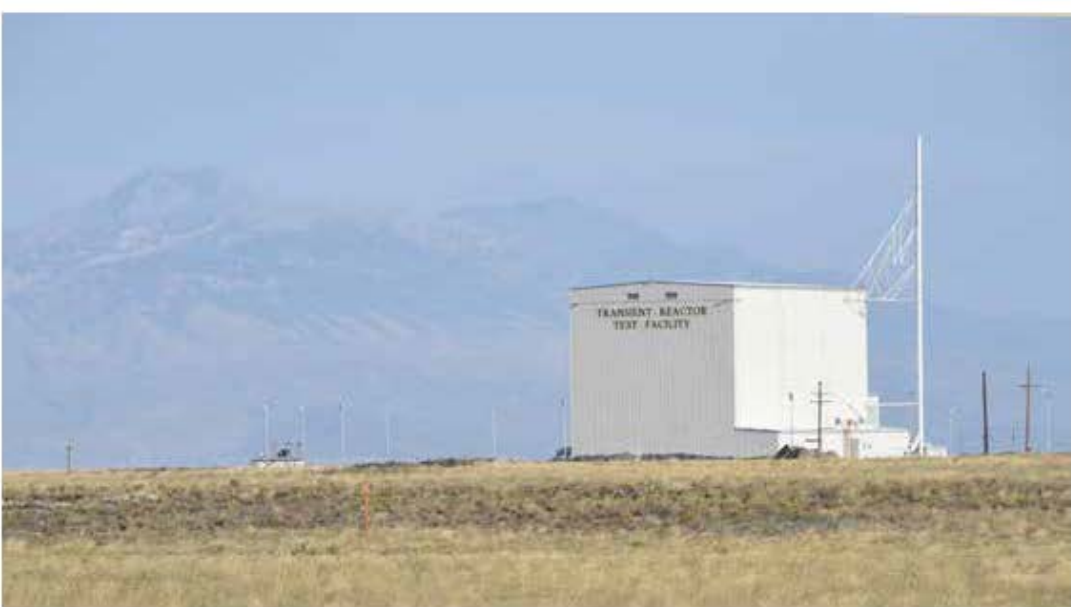

Daniel Wachs daniel.wachs@ini.gov (208) 526-6393

wuwioligov

A U.S. Depar tment of Energy Mational Laboratory

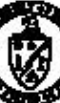

Facility (TRE AT) provides

transient testing of nuclear fuels and materials. The faclity is used to study fuel melting behavior, interactions between fuel and coolant and the potential for propagation of failure to adjacent fuel pins under conditions ranging from mild upsets to severe acoidents.

TREAT is an air-cooled, thermalspectrum test faclity specifically designed to evaluate the response of reactor fuels and structural materials to a ccident conditions. The reactor was originally constructed to test fast-reactor fuels, but its flexible design has also enabled its use for testing of light-water-reactor fuels a swell as other exotic special-purpose fuels, su h as space reactors.TREAT has an open-core design that allows for ease of experiment instrumentation and real-time imaging of fuel motion during irradiation, which also makesTREAT an ideal platform for understanding the irra diation response of materials and fuels on a fund amental level.

TREAT was placed on stand by in 1994. TREAT wa srestarted in 2018 and is currently supporting experiment programs. TREAT provides a valuable capability to support efforts to develop accident-tolerant fuels for lightwater reactors as inell as the advanced reactor fuels, both of which will allow nuclear powe to remain the primary source of emission-free baseload energy in the future.

\section{Basic Capabilities:}

- High-intensity (20 GW), shortduration ( $<100$ ms) neutron pulses for severe accident testing

- Shaped transients at intermediate powers and times (flexible power shapes with up to 60 seconds duration?

- 120 kw steady state operation

- Testing capability for static capsules, sodium loops and water loops

- Neutron-radiography fa oility

\section{Key Instruments:}

- Nondestructive examination of assemblies up to 15 feet long in steady state operating mode by neutron radiography

- Neutron'hodoscope; providing real-time imaging of fuel motion during testing

- Open core design suitable to instrument experiments during testing 
The Zero Prower Physics fieacior was placed in nonoperationa! standby in 1992, and has since been disman ted, which frees the space for nuclear material storage, inspection, and repackaging.

\section{Zero Power Physics Reactor Facility}

\section{Technical Information}

- ero Power Physics Reactor (ZPPR) is a Hazard Category 2 nuclear facility that consists of a workroom, cell area and material storage vault The workroom houses the equipment utilized for material inspection and repackaging. The cell area is used for experiment and detection training for various customers, including National and Homeland Security. The vault contains and supplies materials used for programs in multiplefacilities at the Materials and Fuels complex and other Idaho National Laboratory locations.

\section{Basic Capabilities:}

- Transuranic and enricheduranium materials storage

- Transuranic and enricheduranium material inspection/ repackaging

- Transuranic and enricheduranium material handling for experiments/training
Keylnstruments:

- Transuranic surveillance gloveboxline

- Vault storage

- Cell area that can be reconfigured as necessary for experiment/training activities

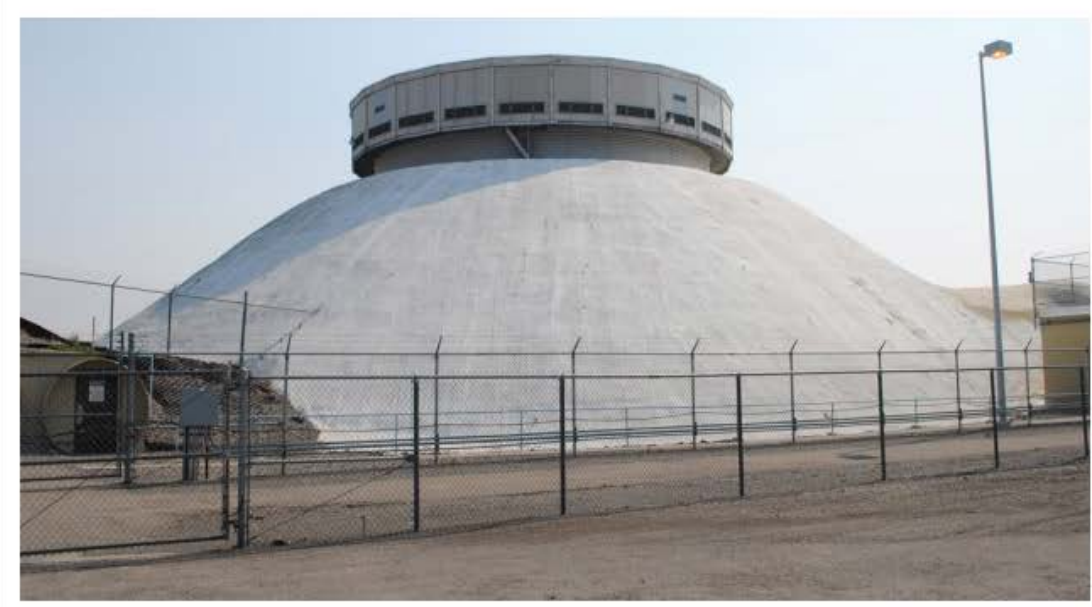

\section{Larry Evens}

larry.evens@inigov

(208) $533-8036$

wuwinigov

A US. Department of Energy Plational Laboratory

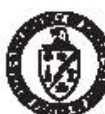

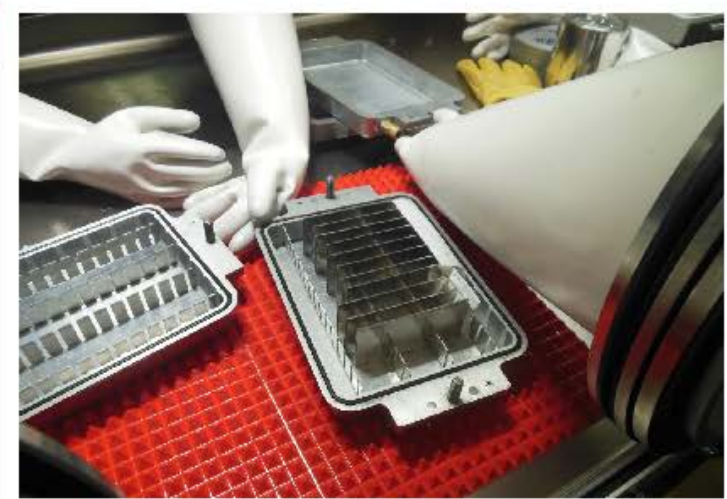

ZPPR operators performing material inspections in the

transuranic survedlance

glovebox. 
MFC FIVE-YEAR MISSION STRATEGY

Appendix B

MFC Facility Data Sheets

Page intentionally left blank 
MFC FIVE-YEAR MISSION STRATEGY

Appendix C

MFC Core Competencies

\section{Appendix C}

\section{MFC Core Competencies}


MFC FIVE-YEAR MISSION STRATEGY

Appendix C

MFC Core Competencies

Page intentionally left blank 


\section{Appendix C}

\section{MFC Core Competencies}

Additional information on the core competencies supplied by the MFC Research and Production Divisions (Section 4) is provided in this appendix, including proposed areas of research to advance the knowledge base of the competencies. To recap, these core competencies are

- Nuclear fuels fabrication

- Fuel characterization

- Characterization of radiation damage in cladding and in-core structural materials

- Fuel recycling and nuclear material management

- Transient irradiation testing

- Nuclear nonproliferation and nuclear forensics

- Space nuclear power and isotope technologies

- Radioanalytical chemistry

- Focused basic research.

\section{C-1. NUCLEAR FUELS FABRICATION}

The $\mathrm{UO}_{2}$-zircaloy fuel system utilized today in commercial nuclear reactors has been in use throughout the history of commercial nuclear power. Incremental improvements in the basic design have been made over many decades to increase fuel lifetime and reliability. $\mathrm{UO}_{2}$-zircaloy fuel has an excellent performance history; however, it is limited to use in LWR systems.

Developing advanced nuclear fuels is central to deploying advanced nuclear systems that have significant advantages over LWRs in terms of efficiency, waste generation, proliferation resistance, and safety. These advanced reactors cannot function without advanced fuels, however, and knowledge of advanced fuel performance in advanced reactors is critical to demonstrating and deploying these systems.

MFC has the capability, experience, feedstock, and facility licensing that allows development of a wide breadth of fuel types that will significantly expand the range of technologies available to power nuclear reactors. MFC has been critical in positioning INL as a leader in the development of accident-tolerant fuels, including development of an $\mathrm{U}_{3} \mathrm{Si}_{2}$ fabrication process and processes for joining difficult-to-weld cladding alloys. MFC has been largely responsible for development work with plate-type research reactor fuels that has led to high-density uranium fuel meats and cladding systems that are currently being qualified. In addition, MFC and INL retain most of the world's expertise in fast reactor metal fuel.

Recent developments abroad have led to the shutdown of the Halden Reactor in Norway, where the Halden Reactor Project served the international LWR industry with irradiation testing services and valuable expertise in devising and interpreting irradiation tests. INL personnel have evaluated the void created by loss of the Halden capability and determined how DOE and INL can best contribute to meeting the new needs. ${ }^{\mathrm{m}}$ This evaluation recommended that INL establish the following capabilities to ensure the LWR community continues to have the RD\&D platform needed to support continued development of new fuel designs and to address regulatory issues around fuel behavior under increasingly challenging operating conditions:

m. C. Jensen, et al., Post-Halden Reactor Irradiation Testing for ATF: Final Recommendations, INL/EXT-18-46101, Rev. 1, December 2018. 
- Establish in-pile pressurized water irradiation loops in ATR and TREAT

- Establish advanced refabrication and re-instrumentation facilities needed for testing materials irradiated in commercial NPPs

- Develop and implement reliable instrumentation for key fuel performance measurements and materials testing.

The MFC role in establishing and supporting these LWR irradiation testing capabilities is elaborated in different ways throughout the rest of this section. In addition, research on fuel systems presents a number of scientific and engineering challenges that are discussed in the following subsections.

\section{C-1.1 Fuel Research and Development Focus Areas}

\section{C-1.1.1 Accident-Tolerant Fuels}

Fuels with enhanced accident tolerance are those that, in comparison with the $\mathrm{UO}_{2}$-zircaloy system currently used by the nuclear industry, can tolerate loss of active cooling in the reactor core for a considerably longer time duration (Figure C-1). This performance must be maintained during normal operations, operational transients, and design-basis and beyond-design-basis events. Fuel system design objectives that are potentially important for improving accident tolerance include reduced hydrogen generation, improved fission product retention, improved cladding reaction to high-temperature steam, and improved fuel cladding interaction for performance under extreme conditions. Challenges specific to developing accident-tolerant fuels include fabricating new fuel types and determining off-normal behavior using transient irradiation tests and out-of-pile safety testing.
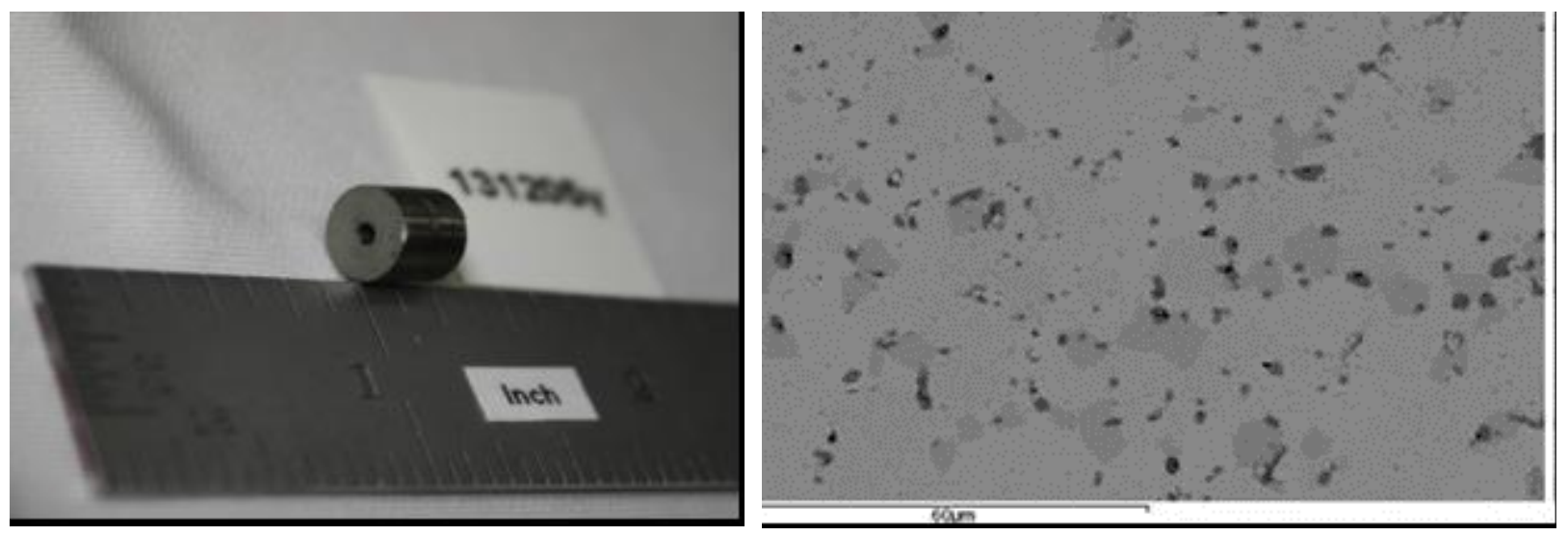

Figure C-1. Sintered high-density $\mathrm{U}_{3} \mathrm{Si}_{2}$ pellets (left) and $\mathrm{U}_{3} \mathrm{Si}_{2}$ microstructure (right). ${ }^{\mathrm{n}}$

\section{C-1.1.2 Driver Fuel for a Versatile Test Reactor}

In FY-17, DOE-NE began funding a program to scope out and specify a new fast test reactor facility, currently known as the Versatile Test Reactor (VTR), which would address the U.S. need for fastspectrum irradiation testing and is proposed to be located at or near the MFC site at INL. Key features targeted for the facility are a peak fast flux of $\sim 4 \times 10^{15} \mathrm{n} / \mathrm{cm}^{2} / \mathrm{sec}$, sufficient versatility to accommodate testing in closed loops containing lead or lead-bismuth, sodium, and helium, and selection of tried and mature fast reactor technology to minimize cost and operational uncertainty. Current planning calls for the reactor to be fueled with metallic U-20Pu-10Zr fuel, based on prior U.S. experience with metallic fuel in EBR-II and FFTF. Use of Pu in the fuel alloy is highly preferred to achieve desired irradiation

n. Jason M. Harp, Paul A. Lessing, Rita E. Hoggan, 2015, "Uranium silicide pellet fabrication by powder metallurgy for accident tolerant fuel evaluation and irradiation," Journal for Nuclear Materials. 
characteristics in a core of modest size (for VTR, a peak fast flux of $4 \times 10^{15} \mathrm{n} / \mathrm{cm}^{2} / \mathrm{sec}$ with core power of $300 \mathrm{MW}$ has been selected as a design objective). Current efforts are assessing potential sources of $\mathrm{Pu}$ feedstock for the VTR driver fuel. Because the U.S. does not have an operating Pu fuel production facility available, VTR planning necessarily includes establishing such a facility, and the MFC site is one of the alternative locations being evaluated. The VTR program, then, has prepared a conceptual design and cost estimate for the $\mathrm{Pu}$ fuel fabrication facility, which entails laying out and specifying a fabrication process line. The envisioned process calls for known metal fuel fabrication technology but will incorporate proven improvements that have been developed since metal fuel was last produced for EBR-II in the early 1990s.

U-Pu-Zr fuel injection casting and fuel rod fabrication scale-up from EBR-II fuel dimensions and production rates to VTR fuel dimensions and production rates must be demonstrated to reduce VTR planning and cost estimating uncertainties. This will entail re-establishing successful U-Pu-Zr casting parameters on equipment prototypic of production size and demonstrating reliable fabrication rates, thereby completing the scale-up of $\mathrm{U}-\mathrm{Pu}-\mathrm{Zr}$ production from lab-scale to the engineering-scale production previously established for EBR-II U-Zr driver fuel. Irrespective of the selected location for VTR fuel production, the developmental testing and demonstration of VTR fuel fabrication processes is likely to be located in the FMF at MFC.

\section{C-1.1.3 Transmutation Fuels}

Sustainable fuel cycle options improve uranium resource utilization, maximize energy generation, minimize waste generation, improve safety, and limit proliferation risk. These fuel cycle options focus heavily on advanced fuels containing TRU elements (e.g., neptunium, plutonium, americium, and curium), with second-tier options involving thorium. The greatest challenge associated with these fuels is in acquiring the ability to understand and predict the broad range of nuclear, chemical, and thermomechanical phenomena that synergistically interact to dictate fuel behavior over a wide range of fuel chemical compositions and operating conditions. An important obstacle in demonstrating the feasibility of candidate advanced fast-spectrum fuels that support these fuel cycles is the absence of an available fastspectrum test facility. Until a new test facility, such as the VTR proposed by DOE-NE, is built, overcoming this challenge requires that revolutionary advances in electronic structure theory, computational thermodynamics, and innovative, science-driven experiments be integrated to obtain the required understanding of nuclear materials and their behavior. The knowledge gained from combining thermal-spectrum reactor irradiations, past fast-spectrum irradiation experiments on cladding materials, and modeling and simulation can be used to show the feasibility of candidate transmutation fuel/cladding systems. Eventually, fast-spectrum irradiation testing will be required to demonstrate performance at scale in the design environment.

Most sustainable fuel cycle scenarios require that fuel be fabricated remotely in shielded facilities because of gamma ray emission from TRU elements and fission product carryover from recycling. The difficulty in remote fabrication is compounded by the necessity to reduce TRU material loss to ensure the maximum benefit to a geological repository. The highest potential for material loss occurs during fuel recycling and fuel fabrication. Extending the fuel burn-up lifetime reduces the number of fuel processing cycles and is one method of reducing these fabrication losses (Figure C-2). Design of efficient, low-loss fabrication processes is essential for success. 


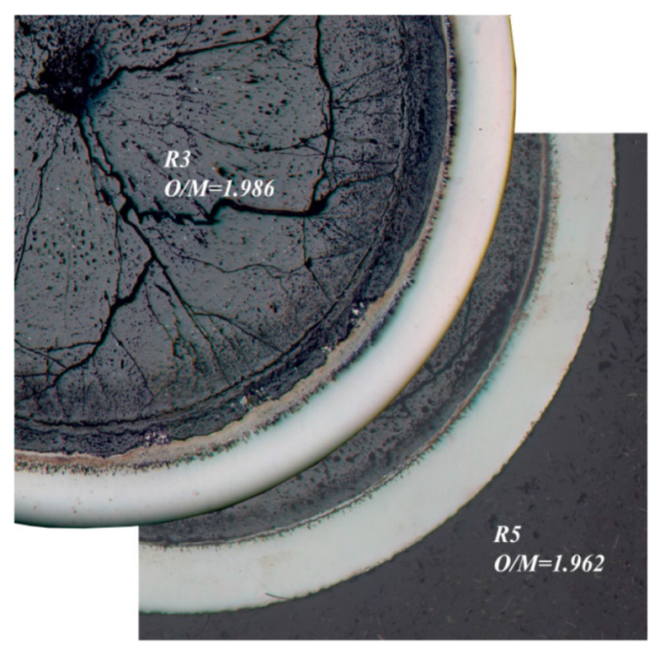

Figure C-2. Comparison of the effect of the oxygen-to-metal ratio (i.e., $\mathrm{O} / \mathrm{M}$ ) in minor actinide mixed oxide fuel. A lower oxygen-to-metal ratio results in reduced fuel-cladding chemical interaction.

\section{C-1.1.4 High-Temperature Gas Reactor Fuel}

High-temperature gas reactor concepts are based on tristructural isotropic (TRISO)-coated particle fuels (Figure C-3). The silicon carbide and pyrocarbon layers in the TRISO particles provide excellent retention of fission products during normal operation and during accident conditions. Fuel performance is closely tied to the fabrication process and to fuel product quality in this highly engineered system. A number of known degradation mechanisms that are temperature- and burnup-dependent have the potential to affect TRISO fuel performance. These include the thermomechanical response of pyrocarbon layers, fission gas release and carbon monoxide production, the 'amoeba' effect (i.e., migration of the kernel due to chemical reactions in a thermal gradient), and palladium attack of the silicon carbide layer. The ties between the fabrication process, resulting particle structure, microstructure, chemical composition, and performance must be well understood to define a fabrication process with control limits that ensure fuel performance. Qualifying fuel for use in a licensed reactor involves experiments and examinations to gain an understanding of the behavior of the TRISO fuel under the radiation and temperature environment expected in a high-temperature gas reactor. It also involves experiments to allow for understanding how well the fission products (i.e., the elements produced when uranium fissions) stay inside or move outside the coated fuel particles and through the graphite reactor core. Testing involves identification and sorting of a very small fraction of failed test fuel particles and detailed investigation of the failure modes.

Validation through experimentation of modeling and simulation tools that analyze and predict behavior is also vital. 


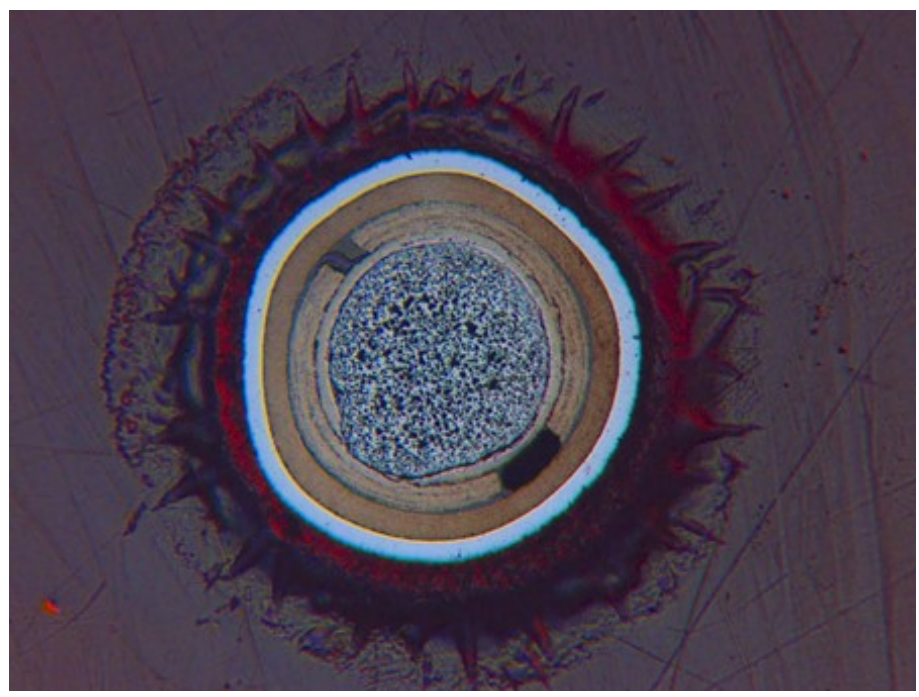

Figure C-3. Next-generation nuclear reactor fuels are designed to be more efficient and resistant to accident conditions. TRISO fuel contains a layer of silicon carbide that serves as the primary containment for radioactive material (center). Researchers have subjected TRISO fuel to extreme temperatures well above postulated accident conditions and found that most fission products remained inside the fuel particles.

\section{C-1.1.5 Support for the U.S. Commercial Reactor Fleet}

It is vital to the economic competitiveness and well-being of the United States that the commercial LWR fleet continue to produce electricity at its current high level of reliability. Fuel vendors continue to improve fuel performance and lifetime through use of fuel assembly design changes, fuel pellet additives, and improved cladding materials; however, the nuclear industry no longer has the capability to perform the PIE necessary to confirm performance or understand the cause of failure. Conversely, DOE does not have capabilities for full-scale demonstration of fuels in a representative LWR environment and requires cooperation with industry for demonstration testing. Developing close, mutually beneficial relationships between national laboratories and nuclear industry provides opportunities for injecting innovative technologies into the commercial marketplace. Securing INL's role as a partner to the commercial industry requires resolving current issues with bringing research quantities of used commercial nuclear fuel into the State of Idaho. Rapid turnaround on fuel examinations that produce high-quality data using a sustainable cost model is required to meet industry needs.

\section{C-1.1.6 Low-Enriched Research Reactor Fuels}

Research reactor fuels are the largest remaining source of civilian commerce in highly enriched uranium. Many reactors have converted to low-enriched uranium using conventional dispersion fuels. The remaining high-power reactors, which by far consume the most highly enriched uranium, require a new type of very-high-density fuel to allow for their conversion. Equally important to the nuclear research community is ensuring low-enriched fuels are available for use in future high-power density research and test reactors. Because this fuel attains extremely high fission density, it undergoes a series of transitions in behavior that are linked to the starting microstructure and its evolution (Figure C-4). Defining the linkage between fabrication process parameters, microstructure, performance, and, ultimately, failure as the fuel achieves increasingly higher burnup is an important challenge for development of this fuel system. Because it is a plate-type fuel and has very different failure mechanisms than rod-type or particle fuels, identifying these linkages requires specialized instrumentation installed in a hot cell. Additionally, geometry and failure mode-specific methods need to be developed to measure fuel performance parameters. 

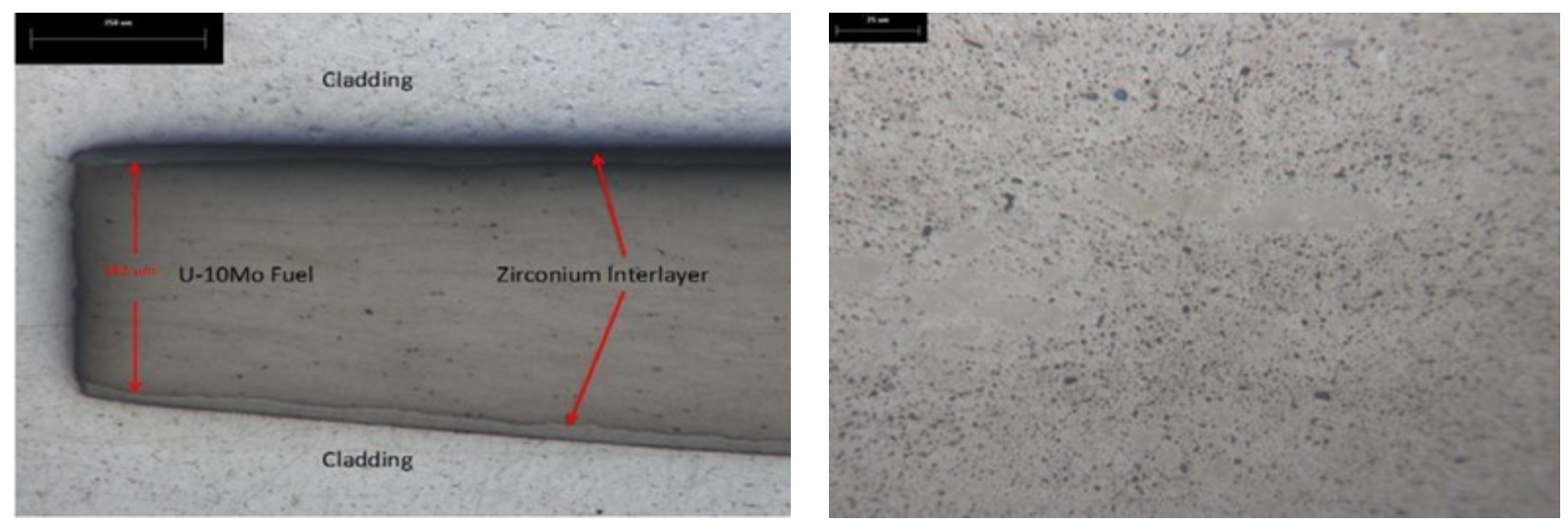

Figure C-4. An optical micrograph of an irradiated low-enriched uranium monolithic fuel plate showing laminated fuel structure (top) and fuel microstructure (bottom) after irradiation to a fission density in excess of $4.1 \times 10^{21}$ fissions $/ \mathrm{cm}^{3}$, showing fission-gas bubbles within recrystallized regions, remnants of original grains, and precipitates.

In addition to development of new low-enriched uranium fuels, a gap in production of existing low-enriched uranium TRIGA reactor fuel exists. TRIGA reactors are the single most widely deployed research reactor in the world and support a wide range of research, training, and isotope production activities. INL has explored the possibility of production of these fuels to meet the needs of the nuclear community, and although there does not currently appear to be an INL role in TRIGA fuel production, MFC personnel will periodically revisit this matter.

\section{C-1.1.7 New Fuel Concepts}

Many concepts for new fuels that may have economic, performance, and/or safety advantages or that are required to enable new reactor concepts are generated by universities, small businesses, and industry. Fundamental research on fuel behavior is of great interest to the scientific research community and is used to validate specific fuel behavior models through separate effects testing. The NSUF program provides opportunities for a broad range of researchers to conduct scoping testing of novel fuels and fundamental research by providing support for fuel fabrication, irradiation testing, and PIE. Developing new fabrication processes is often required. In fact, application of advanced manufacturing techniques may allow use of fuel design features previously not practical (or even possible) with conventional fuel fabrication methods. Assessing new designs may also require new or modified PIE instruments and techniques.

\section{C-1.2 Nuclear Fuel Development Cycle Improvement Goals}

Historically, nuclear fuel development has been empirical. The massive amount of atomic displacement damage the fuel microstructure sustains, along with changes in chemical composition during fission, complicate the understanding of microstructural evolution and the interaction between radiation damage processes, and challenge the formulation general models that accurately predict the evolution of microstructure and associated physical properties. These limitations confound efforts to understand fuel behavior and apply a systemic approach to fuel design. As a result, the experimental cycle for fuel development is currently long and expensive. The following opportunities exist to decrease fuel development time and expense:

- Develop flexible fabrication capabilities that increase the ability to develop fabrication processes and produce unique experimental fuel test specimens.

- Implement modern non-contact measurement tools in hot cells and in-canal examination instrumentation to acquire engineering-scale irradiation performance data more rapidly and in three dimensions. 
- Increase the scientific understanding of fuel behavior through detailed microstructural examinations, chemical and isotopic analysis, and property measurements essential to the more fundamental understanding of fuel behavior required for modeling and simulation.

- Integrate experimental and modeling and simulation activities to ensure experimental measurements support development and validation of computational models and modeling and simulation are used to inform and focus experimental measurements.

- Implement a transient testing capability to demonstrate fuel behavior during off-normal occurrences for both research and licensing purposes.

Achieving these goals, coincident with establishing robust modeling and simulation tools, will provide the information required to move away from lengthy and costly empirical approaches to fuel development and qualification, decreasing the time to market for new or improved fuels.

\section{C-1.2.1 Fabrication Process Improvement}

The importance of a thorough and disciplined approach to fuel fabrication process development is often overlooked. Fabrication is one of the most important aspects of the development cycle for advanced fuels and, as such, has high potential to enable compression of the nuclear development cycle. MFC has broad experience with fuel fabrication development. FCF was used to demonstrate remote fuel fabrication of recycled metal fuel to close the fuel cycle. FMF and the AL Casting Laboratory produced the U-Zr driver fuel and experimental U-Pu-Zr fuel required to fuel EBR-II. Refocusing these production facilities and development of additional R\&D capability in FASB, EFF, and AFF has allowed development and fabrication of many first-of-a-kind fuels, including transmutation fuels (containing plutonium, neptunium, americium, and curium), accident-tolerant fuels for commercial LWRs, extruded metallic fuels, annular fuels, dispersion fuels, and uranium-molybdenum monolithic fuel.

Fuels that are different from those currently in commercial use drive the need for new fuel fabrication technology. Fabrication development of fuels historically has relied on a trial-and-error approach. Past experience is used to establish a recipe that provides a consistent and reproducible product. Parametric irradiation testing leads to a limited understanding about the effects of process variables on performance. Operational experience feeds into the fabrication process, allowing incremental improvements in performance. For example, over the last five decades, this process has resulted in a highly reliable LWR fuel system. A shift to using modeling and simulation tools to design fabrication equipment and processes, development of flexible fuel fabrication capability, and real-time feedback on the relationship between fabrication and microstructure during process development will provide more rapid development of fuels with specified and well-defined microstructures.

Modeling and Simulation of Fabrication Processes - Modern modeling and simulation tools, with additional development and validation over a broader range of fuel systems, will soon provide the ability to model changes in fuel behavior as a function of changes in microstructural parameters. Fabrication process models have the ability to design process components (such as casting molds) and fabrication process parameters (such as thermal cycles) to efficiently lead fabricators to a viable laboratory-scale fabrication process and bridge the gap between laboratory-scale and commercial production processes (Figure C-5). Process models also have the possibility of predicting microstructural evolution as a function of discrete process steps (such as solidification and rolling). Mesoscale microstructure/performance models that specify the desired microstructure, combined with process models that aid in design of fabrication process equipment, and parameters have the potential to significantly reduce the number of iterations in the fuel development cycle. 


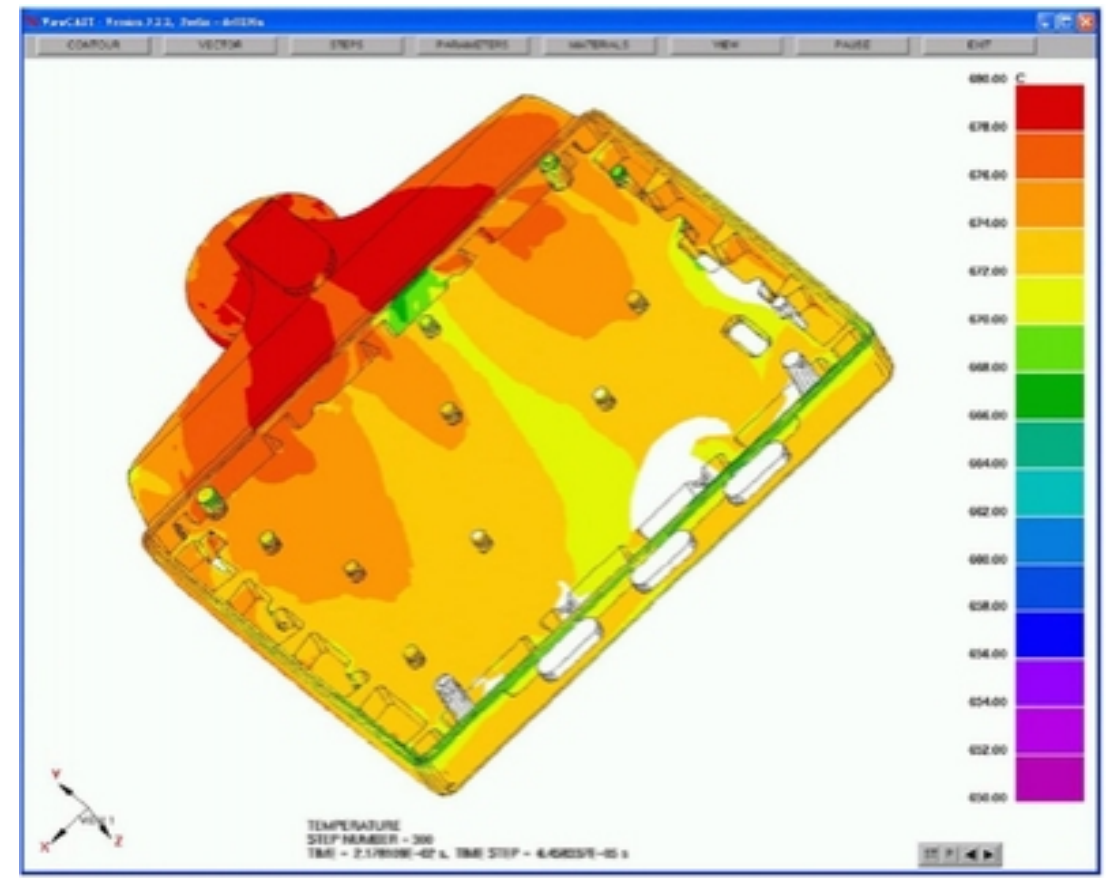

Figure C-5. Fabrication process modeling can be used to determine optimum casting mold geometry and thermal conditions, reducing time for development of advanced fuel fabrication technology.

Flexible Fabrication Capability - MFC fabricates a wide range of fuels for research, ranging from pin-type metallic fuels containing minor actinides, to research reactor fuels, to accident-tolerant LWR fuels. Each of these fuels requires specific fabrication capabilities. These capabilities are normally housed in gloveboxes or hoods and, once installed, are largely static because of the difficulty in modifying contaminated equipment. This capability gap often results in fuel fabrication processes being adapted to installed process equipment rather than equipment being adapted to meet fuel requirements. A relatively wide range of equipment that operates over a wide range of parameters is required to remain responsive to RD\&D needs as they evolve.

Additional configurable fabrication space will be made available for testing and optimization of the new processes required for new fuels as RD\&D needs evolve. In particular, private-sector interest continues for MFC fuel fabrication capability for fabrication process development, lead-assembly fuel fabrication and even first cores for first-of-a-kind demonstration reactors. If those program opportunities emerge with funding, then additional MFC fuel fabrication space will be essential. Space will be made available over the next 5 years through strategic reconfiguration of current fuel fabrication facilities (e.g., FMF, FASB, EFF, the Radioactive Liquid Waste Treatment Facility, and AL) to remove unused equipment and gloveboxes and transfer characterization equipment to new facilities (i.e., IMCL and SPL).

Advanced Manufacturing Techniques Applied to Nuclear Fuel - Advanced fuel systems enabled by advanced manufacturing will potentially lead to revolutionary advances in the nuclear industry. Creating the capability to fabricate and deploy new fuel systems, expand reactor market opportunities, improve economic and safety performance, reduce supply chain challenges and help to re-establish the United States as a global leader in nuclear energy technology development. Recently-developed advanced manufacturing techniques have not been fully applied to the fabrication of nuclear fuel systems. Beyond the potential to produce existing fuels in a less expensive manner, advanced manufacturing technologies have the potential to significantly expand the design options for fuel systems. The ability to fabricate nonhomogeneous distributions of fuel constituents opens the door to possibilities not available with traditional fabrication methods. Advanced fabrication techniques also open the possibility of shapes and microstructures not possible with traditional methods. Because fuel and cladding performance is the basis 
for a reactor's safety performance and its economic competitiveness, deployment of new fuel designs and production techniques made possible by advanced manufacturing methods could have significant impact on the operating economics of the current LWR fleet and could enable operating regimes otherwise not possible in advanced reactors.

Additive manufacturing technology ${ }^{0}$ is currently being developed in other major technology sectors (Figure C-6). ${ }^{\mathrm{p}}$ This technology, when appropriately modified and applied as part of the nuclear fuel fabrication process, has high potential to meet needs for fabrication of fuel test specimens with unique geometry, microstructural features, and chemical composition. This technology is already being developed by DOE-NE for application to nuclear components ${ }^{\mathrm{q}, \mathrm{r}}$ and fuels. ${ }^{\mathrm{s}}$ NNSA is also exploring the use of this technology for fabrication of low-enriched conversion fuel for the TREAT reactor.

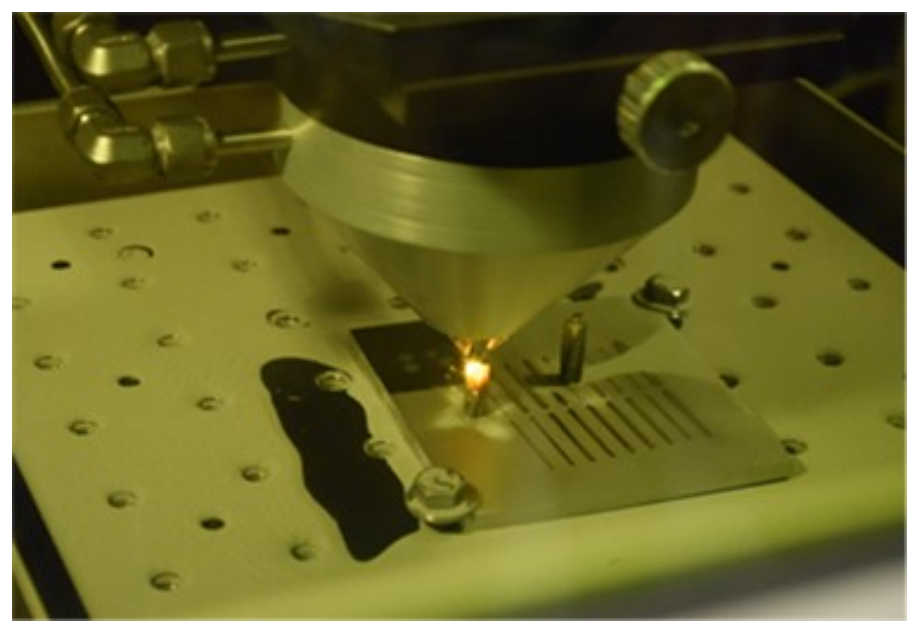

Figure C-6. Laser additive manufacturing is being developed and applied for use in the manufacturing of advanced materials, for example, turbine engine components. The method will be applied to the development of advanced nuclear fuels at MFC.

\section{C-1.3 Proposed MFC New Facility - Reactor Fuels Research Laboratory}

Several advanced reactor concepts under active consideration call for fuel designs which have higher enrichment than that currently in use in commercial reactors. The NRC-licensed commercial nuclear fuel vendors are regulated to less than 5\% enriched uranium and are only licensed for uranium oxide fuels (with one exception). In contrast, the advanced reactor concepts plan to use fuel at uranium enrichment levels between $5 \%$ and $20 \%$. The facilities within the DOE complex are currently limited to research quantities of fuel materials, generally less than one kilogram. There is thus a lack of capabilities at present in the United States for fabrication of test-bed or engineering scale quantities (2-100kg batches) of fuel focused on demonstration and process validation.

To fill this gap, a new facility at MFC, the Reactor Fuels Research Laboratory, is planned that will provide a flexible and reconfigurable Hazard Category 2 (HC-2) fuel development facility within the

o. Ian Gibson, David Rosen, and Brent Stucker, 2015, “Additive Manufacturing Technologies: 3D Printing, Rapid Prototyping, and Direct Digital Manufacturing," second edition, Springer.

p. For example, http://www.geaviation.com/company/additive-manufacturing.html.

q. SBIR contract DE-SC0011874, 2014, “Additive Manufacturing of Nuclear Grade Components," Physical Sciences Inc.

r. SBIR contract DE-SC0011826, 2014, "Development of nuclear quality components using metal additive manufacturing," RadiaBeam Systems.

s. $\quad$ SBIR contract DE-SC0011954, 2014, "An additive manufacturing technology for the fabrication and characterization of nuclear reactor fuel," Free Form Fibers. 
DOE complex that can handle large quantities of uranium with less than $20 \%$ enrichment (HALEU). This facility would allow the fabrication of lead test rods, lead test assemblies, microreactor cores, and the demonstration of new fabrication processes using many kilograms of material. In addition to the direct fabrication capability, an important aspect that will be provided by this facility is the opportunity to evaluate the extent of the quality assurance needed to foster a reduced overall time required to produce a fully inspected fuel product. A critical quality component to nuclear fuel is elemental and isotopic analyses; as a result, the facility pre-conceptual design will evaluate the need for a fresh fuel analytical laboratory that may be included as a part of this facility.

The Reactor Fuels Research Laboratory, if completed, will provide a reconfigurable, long-term solution for meeting DOE, small business, and commercial needs for development of demonstration-scale quantities of fuel for licensing in current and advanced reactors. This facility will support NRIC by providing a capability that is critical to support test bed demonstrations of advanced reactor designs.

\section{C-2. FUEL CHARACTERIZATION}

\section{C-2.1 Engineering-Scale Examination of Irradiated Fuels}

Measuring the irradiation-induced response of fuels on the engineering scale is critical in determining the feasibility of new fuel concepts, establishing a licensing basis for fuels under development, and extending the operating envelope of existing fuels. Characterization at this scale is essential for quantifying fuel swelling response, corrosion behavior, fission product transport, and identifying failure locations and failure modes. Measurements of fuel performance parameters have traditionally been made serially, in two dimensions, using contact measurements. Traditional measurements include visual examination, radiography, gamma scanning, corrosion layer thickness measurement, dimensional measurement, geometrical changes (e.g., bowing and blistering), and gas pressure measurement and analysis; these are conducted in HFEF. Significant increases in data quality and throughput can be made by implementing currently available noncontact measurement technology and expanding PIE capability to the ATR canal. Additional capability is also required to accommodate PIE on transient tests conducted in the TREAT reactor.

Advanced Nondestructive Examination - Current commercially available non-contact measurement technology and advances in tomographic data acquisition and image processing provide the opportunity to transition to new nondestructive examination methods that use parallel acquisition of multiple data types in three dimensions. Data acquired simultaneously from multiple sensors (e.g., visual, dimensional, and gamma tomography) can provide greatly increased data acquisition rates, reducing the time required to conduct a complete examination and providing higher fidelity data. Measurements in three dimensions provide a much richer data stream for visualization and for use in validating models. Noncontact methods do not require use of geometry-specific measurement systems; plates, rods, and cylinders can be measured with no change in configuration. Acquisition of three-dimensional nondestructive examination data will provide more precise information for directing the collection of follow-up samples supporting metallography, radiochemistry, and other types of measurements, removing random chance in the process of identifying and studying stochastic and non-stochastic phenomena in fuel and fuel-cladding systems. It can also extend to chemical analysis using techniques such as laser-induced breakdown spectroscopy. 
PIE capability can also be extended to the ATR canal. Use of the canal provides capability for interim examination between irradiation cycles and may be used to perform a complete nondestructive examination in some cases. This will decrease the burden on HFEF and increase overall PIE throughput. The ATR canal currently provides capability for visual inspection, ultrasonic examination of fuel plates to determine swelling and detect delamination, and capability for precision dimensional measurement of coolant channel gap width. Experiment disassembly is performed on some experiment configurations. The feasibility of gamma-ray scanning has also been demonstrated ${ }^{t}$ and radiographic tomographic visualization is also possible. Installation of a single PIE examination station in the ATR canal would optimize use of limited canal space and provide the most efficient and cost-effective method for conducting these examinations.

\section{C-2.2 Scientific Understanding of Fuel Behavior}

Fuel performance originates in events that occur at the atomic scale and it is important that atomicscale damage processes be well understood. This understanding translates to control of the fuel microstructure, composition, fine-scale geometry, and interfaces to optimize the local response of fuel to the fission environment. It is further applied to the engineering-scale design of fuel elements and assemblies to compensate for material changes. For example, examination of the microstructure of U-10Mo fuel indicates that a stable nanoscale superlattice of fission gas bubbles forms during irradiation and remains stable to very high fission densities (Figure C-7). This superlattice provides an extremely efficient method for storing fission gas and controlling fuel swelling. If the formation mechanism can be understood, it may be applicable to other fuel systems. Other mechanisms for fission gas management and means to mitigate FCCI (fuel-cladding-chemical- interaction) are also of high interest.
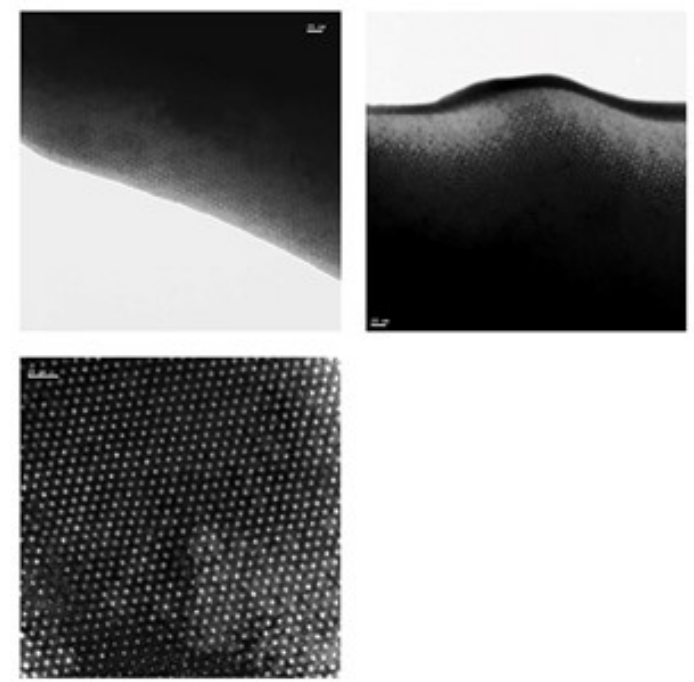

Figure C-7. Transmission electron microscopy images of an ordered array of fission gas bubbles in U-Mo fuel at high burnup. The ordered array of high-pressure gas bubbles provides a stable and efficient mechanism for storing fission gas (INL/EXT-10-20466).

t. J. Navarro, 2013, A Feasibility and Optimization Study to Determine Cooling Time and Burnup of Advanced Test Reactor Fuels Using a Nondestructive Technique, INL-EXT-29997. 
Scientific understanding of fuel behavior requires that microstructural evolution be understood as a function of service conditions, that fuel properties are understood at the mesoscale in terms of nanostructure, and that engineering-scale properties can be derived from mesoscale quantities. This requires that properties be understood at both the mesoscale and engineering scale and that microstructural features be quantified from the nanoscale to the mesoscale. Close coupling of experimental data with computational models is critical to achieving this understanding.

Fuel Properties - A detailed understanding of the properties of nuclear fuels is necessary to formulate a detailed understanding of fuel performance and underlying fuel behaviors. Thermal properties of nuclear fuels and cladding materials are critically important because these properties determine the temperature, temperature gradients, and thermal response of the fuel system during operation. Important fuel behaviors (such as fission product transport, phase equilibria, and swelling) are universally temperature dependent. Properties, in turn, are heavily dependent on microstructure and material chemistry. As fuel fissions, it undergoes displacement damage and compositional changes that generally degrade these properties, potentially affecting margin to failure.

Mechanical properties as a function of fission density and temperature over a wide range of variables are important in determining failure modes, safety of storage and transportation, and accident response; key among these are understanding of fracture and irradiation creep behavior.

With the advent of modern laser-based methods for measurement of thermal and mechanical properties and the advent of in-situ micromechanical testing methods, opportunities exist to conduct these measurements at the mesoscale and connect them to the engineering-scale response. Combining these measurements, along with lower-length-scale microstructural characterization data, allows elucidation of the effects of specific microstructural features on mechanical and thermal properties (Figure C-8). This knowledge allows development and validation of models that accurately predict local thermal conditions and mechanical properties throughout the fuel's life cycle.

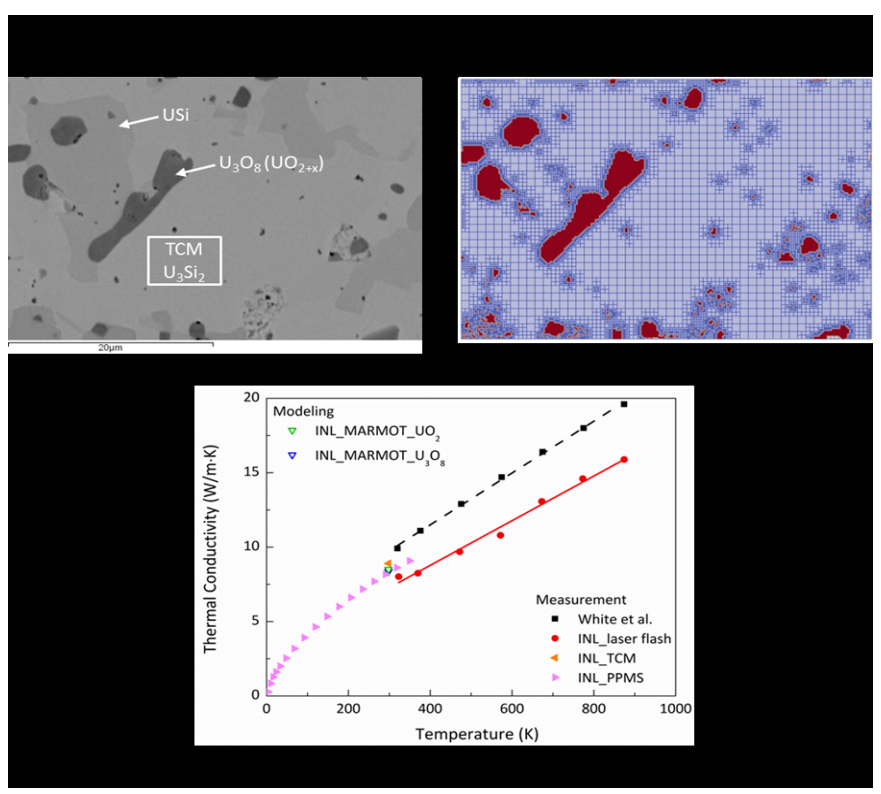

Figure C-8. Thermal conductivity measurements of $\mathrm{U}_{3} \mathrm{Si}_{2}$ using several methods comparing different length scales and a wide range of temperatures. (a) Scanning electron microscopy image of an $\mathrm{U}_{3} \mathrm{Si}_{2}$ sample, (b) reconstructed microstructure and mesh in MOOSE for MARMOT calculations, and (c) thermal conductivity of $\mathrm{U}_{3} \mathrm{Si}_{2}$ as a function of temperature. The solids symbols are experimental measurements from literature and INL. TCM (i.e., thermal conductivity microscope) and PPMS (i.e., physical property measurement system) results are shown as the solid triangles. The MARMOT results, based on the reconstructed mesh, are represented by the open triangles. 
Microstructural Characterization - The engineering-scale response of fuel depends on its response to high-energy damage processes and chemical evolution that occur at the atomic scale. Neutrons and fission fragments displace atoms from their lattice sites, creating defect structures that have both direct short-term impacts on properties and drive longer-term microstructural evolution. Chemical composition changes dramatically as fissile atoms are split, forming both solid and gaseous fission products. Increased populations of irradiation-produced defects allow rapid chemical diffusion to occur in response to chemical potential gradients driven by steep thermal gradients and dissimilar material interfaces. These atomic-scale processes change the mesoscale structure of the fuel materials, generally degrading properties and sometimes causing unpredicted material responses.

Revolutionary advances in materials characterization tools over the last decade now allow probing of the microstructure and materials chemistry at the atomic scale. These advances include routine atom probe tomography, aberration-corrected transmission electron microscopy, nanoscale measurement of grain orientation, nano and pico-indentation, and high-resolution x-ray tomography. Close coupling of data from these characterization tools with multiscale modeling and simulation will allow scientific discovery of the mechanisms that promote fuel stability and application to other fuel systems. Work at INL is establishing possible links between fabrication conditions, microstructure, and fission product transport behavior. Figure C-9 is an example of nanoscale analysis from a neutron-irradiated TRISO particle that was fabricated with different conditions to achieve smaller grain sizes in the silicon carbide layer. This is an analysis of the orientation of individual silicon carbide grains using scanning transmission electron microscopy energy dispersive spectroscopy and ASTAR (grain orientation mapping in transmission electron microscopy) by MFC staff at the Center for Advanced Energy Studies MaCs Lab (INL-owned instruments). Analysis on this scale is essential to understanding fuel behavior.

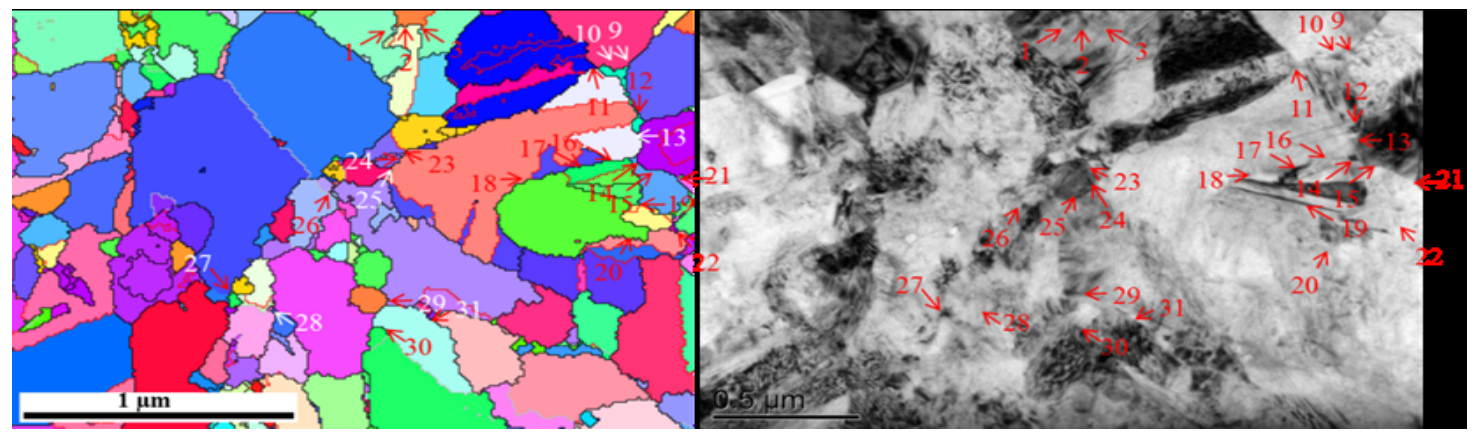

Figure C-9. Silver transport through the silicon carbide layer in TRISO fuel has been a known issue for more than four decades, but has not been understood. Analysis using advanced PIE in HFEF, AL, and ORNL, coupled with high-resolution transmission electron microscopy is now helping to identify transport paths and understand the mechanism.

Neutron and photon-based scattering methods that probe the atomic structure of matter are key materials science tools. These methods are commonly used to elucidate crystal structure, phase array, orientation, and strain, which are important parameters for understanding response to irradiation. Major national user facilities such as the Spallation Neutron Source, High-Flux Isotope Reactor, and National Institute of Standards and Technology Center for Neutron Research provide specialized and highly subscribed neutron beam lines. The Advanced Photon Source, National Synchrotron Light Source-II, and facilities at Stanford National Accelerator Laboratory provide top-level capabilities for $\mathrm{x}$-ray scattering and imaging. 
The Advanced Photon Source (Figure C-10) currently accepts small (i.e., less than $0.08-\mathrm{mm}^{3}$ ) samples of irradiated fuel produced using focused ion beam techniques. The use of national neutron and photon scattering facilities has the potential to provide very high-quality data, but with severely restricted access, very small sample size, and with the added complexity of nuclear material shipping. Development of neutron and/or x-ray scattering capabilities at MFC would provide the ability to rapidly acquire critical information about fuel and material evolution under irradiation with larger specimens, but at low resolution relative to national user facilities. A three-tiered approach is being pursued to develop the capability for routine access to neutron and photon scattering data:

- INL is partnering with Brookhaven National Laboratory to develop a capability that allows routine acceptance and analysis of high activity samples at the National Synchrotron Light Source-II. A preconceptual design and cost estimate for the MRE (Materials in Radiation Environment) beamline facility outside of the NSLS-II ring have been completed. The Advanced Photon Source has also proposed a beamline to routinely accept and analyze radiological samples.

- Development of neutron scattering based on the Neutron Radiography reactor (NRAD) as the neutron source. An initial demonstration will be made using a conventional goniometer. A wide-angle detector has been acquired for future use. This capability will be most suitable for providing basic, but very important, information on crystal structure and phases present in larger samples of highly active materials, such as intact fuel rods. Collocating the MEITNER PIE station with neutron diffraction and neutron imaging in the NRAD North Radiography station (NRS) provides an opportunity for correlated, multimodal nondestructive characterization, for example linking macrostructural information from gamma emission tomography to data on crystal structures from specific microstructural locations. Collaborations are ongoing with LANL and ORNL to develop facilities capable of routine examination of nuclear materials at LANSCE (Los Alamos Neutron Science Center) and SNS (Spallation Neutron Source).

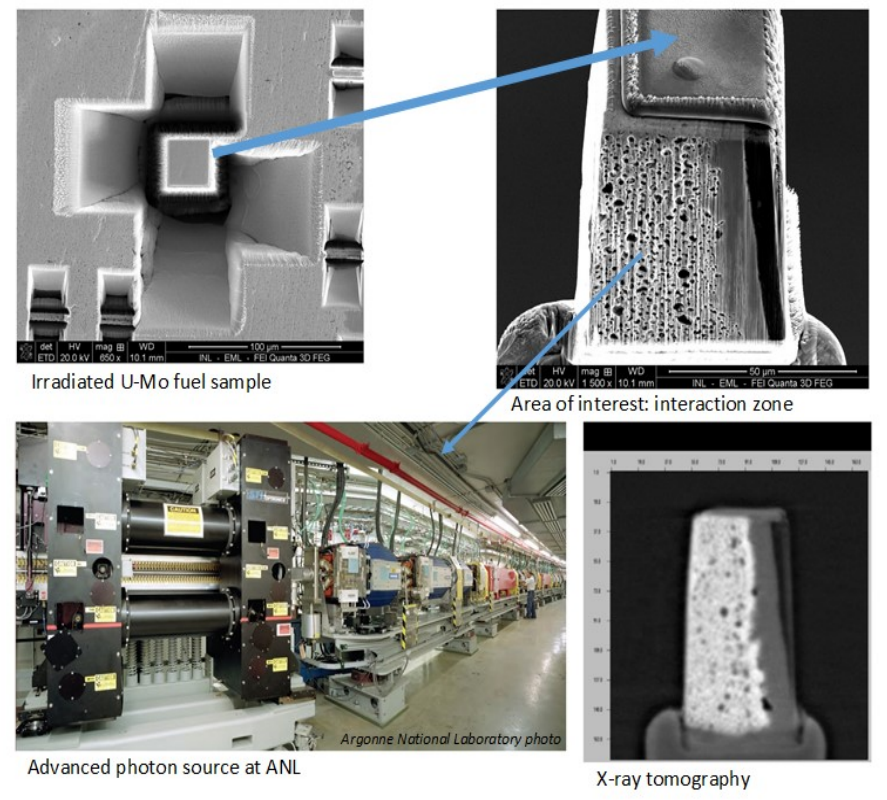

Figure C-10. Focused ion beam sample preparation at MFC allows INL staff to conduct fuel experiments at other national user faculties. An irradiated U-Mo fuel sample was prepared for characterization at the Advanced Photon Source at Argonne National Laboratory. Access to Advanced Photon Source beam lines provides a combination of three-dimensional data on fuel behavior that is not otherwise available, such as three-dimensional phase analysis, three-dimensional grain size analysis, grain orientation, lattice parameters, microstrain, dislocation density, and pores, cracks, and bubbles. 
- Development of concepts for a high brightness, laboratory-scale x-ray and neutron scattering capability at MFC as a supplement or backup to a dedicated beamline at a synchrotron facility. Leading concepts are based on inverse Compton scattering using laser light sources of varying frequency coupled with LINAC or cyclotron electron sources. One company has entered commercial production, and several others have developed prototypes. The state of technology and reliability will be monitored as it continues to mature. These compact light sources offer greater ease of access, but at a penalty in X-ray brightness. Cost of an installed capability is estimated to be in the range of $\$ 30 \mathrm{M}$, roughly divided between the instrument and the facility (or facility modifications) required to host it.

\section{C-3. CHARACTERIZATION OF RADIATION DAMAGE IN CLADDING AND IN-CORE STRUCTURAL MATERIALS}

The limiting factors in both fuel and reactor operating lifetime are cladding ${ }^{\mathrm{u}}$ and structural materials. Research for developing the scientific basis for understanding and predicting the response of materials to the nuclear environment allows deliberate design of materials better suited to the in-core nuclear operating environment than current off-the-shelf materials. Critical to success in this area is a capability for rapid development of materials, including fabrication, performance testing in a realistic environment, and characterization. Also key are the availability of materials for study by the nuclear energy research community, the ability to fabricate standard test samples from irradiated materials mined from current reactors, and the ability to transport materials to and from NSUF partner facilities as appropriate.

\section{C-3.1 Cladding and In-Core Structural Materials Research, Development, and Demonstration}

Damage processes in materials are driven by neutron damage cascades and, in principle, are easier to understand at a fundamental level in materials than in fuels. Structural materials research provides a fertile basis for collaborative scientific investigation by INL, other national laboratories, and universities/ industry partners.

Irradiated materials (i.e., non-fueled and non-alpha-contaminated) can be more easily handled than fuels at universities, national user facilities, and low-level radiological facilities at other national laboratories, allowing more diverse data streams and enabling a broader collaborative approach (Figure C-11). At INL, SPL will serve as a user facility and as a material supply hub in national and international efforts to develop these materials.

u. Although fuel cladding materials are integral and essential to fuel performance and are normally grouped with fuels, initial development of new cladding materials that meet basic requirements (i.e., strength, creep resistance, fabrication, and joining) primarily requires consideration of high dose material irradiation damage mechanisms and are included here. 

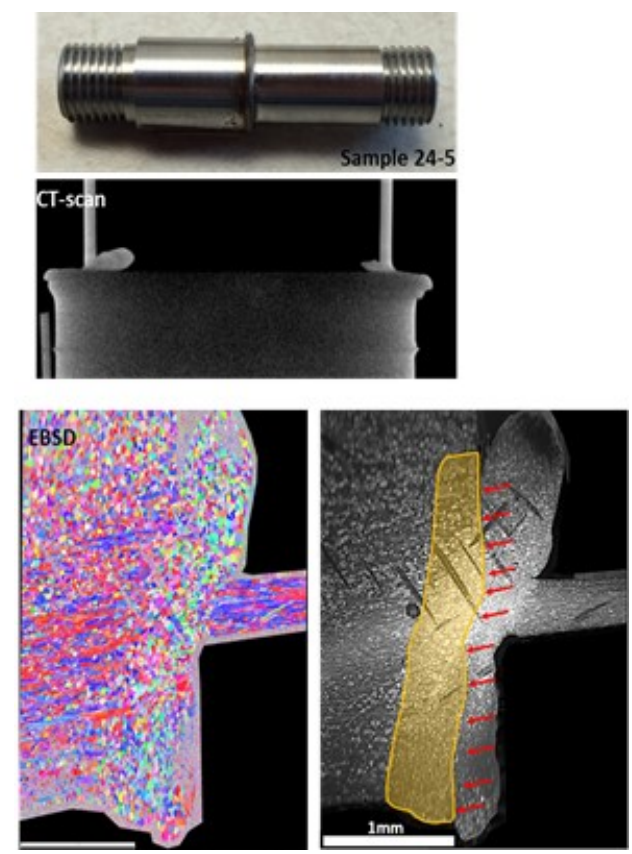

Figure C-11. Thin-walled tubing is being developed as an alternative to zircaloy cladding for use in LWRs.

\section{C-3.2 Cladding and In-Core Structural Materials Research, Development, and Demonstration Goals}

\section{C-3.2.1 Zirconium-based Light Water Reactor Fuel Cladding}

Significant reduction in LWR operating costs may be achieved by a reduction in outage costs. This entails extending fuel burnup and increasing the number of maintenance activities conducted while the reactor is online. Both of these strategies require improvements in current fuel cladding performance and testing to validate the thermomechanical response of cladding materials to RIA (Reactivity Insertion Accidents) and LOCA (Loss of Coolant Accident) events. The required improvements in cladding performance may be realized through development of and effective coating technology. This development involves a combination of steady-state irradiation testing, transient irradiation testing, out-of-pile thermal testing, and standard and specialized mechanical testing to determine cladding embrittlement thresholds.

\section{C-3.2.2 Accident-Tolerant Cladding Materials}

Developing accident-tolerant fuel concepts revolves around improving oxidation behavior of current zircaloy cladding materials through surface modification, or developing oxidation-resistant steel or ceramic materials. These cladding materials are currently being irradiated in ATR and in commercial light water reactors as part of the Accident-Tolerant Fuel Experiment series of experiments and tests. Availability of these cladding materials at MFC after irradiation presents a unique opportunity for collaboration with other national laboratories, industry, and universities to understand the response of these materials in detail when integrated into a fuel system.

The Sample Preparation Laboratory mission for development and testing of materials will include the testing of light water reactor cladding materials, with the risk of alpha cross contamination mitigated through defueling of cladding and use of local confinement barriers, such as gloveboxes, where necessary. 


\section{C-3.2.3 Radiation-Tolerant Cladding Materials for Fast Reactors}

Development of cladding for fast-spectrum reactor systems seeks to improve on the excellent swelling resistance of ferritic/martensitic steels, such as 12Cr-1Mo-based alloys (e.g., HT9) and 9Cr-1Mo-based alloys (T91) with improvements in high-temperature strength and irradiation creep resistance. Ferritic/martensitic steels experimentally have been shown to exhibit radiation resistance to neutron doses as high as 200 displacements per atom. High creep rates and a significant decrease in tensile strength limit the operating temperature of ferritic/martensitic steels to less than $600^{\circ} \mathrm{C}$. Certain reactor systems that propose extended core residence times can require that cladding materials perform to 400 displacements per atom or above. The introduction of nanoscopic features, typically Y-Ti-O particles, into the microstructure to form oxide dispersion strengthened alloys dramatically improves hightemperature creep resistance, strength, and radiation tolerance. To realize the potential of these materials, the relationship between microstructural characteristics of oxide dispersion-strengthened alloys and their irradiation performance must be understood and issues with fabrication and joining (i.e., welding) resolved. A promising alloy developed at ORNL is a nano-structured ferritic alloy (NFA), which uses a very high density of Y-Ti-O nano-features to impart resistance to dislocation climb and glide and to enhance point defect recombination. ${ }^{v}$ MFC's role in development of new cladding alloys is to collaborate broadly to facilitate progress through established research programs to make materials, instrumentation, and expertise available during analysis that result in advancement of this technology. The SPL will play a central role in this effort.

A new class of high entropy alloys has shown promising radiation-resistant behavior during early testing. This class of alloys occupies a large compositional parameter space, and will require considerable initial development, out-of-pile testing, irradiation exposure, and testing of irradiated material. Because of the large parameter space and extensive testing required, development of this alloy class is a candidate test case for the application of high-throughput and combinatorial material science methods to nuclear materials.

Many of these materials are difficult to join; alternatives to traditional fusion welding are being developed. As an example, electron backscatter diffraction results from a pressure-resistance welded sample that encompasses the weld and sections of the tube and plug microstructures are shown in Figure C-11 (lower left), along with a computed tomography image and photo of the weld joint (top). The results reveal the microstructure of the bond that developed in the weld because of rapid melting coupled with the mechanical load applied during welding. Equiaxed grains suggest that the redistributed material fully melted and re-solidified, with a resulting acceptable bond line.

The SPL will be central to the research and development of improved fast reactor cladding alloys through conventional testing and through the development and application of high throughput and combinatorial material science methods to nuclear materials.

\section{C-3.2.4 Irradiation-Assisted Stress Corrosion Cracking and Fracture Toughness}

There is a large environmental and economic benefit to extending current commercial nuclear plant lifetimes beyond 60 years. The key issue facing life-extension efforts for current reactors is radiation-induced degradation of materials. One of the most important issues facing further extension of reactor lifetimes is IASCC, where exposure to neutron irradiation increases the susceptibility of in-core structural stainless steels to stress corrosion cracking. IASCC is a complex phenomenon that involves simultaneous actions of irradiation, stress, and corrosion that, despite five decades of research, is not well understood. In recent years, as nuclear power plants have aged and irradiation dose increases, IASCC has become an increasingly important issue. Gaining a better understanding of IASCC in reactor materials is a high priority for the Electric Power Research Institute (representing nuclear industry research), the Nuclear Regulatory Commission, and DOE’s LWR Sustainability Program. From an applied

v. G. R. Odette and D. T. Hoezler, "Irradiation-tolerant Nanostructured Ferritic Alloys: Transforming Helium from a Liability to an Asset," JOM, September 2010, 84-92. 
(i.e., industry) perspective, it is essential to measure and understand changes in crack growth rates and fracture toughness as a function of radiation fluence; therefore, when cracks are identified during outage inspections, quantitative decisions can be made as needed for component replacement. Capability at MFC (Figure C-12) is used to make these measurements on materials with gamma dose rates up to 40,000 R/hr.

Developing a scientific basis for understanding and predicting long-term degradation behavior and the operational limits of materials relies on detailed examination at the lower-length scales (i.e., micrometers to nanometers). Critical to this effort is the ability to generate high-dose materials by reconstituting material mined from commercial reactors for accumulation of additional dose in test reactors. These data are required to build accurate, predictive computational models useful for prediction of reactor service life.

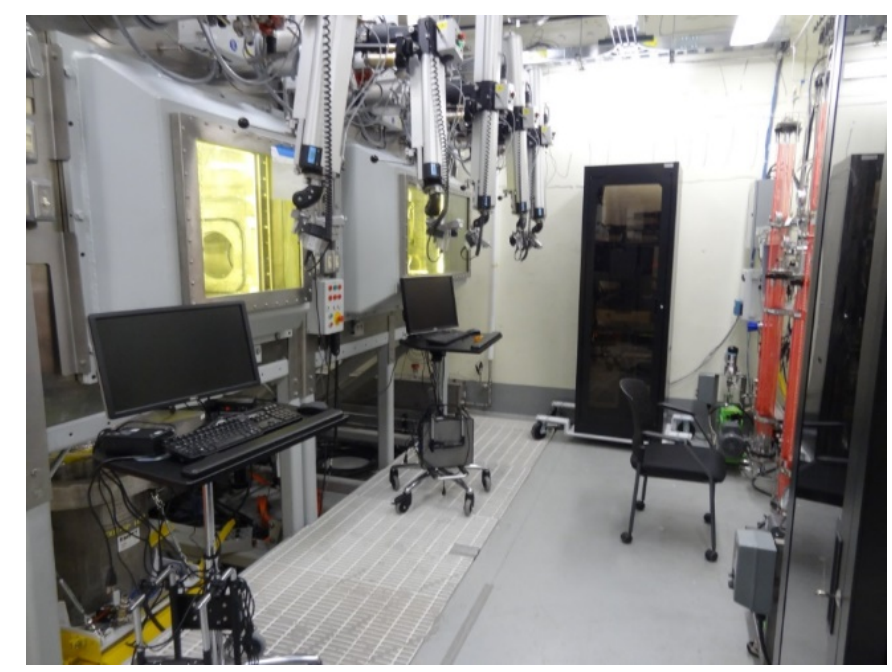

Figure C-12. IASCC test rigs for high-activity materials

\section{C-3.2.5 Improving Structural Material Performance}

Improving the performance of structural materials can improve the life-cycle economics of advanced reactors by potentially allowing both higher operating temperatures (i.e., higher thermal efficiency and power output) and longer lifetimes. Alloy X-750 is a material used today in many commercial reactor applications, but its performance is not as favorable as expected (Figure C-13). Advanced materials could have a significant impact on life-cycle costs, even if raw material costs are higher than the currently used stainless steels. Improved materials performance also improves safety performance through improved reliability and greater design margins. Requirements for advanced structural materials include dimensional stability, acceptable mechanical properties at high fluence, and good corrosion resistance. Considerable overlap exists between this area and development of advanced cladding materials. Understanding this issue and incorporating modified or alternative materials, based on what is learned from currently used materials, into design of new reactors that further increase the operating lifetime would provide substantial benefit to the nuclear industry. 

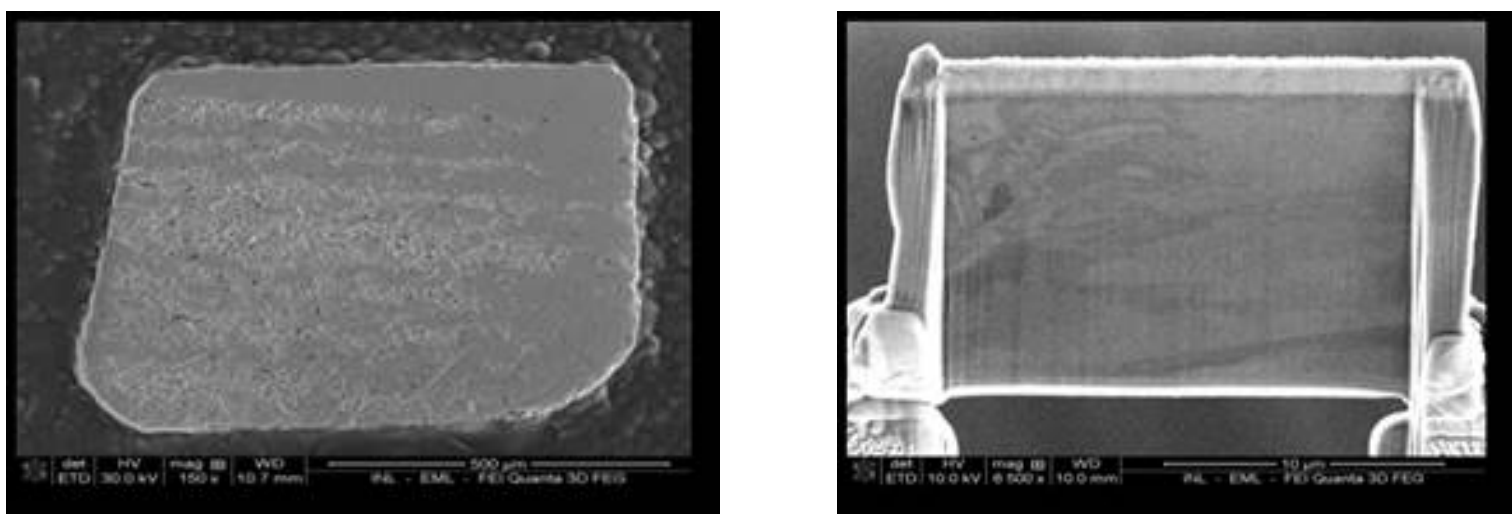

Figure C-13. Irradiated X-750 nickel alloy specimens (left) were prepared by focused ion beam (right) for Atomic Energy Canada Limited. This joint work helps to address the root cause of a material performance issue in CANDU reactors and define improved material specifications.

\section{C-4. FUEL RECYCLING AND NUCLEAR MATERIAL MANAGEMENT}

Nuclear fuel cycles that increase uranium resource utilization and reduce high-level waste require a comprehensive recycling strategy. In general, all actinides important for resource utilization and waste management can be productively recycled in thermal or fast-spectrum systems to reduce the decay heat and radiotoxicity of the waste placed in a geologic repository. Only those elements that are considered to be waste (i.e., select fission products) are interred in a repository for disposal. Recycling requires extensive use of separations technologies. Long-term radiotoxicity of waste decreases as more elements are separated and recycled, but this increases the complexity of the separation process. In the case of fast reactors, minor actinides will be transmuted, resulting in 8 to 12 times less high-level waste than the amounts of spent nuclear fuel processed and will require less repository capacity when compared to direct disposal.

Nuclear separations RD\&D requires highly specialized facilities because many of the important species are radioactive and/or entail extensive safeguards and security. Outside INL, few laboratories exist in the United States that are capable of doing research in actinide separations chemistry. The skills and capabilities at MFC have been traditionally geared toward applied and developmental research in radiochemical separations for the nuclear fuel cycle.

Recycling of spent fuel today can be conducted using either aqueous chemical methods or pyrochemical methods, typically using electrochemistry and chemistry in a molten salt electrolyte.

\section{C-4.1 Aqueous Recycling Research, Development, and Demonstration Focus Areas and Goals}

\section{C-4.1.1 Aqueous Recycling Research Focus Areas}

The current U.S. baseline for managing commercial used nuclear fuel is direct disposal in a geologic repository after a single burn in a reactor. This has the advantage of no processing of used nuclear fuel and reduced low-level waste generation. However, compared with the used fuel recycle, the disadvantages include increased mass and volume of high-level waste requiring geologic disposal, increased radiotoxicity associated with the waste (i.e., spent nuclear fuel), a less durable disposal waste form that requires more elaborate engineered barriers, higher demand for uranium ore, and higher longterm heat loading of the repository.

Although aqueous separations and waste forms technologies are not currently developed to the point necessary for commercially implementing a sustainable fuel cycle, preliminary results from the United 
States and abroad have demonstrated sufficient promise to be confident of success if sufficient technology development is performed. For this reason, there is an ongoing challenge in the area of nuclear separations involving the need to understand how actinide, lanthanide, and fission product extraction changes with differing solvents in the presence of a radioactive environment. The complex chemical properties of actinides are less explored and more difficult to model than other elements that present a unique challenge within separation science.

\section{C-4.1.2 Aqueous Recycling Research Goals}

Implementation of a sustainable fuel cycle requires a long-term investment in separations research. Technology developments must be made on a firm foundation of scientific understanding. This understanding will allow for application of technologies to changing potential flowsheets, will be more easily licensed and operated, and will support technology and fuel cycle options screening and demonstrations. Technologies developed for a fast reactor fuel cycle must also be amenable to commercial deployment. This demands a cost-effective, robust, and integrated process, where each individual technology or unit operation is integrated into an entire flowsheet. With these overriding principles in mind, two of the primary technological gaps for an aqueous fuel recycle flowsheet are as follows:

- Efficient separation of the actinides from the chemically similar lanthanides and, potentially, from each other in an aqueous reprocessing flowsheet. A better fundamental understanding of the chemistry of actinides and lanthanides in aqueous and organic solutions will greatly help in development of a more efficient and cost-effective recycling process. Once developed, the process will need to be scaled-up and integrated with the other required processes.

- Management of process off-gasses that meet U.S. regulatory constraints. The isotopes Kr-85, I-129, H-3, and, potentially, C-14 require capture and immobilization; however, several challenges remain. The first challenge is the very high decontamination efficiency required for iodine (plant wide decontamination factor of 380 to 8,000 ) combined with data, suggesting that greater than $2 \%$ of the iodine remains in the aqueous stream, leaving the dissolver, and is emanated from virtually all vessel vent and process off-gas streams in small concentrations. A second challenge involves the capture of krypton, which requires cryogenic separations from a gas stream devoid of any gasses except for nitrogen and noble gasses. Although this is a relatively proven technology, it is expensive and typically captures xenon, which is nonradioactive and at a much higher concentrations than krypton.

To support these efforts, several areas of aqueous separations research are being performed at MFC, including the following:

- Evaluation of radiation effects and the resulting degradation products on the various solvents and extractants being developed for separation of uranium and TRU from dissolved used nuclear fuel

- Developing a better understanding of the thermodynamics and kinetics of actinides and lanthanides with various separations processes

- Understanding the impact of radiation on newly developed sorbents for the separation of krypton, xenon, and iodine from aqueous separations off-gas

- Developing an understanding of the behavior of technetium in the separation of uranium/ plutonium/neptunium utilizing tributyl phosphate-based separation processes that do not separate pure plutonium

- Utilizing data obtained from separations research to support development of predictive capabilities to inform future research and support, eventual scale up, and design of robust separation processes. 


\section{C-4.2 Pyrochemical Research, Development, and Demonstration Focus Areas and Goals}

\section{C-4.2.1 Pyrochemical Research Focus Areas}

The terms pyrochemistry and pyroprocessing refer to a family of technologies involving hightemperature chemical and electrochemical methods for separation, purification, and recovery of fissile elements from used nuclear fuel. Pyrochemical technologies can be applied to oxide fuels and metallic fuels; however, the fissile elements are generally recovered as metals for fabrication of new fuels. Presently, pyrochemical technologies are being actively researched by the United States, Japan, France, Republic of Korea, China, India, and Russia. Research aims not only at the challenges of implementing the technologies for commercial-scale applications, but also effective safeguards methods and technologies for such facilities to the standards required by the International Atomic Energy Agency.

Pyrochemical recycling has some unique advantages as a recycling technology for used nuclear fuel. For example, molten salts are impervious to the radiolysis and thermal effects of used nuclear fuel, unlike aqueous organic solvents, allowing for the treatment of 'fresh' used nuclear fuel recently discharged from a reactor core. Effective neutron moderators are absent from these processes, providing distinct advantages for processing high-fissile content fuels and enabling compact processes in right-sized facilities. These processes allow effective group separation of re-usable actinide components from fission products, potentially significantly reducing high-level wastes. Opportunities also exist to use these technologies to recover useful products from a variety of high-residual value legacy used research fuels. Current MFC activities in this area include those mentioned in the following subsections.

Joint Fuel Cycle Study - MFC supports a jointly-funded pyrochemistry study with the Republic of Korea on the Joint Fuel Cycle Study's Integrated Recycling Test. In this study, LWR fuel is used as the feed for kilogram-scale pyroprocessing equipment installed in the HFEF argon-atmosphere hot cell. Through electrochemical oxide reduction and electrorefining, the oxide fuel is reduced to a metal, and TRU accumulates in the molten electrorefiner salt. When sufficient TRU has accumulated, these metals are recovered in a liquid cadmium cathode at an approximately 50:50 uranium:TRU ratio. The recovered uranium/TRU alloy has been used to make a series of recycled fuel samples for irradiation testing in ATR and subsequent PIE analyses in HFEF. Process testing in this research equipment is planned when additional irradiated commercial fuel is received at INL.

Experimental Breeder Reactor-II Driver Fuel Initiative - The Driver Fuel Initiative Program for treating the remaining inventory of EBR-II sodium-bonded metallic fuel is being performed in the FCF argon-atmosphere hot cell using the Mk-IV electrorefiner and cathode processor. Processing the EBR-II driver fuel is necessary to meet DOE obligations under the 1995 Settlement Agreement with Idaho, which will enable INL to maintain its role as a world leader in nuclear energy research.

A small fraction of the EBR-II irradiated fuel inventory is corroded (i.e., oxidized) as a result of decades of storage in hot cells and water pools. These corroded materials are not amenable to treatment by pyroprocessing equipment in FCF. Alternative disposition technologies and paths are being evaluated for these corroded fuels.

Safe storage and disposition options for residual materials such as cladding hulls and process salts are being evaluated given the absence of a high-level repository. The current focus of these efforts is longterm storage options which provide the flexibility to accommodate multiple final disposition options. 


\section{C-4.2.2 Pyrochemical Research and Development Goals}

Research in pyrochemistry focuses on development of fundamental process understanding, safeguards, commercial-scale flowsheets, and waste forms. Active research projects that are working toward the deployment of pyroprocessing supported by MFC include the following:

Fundamental Chemistry and Theory of Pyroprocessing Operations - A primary area of interest is the technology for recovering TRU from molten salt that develop in the electrorefining cell. Research is being performed on methods (such as liquid cadmium cathode, solid cathode, chemical drawdown, and electrolysis) to increase separation efficiencies, simplify processes, and improve technical readiness of these technologies for used fuel recycling scenarios.

Modeling and Simulation of Pyrochemical Operations - These theoretical-based efforts provide a means of assessing performance of process flowsheets with regards to the layout and performance of the individual unit operations, identify key opportunities, and extend knowledge to new recycling scenarios. Verification of performance requires experimentation and testing.

Technology Development for Commercial-Scale Operations - Flowsheets are under development for pyroprocessing of oxide fuels and metallic fuels based on both U-235 and Pu-239 as the primary fissile element. The flowsheets are used to benchmark and reference the present state of technology development and identify those areas most deserving of the limited resources available for focused research.

Technology Development for Safeguarding Commercial-Scale Operations - The international safeguards community is increasingly concerned as more countries begin to show interest in pursuing pyroprocessing technologies. Research is underway to determine a safeguards strategy for a declared pyroprocessing facility that will satisfy International Atomic Energy Agency standards. An understanding of signatures and observables is vital to the detection and surveillance of pyroprocessing facilities for safeguard and security applications.

Waste Form Development - Characterization and assessment of wastes from pyrochemical processes is a key component of determining the efficiency and viability of any proposed recycling scheme. Both the ceramic and metal waste forms were developed to immobilize high-level waste from the treatment of EBR-II used fuel and are recognized world-wide as the baseline pyroprocessing waste forms. Development of simplified processes which can accommodate a broader spectrum of fission products is also a key activity, and MFC continues to lead in development of advanced waste forms.

\section{C-4.3 Used Fuel Disposition}

Understanding the behavior of used nuclear fuel during interim storage is required to extend the dry storage period while a permanent repository is being developed. Additionally, as commercial utilities pursue higher fuel burnup, information about the impact on storage must be provided to the Nuclear Regulatory Commission to allow storage licenses to be considered. Understanding the performance of fuel, fuel cladding, assembly components, and cask material degradation as a function of time and environment is essential to development of predictive models that will be used to analyze performance during long-term dry storage with confidence. Detailed fuel examination and testing required to characterize the fuel and support a science-based approach are intended to reduce the cost and schedule required to obtain data necessary to extend the licensed, interim, dry storage period. Conducting this important long-term research program requires that current barriers to bringing research quantities of used commercial nuclear fuel into the State of Idaho be resolved as soon as possible. 


\section{C-5. TRANSIENT IRRADIATION TESTING}

The TREAT facility (Figure C-14) provides the ability to conduct state-of-the-art in-pile transient tests that are required to evaluate the behavior of fuel during off-normal conditions helping advance the state of nuclear energy science and technology. TREAT capability for testing LWR fuel is even more important with the shutdown of the Halden Reactor. These evaluations are central to the development and eventual qualification of advanced fuel designs and the licensing and regulation of reactors to operate with them. Transient testing occurs in parallel with the rest of the fuel development cycle through the research, development, and qualification/demonstration phases:

- Application of the goal-oriented, science-based approach to R\&D initially requires a set of transient testing capabilities designed to isolate specific phenomena that occur in individual materials or at their interfaces. The results of this testing feeds into advanced modeling and simulation development at INL and in the industry.

- Development of advanced fuel technology requires a wide range of testing under a variety of conditions, ranging from benign to extreme, in order to properly screen fuel designs and select materials used in them. These tests are used to identify a range of fuel performance features that may be used to guide fuel design and advanced reactor design.

- Considered in design of a new reactor system that will utilize a given fuel system, a qualification program is planned to establish the fuel system's operating parameters and performance limits. These parameters and limits become the basis for design criteria and regulatory assessment of a particular reactor design (or underpin the design criteria and regulatory assessment).

- In addition to supporting the specific missions of DOE-NE, the capabilities resident in the transient testing facility support fuel development for NNSA, National and Homeland Security, the U.S. Nuclear Regulatory Commission, propulsion and terrestrial space power systems, nuclear vendors, the Electric Power Research Institute, domestic and foreign regulators, and nuclear power generating companies. TREAT capability also is available to support forensics, nuclear attribution, and component testing for NNSA.

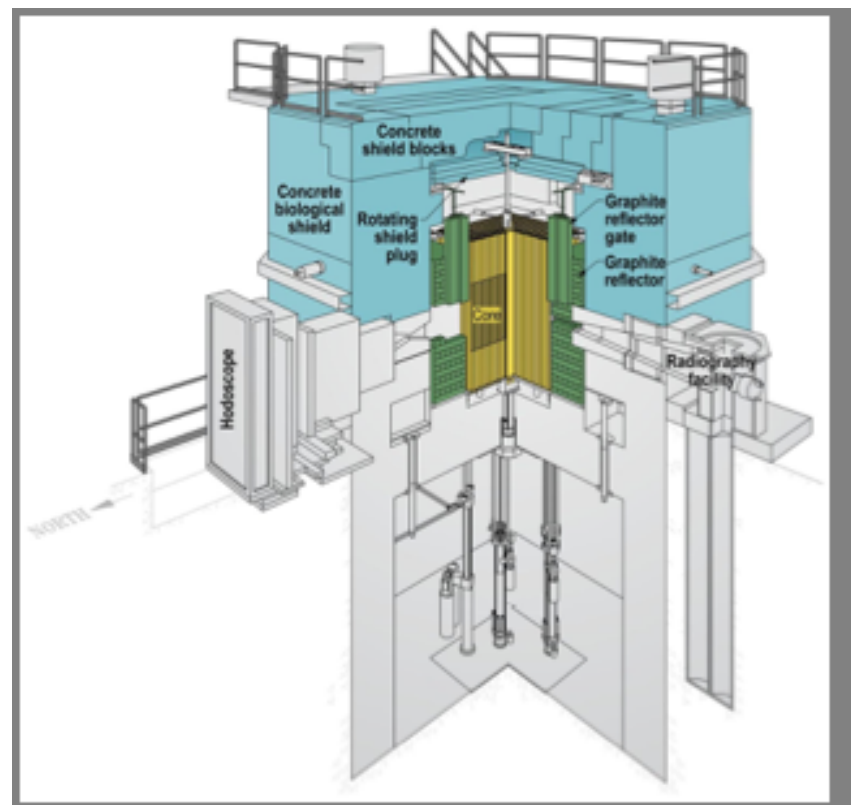

Figure C-14. Cutaway sketch of the TREAT reactor illustrating core configuration and accessibility to the core for emplacement of experiment vehicles. 


\section{C-5.1 Advanced Flowing Vehicle Loops}

Design and development of advanced flowing loop transient test experiment vehicles is underway to provide the extreme environment needed to simulate actual reactor transient conditions. The loops will be capable of providing flowing liquid metal reactor conditions, Boiling Water Reactor (BWR) conditions, and Pressurized Water Reactor (PWR) conditions. These vehicles will provide the conditions needed for fuel qualification testing.

\section{C-5.2 HFEF Transient Testing Infrastructure}

Transient testing of irradiated fuel requires a station to assemble highly irradiated fuel into an experiment assembly prior to transport to TREAT. Interpreting results of transient testing requires the capability to disassemble TREAT test vehicles, extract the fuel, and introduce it into the HFEF PIE line. Preparing, operating, and dispositioning test loops with appreciable quantities of contaminated sodium and pressurized water is a key part of DOE's transient testing capability. A description of the transient testing PIE capability needed to support basic and complex transient testing is provided in an INL engineering document. ${ }^{\mathrm{w}}$

\section{C-5.3 Test Rod Instrument Application}

A shielded experiment handling cell, (named the Experiment Preparation and Inspection Cell, or EPIC) preferably collocated at the TREAT facility, is needed for applying instrumentation to re-fabricated LWR fuel rods. EPIC would include the capability to install instrument sensors onto test rods refabricated from shortened pre-irradiated LWR fuel rods (and perhaps fast reactor test rods at some time in the future). The refabrication effort will be performed at HFEF and the process will complete with instrument installation performed at the collocated facility at TREAT. Both these capabilities will provide functions necessary for ATR and TREAT to backfill the Halden Test Reactor, which was recently shut down. The facility that could be used to house the instrument installation capability is the TREAT Experiment Support Building (TESB), a repurposed TREAT warehouse, which will undergo facility upgrades to house TREAT test train assembly and low-activity experiment disassembly and examination and to prepare for potential installation of EPIC.

\section{C-5.4 Narrow Pulse Width for Prototypic LWR Transients}

Power pulse widths, defined as the full width at half maximum (FWHM) of time-dependent reactor fuel power, of Reactivity Insertion Accidents (RIAs) for pressurized water reactors (PWR) are in the range of 25-65 ms. The pulse width for boiling water reactors is on the order of 45-75 ms. TREAT's minimum pulse width demonstrated in FY-18 is 89 ms. For TREAT to more accurately simulate Light Water Reactor (LWR) RIAs, pulse-width narrowing capability is needed for TREAT. The development of poison assemblies is underway for strategic placement in TREAT to change the effective size of the core and shorten the neutron lifetime. This is expected to result in a pulse width around $70 \mathrm{~ms}$, which approaches the pulse width of a BWR RIA. Designing and incorporating a He-3 injection system will shorten the pulse width to as low as $40 \mathrm{~ms}$ making it possible to simulate PWR RIAs.

\section{C-5.5 TREAT Reactor Parameter Measurement Capability}

Development of measurement capability at TREAT is needed to understand and tune the transient parameters needed for successful transient testing. The developed method will provide fast turnaround of data including fission rate, Power Coupling Factor (PCF), and neutron spectrum enabling better customer response. The capability will also allow the measurement of more parameters to feed advanced modeling and simulation of the TREAT reactor enabling better and faster design of transient experiments.

w. K. Davies, "Evaluation of HFEF capability to Support TREAT Restart," TEV-3093, November 7, 2017. 


\section{C-5.6 Advanced In-Pile and In-Experiment Instrumentation}

Instrumentation is under development and being tested to provide real time transient parameter measurements. The instrumentation, including Linear Variable Differential Transformers (LVDT), MicroPocket Fission Detectors (MPFD), Infrared (IR) pyrometers, boiling water detectors, Self Powered Neutron Detectors (SPND), Self Powered Gamma Detectors (SPGD), and advanced thermocouples, is designed with the form factor to be able to be included in the very limited space of the transient test vehicles as well as the cooling channels of TREAT. The real time data will not only provide experiment and reactor conditions for experimenters, but will also feed into improving the advanced modeling and simulation efforts to model 3D kinetics of reactors.

\section{C-5.7 Fuel Motion Monitoring System}

A key nondestructive examination system at TREAT is the Fuel Motion Monitoring System, also called the Hodoscope. The Hodoscope is a fast-neutron detection and imaging system mounted at the reactor's north beam port that provides real-time information about the location, deformation, and relocation of experimental fuels held within test devices during high-power transient events. This information is used to assess fuel behavior during a transient and to assess implications and consequences of fuel failures. The system currently incorporates about a hundred channels of the possible 360 channels of data operated in parallel and is capable of recording movement at sub-millisecond timescales over a large field of view. The additional detectors needed to fill the full 360 channel capacity are currently being prepared, but installation has been deferred due to limited available funds. It is capable of simultaneously imaging an entire advanced-reactor fuel assembly. However, individual image pixels within the hodoscope are coarse and are not optimized for studies of small-scale effects in single fuel pins, such as the quantification of minor axial fuel swelling or fuel-clad bowing. New investments are needed to design and develop a new FMMS optimized for the measurement and analysis of smaller-scale phenomena in single pins, with higher image-plane spatial resolution, higher signal rates, and better signal-to-noise performance than the current hodoscope.

\section{C-5.8 Neutron Radiography}

Neutron radiography capability is collocated at TREAT providing in-process, non-destructive irradiation examination capability for experiment campaigns of multiple planned transients including multiple specimen irradiations. With simple movement of a test vehicle from the TREAT core to the adjacent neutron radiography stand, neutron images of the experiment configuration inside the vehicle can be obtained for assessing experiment effects and determining the next steps for an experiment (e.g., whether to expose an unfailed fuel specimen to another transient to determine failure thresholds). The inprocess radiography can provide data for tuning the subsequent transients in the irradiation campaign without waiting for detailed Post Irradiation Examination (PIE). The current neutron radiography capability is able to identify initial test configuration pre-irradiation and test configuration and fuel disruption post- irradiation. The resolution is adequate to potentially see major fuel cladding deformation. Radiograph processing capability was recently updated to digital format, and further digital improvements are possible. The development of a new collimator is under way to increase the resolution of the system to better inform experiment campaigns though TREAT radiographs will not approach the capabilities of NRAD. NRAD will still be used for high-resolution neutron radiography.

\section{C-6. NUCLEAR NONPROLIFERATION AND NUCLEAR FORENSICS}

For nuclear power to continue to be a viable energy option in any country, including the United States, nuclear security, material protection control and accountancy, and safeguards must be maintained at a high level. A key approach to increasing the proliferation resistance of nuclear facilities and processes is the development of improved technologies to track and account for fissile material in nuclear systems. By making a nuclear system more transparent for material accountancy and process monitoring, it 
becomes easier to safeguard and improve proliferation resistance. These technologies cover the full spectrum of the nuclear fuel cycle, including uranium enrichment, fuel fabrication, reactor operations, fuel recycling, used fuel storage, transportation, and disposal. Safeguards technologies and integrated systems must be developed for current and potential future domestic and international fuel cycle options. INL researchers from the nuclear nonproliferation directorate are currently leading research activities in the following areas:

- Study and development of new approaches and methodologies for addressing nuclear cyber security threats at nuclear reactors and facilities

- Understanding how safeguards- by-design approaches can and should be applied for small modular reactors

- Invention of wholly new methods for safeguarding pyroprocessing technology

- Development of new instruments for assaying the uranium and plutonium content of advanced LWR fuels for current generation nuclear reactors; Non-destructive assay techniques, both passive and active, are desired to determine ingoing spent-fuel inventories to head-end fuel processing techniques, and residual fuel hold-up in waste streams, such as residual fuel in cladding

- Applying predictive algorithms integrated with process models and measurements to assess SNM the magnitude of SNM processing, or deviations from declared operations and inventories

- In partnership with NE programs develop engineering-scale demonstration facilities that are designed to test advanced process monitoring instrumentation for nuclear safeguards and accountability, and remote monitoring technologies and prediction algorithms to detect and assess the magnitude of undeclared nuclear fuel processing or conversion activities

- Offering world-class training courses for domestic and international students to learn about the nuclear fuel cycle and methods and best practices for safeguards

- Expand the use of INL's demonstration facilities to training the next generation of nuclear and chemical engineers, chemists and nuclear physicists.

These activities include work funded by multiple U.S. government agencies and involve partnerships with other U.S. national laboratories, foreign national laboratories, universities, the IAEA, and companies, including small businesses, large businesses, and a potential small modular reactor vendor.

The need for adaptive approaches to the physical and cyber security of nuclear facilities is needed in conjunction with the development of instruments and methods to support safeguards and material accountancy. MFC (and other fuel-cycle facilities at INL, including ATR and INTEC) presents unique capabilities for performing R\&D in these areas.

Because of INL's legacy activities related to nuclear energy R\&D and its current hands-on experimental activities related to handling nuclear and radiological materials, the laboratory also plays a key role in support of important U.S. National Technical Nuclear Forensics programmatic activities. The programmatic mission is supporting the development of test and measurement standards and materials for the nuclear forensics community. This work takes advantage of many facilities at MFC, including AL, Radiochemistry Laboratory (RCL), EFF, FASB, FCF, FMF, HFEF, and the ZPPR. INL work in this area also strongly leverages the MFC workforce and the cadre of uniquely trained personnel with key skills related to handling and safely working with radioactive and nuclear materials.

\section{C-6.1 Nuclear Nonproliferation and Nuclear Forensics Research, Development, and Demonstration Focus Areas}

New challenges are evolving in the area of nuclear nonproliferation and nuclear forensics research due to the continued spread of nuclear technology throughout the world, the international expansion of nuclear energy, changes in the nature of physical threats against nuclear facilities and materials, and the 
constantly changing nature of cyber threats. Specific scientific challenges exist in relation to understanding and characterizing the materials and processes taking place in nuclear facilities, especially hot cells; working with complicated actinide-bearing materials to perform uranium and plutonium accountancy; developing methods and protocols for understanding current cyber security vulnerabilities at nuclear facilities and predicting future threat pathways and how they might develop at these facilities; and developing faster and more sensitive analytical methods for nuclear forensics. Examples in these areas include the following:

- Developing assay methods for quantifying uranium and plutonium in traditional and non-traditional matrices containing higher-order actinides. Examples in this category include the need for the ability to assay plutonium in advanced transmutation fuels and the need to assay U-235 in advanced LWR fuel assemblies containing high levels of burnable gadolinium (and potentially hafnium) poisons.

- Developing real-time measurement methods for quantifying plutonium within hot cells.

- Developing advanced process monitoring approaches for monitoring activities within hot cells.

- Developing real-time process monitoring methods for assaying electrorefiner salts to quantify plutonium concentration and total mass.

- Developing advanced safeguards methods for characterizing and monitoring plutonium and uranium within used nuclear fuel stored in cooling ponds and dry-cask storage containers.

- Developing advanced detection methods for characterizing and monitoring the transportation of plutonium, uranium and spent fuel between irradiation facilities, used nuclear fuel storage cooling ponds, dry-cask storage containers and fuel processing facilities.

- Developing approaches to improve the physical security of nuclear facilities and developing methods to assess the performance of these approaches.

- Developing approaches to improve the cyber security of nuclear facilities and developing methods to assess the performance of these approaches.

- Improving our understanding of the physical and chemical characteristics of radiological and nuclear materials found throughout the nuclear fuel cycle, the radiation signatures emitted from materials, and using this information to support nuclear forensics.

\section{C-6.2 Nuclear Nonproliferation Research, Demonstration, and Development Goals}

Many advanced fuel cycle processes (such as advanced aqueous reprocessing, electrochemical separations, and recycled fuel fabrication) pose new challenges for safeguards and nuclear material management. Similarly, new small modular reactor designs require comprehensive safeguards-by-design evaluations to ensure they can economically and practically meet international safeguards implementation requirements. Early integration of safeguards concepts into nuclear facility design (i.e., the safeguards-bydesign concept [developed at INL]) is optimal for meeting U.S. and international standards with a minimal impact on operations. This requires developing a solid understanding about how nuclear facilities are built and operated together with support for development of advanced technology so that it is ready for deployment during the design process. State-of-the-art will be advanced through a developmental program to improve the precision, speed, sampling methods, scope of nuclear process monitoring and accountancy measurements, and innovative approaches for containment and surveillance.

Multiple opportunities exist for INL to take advantage of the unique, diverse special nuclear materials inventoried at MFC to facilitate this research. Similarly, the nuclear facilities operated at MFC present fertile testing grounds for developing and evaluating new technologies across the spectrum of nuclear security R\&D. For INL to fully realize the DOE-NE goals to understand and minimize the risks of nuclear proliferation and terrorism, continued progress must be made to integrate nuclear nonproliferation and 
nuclear forensics activities into nuclear fuel, fuel recycling, and focused basic research activities at MFC. Projected developments and R\&D activities at AL, EFF, HFEF, IMCL, FCF, FMF, RCL, SPL, and ZPPR all provide opportunities for future nuclear nonproliferation and nuclear forensics programmatic activities.

Potential growth areas include the following:

- Domestic and international safeguards and emergency response research, development, and training focused on developing and testing instruments and methods for safeguarding current LWRs and training for nuclear nonproliferation and international safeguards inspectors

- Safeguards by design outreach activities at INL, including ongoing engagement with a leading small modular reactor developer

- Development of actinide radiochemistry methods in support of INL's expanding nuclear forensics $R \& D$ activities.

\section{C-7. SPACE NUCLEAR POWER AND ISOTOPE TECHNOLOGIES}

\section{C-7.1 Space Nuclear Power}

Production of RPS has been an ongoing endeavor for DOE and its predecessor agencies for the past five decades. The overall mission of the RPS Program is to develop, demonstrate, and deliver compact, safe nuclear power systems and related technologies for use in remote, harsh environments (such as space), where it is impractical to provide the fuel and maintenance that more conventional electrical power sources require. This program was moved from the DOE Mound facility in Ohio to INL in 2002 due to security concerns after the 2001 terrorist events. Space nuclear power assets at MFC provide unique U.S. capability for assembly, testing, servicing, storage, transport, and ground support operations for RPS used in space and terrestrial missions. Space Nuclear Power and Isotope Technologies personnel provide turn-key services to support these capabilities, including establishment and management of temporary nuclear facilities at RPS launch or other user locations to meet DOE nuclear safety requirements.

\section{C-7.2 Isotope Technologies}

The production and distribution of isotopes for use in medical, industrial, and scientific endeavors, along with research and development to support this, is the primary focus for the Isotope Program of the Office of Nuclear Physics in the DOE Office of Science (DOE-SC). One exception is for the isotope $\mathrm{Pu}-238$ which by mutual agreement is administered by the DOE-NE Nuclear Facilities Infrastructure Program. Both of these DOE programs work through the national laboratory systems and affiliate partners to provide these isotope services. The Idaho National Laboratory (INL) currently is engaged with both DOE providers of isotopes (DOE-SC and DOE-NE).

\section{C-7.2.1 Pu-238}

The recent efforts of DOE-NE to re-establish domestic production of $\mathrm{Pu}-238$ for use in power systems for use by the National Aeronautics and Space Administration (NASA) have been supported by the INL in several ways. The INL houses essentially all of the United States store of neptunium-237 (Np-237), which is the precursor target material required to make Pu-238. The INL also operates the Advanced Test Reactor (ATR), which will be used along with the High Flux Isotope Reactor (HFIR) at Oak Ridge National Laboratory (ORNL) to produce $\mathrm{Pu}-238$ from the Np-237 target material. The role of the INL is to supply Np-237 to ORNL to fabricate targets for both reactors. The INL will also provide irradiation services in ATR and ship irradiated targets to ORNL for processing into purified $\mathrm{Pu} 238$.

To better serve this mission, INL staff are currently investigating approaches to accelerate and increase $\mathrm{Pu}-238$ production from ATR irradiations. DOE-NE and NASA managers have recently indicated a need for accelerated production to reduce risk to continued space exploration missions, which 
relies on the availability of this isotope. Initial, short-term efforts include scoping and trade studies to assess production potential from each of the types of ATR irradiation positions, considering neutronic, thermal and structural factors that impact production rates. In the longer term, slight variations in the ATR target pellet or capsule design could be considered for additional production improvements and to reduce the thermal limitations; such changes could include smaller diameter pellets, target length (longer or shorter), addition of spacer pellets, increasing neptunium oxide loading, etc.

\section{C-7.2.2 Cobalt-60}

Current DOE-SC isotope production activities at INL entail irradiation of Co-59 targets in ATR to produce Co-60. This program is also performed in conjunction with ORNL. ORNL led the target design effort and fabricated the latest target type in 2014-2015, of which 67 targets are currently being irradiated in ATR. These are planned for discharge beginning in summer 2019 through approximately 2022. There are currently no subsequent contracts for additional cobalt targets (beyond the 67) to be irradiated. However, some new end-user customers for various specific activities of Co-60 have recently been identified and negotiations have begun with the Isotope Business Office, operated by DOE-SC.

\section{C-8. RADIOANALYTICAL CHEMISTRY}

The radioanalytical chemistry competency at MFC underpins several of MFC's other core competencies, providing expertise and resources to perform

- chemical and isotopic characterization that includes shielded cells for chemical analysis,

- state-of-the-art methods for analysis of fuels and materials up to Hazard Category 3 limits,

- transuranic (TRU) thermophysical property measurements, and

- development of bench-scale methods for aqueous reprocessing technology.

Radioanalytical chemistry capabilities are embedded primarily within the Analytical Research Laboratories Division, whose strategic objectives are to

1. Conduct analytical chemistry on nuclear fuels and materials in support of INL research programs and outside customers including advanced nuclear fuel design, nuclear waste management, and nuclear nonproliferation

2. Conduct analytical chemistry on environmental samples for regulatory compliance

3. Provide data analyses on samples that meet or exceed the requirements of the customer

4. Develop cutting edge chemical methods to meet the growing analytical challenges of the nuclear fuels community

5. Provide modern instrumentation and subject-matter expertise for analyses in the areas of radionuclide separations, mass spectrometry, elemental analysis, and radio-analytical measurement (counting)

6. Foster development of scientific and operational talent.

As was the case for development of EBR-II and the Integral Fast Reactor (and for nearly every other RD\&D program activity at the MFC site), pilot-scale development of advanced reactor technology as part of the nuclear test bed will require comprehensive and flexible analytical chemistry capability.

\section{C-9. FOCUSED BASIC RESEARCH}

Focused basic research sets the stage for advances in technology through revolutionary advances in the fundamental understanding of the underlying physics and chemistry of material behavior in the nuclear environment. Effectively exploring the fundamental behavior of actinide elements requires that capabilities for the study of actinide materials be made available to a broad spectrum of the nuclear science and physics research community through NSUF or other collaborations (Figure C-15). 


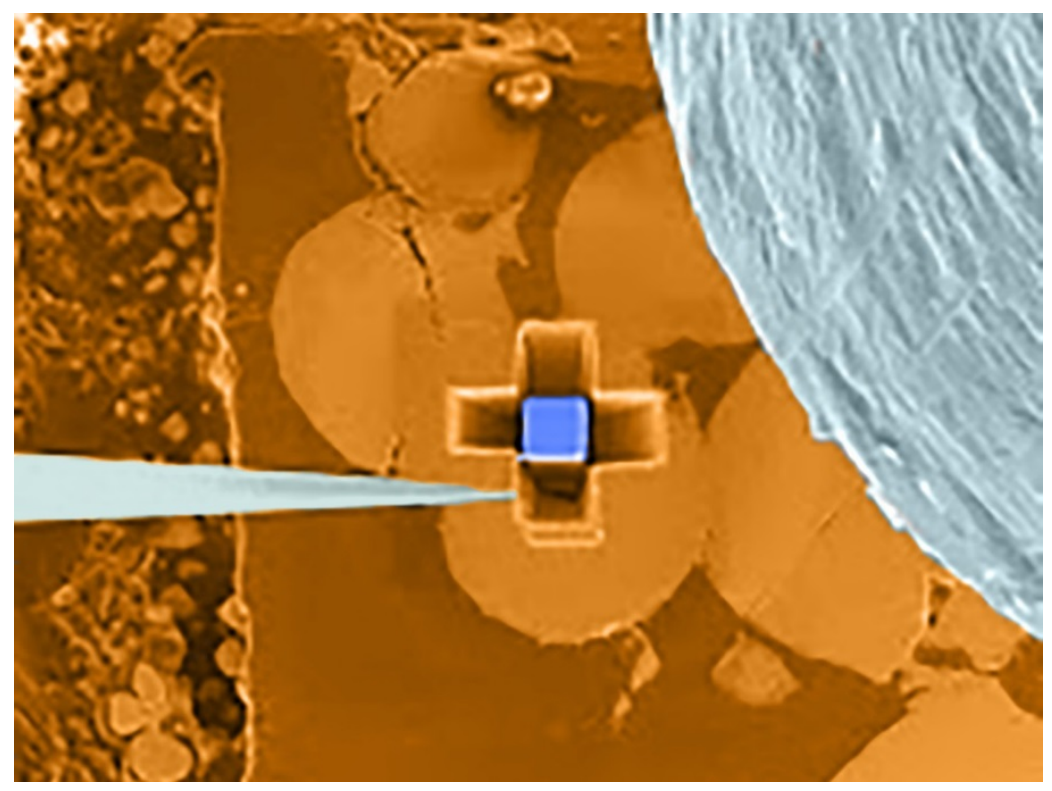

Figure C-15. INL researchers have demonstrated a new sample preparation technique that makes it easier to examine irradiated fuel at the nanoscale. The new technique uses an ion beam to mill material sections that are just tens of nanometers thick. A platinum layer (i.e., the blue square) protects the surface and an Omniprobe needle (i.e., gray) is used to lift the tiny sample. After preparation, the sample has low radiological activity and can be used for a variety of characterization activities that probe fundamental properties

\section{C-9.1 Basic Research Challenges}

Basic research priorities supporting an advanced nuclear energy system have been identified by DOE's Office of Science through a series of workshops on nuclear energy and related topics. Research priorities identified in a 2006 workshop, Basic Research Needs for Advanced Nuclear Energy Systems, ${ }^{\mathrm{x}}$ include the following:

- Nanoscale design of materials and interfaces that radically extend performance limits in extreme radiation environments

- Physics and chemistry of actinide-bearing materials and the 5f-electron challenge

- Microstructure and property stability under extreme conditions

- Mastering actinide and fission product chemistry under all chemical conditions

- Exploiting organization to achieve selectivity at multiple length scales

- Adaptive material environment interfaces for extreme chemical conditions

- Fundamental effects of radiation and radiolysis in chemical processes

- Fundamental thermodynamics and kinetic processes in multi-component systems for fuel fabrication and performance

- Predictive multiscale modeling of materials and chemical phenomena in multi-component systems under extreme conditions.

x. "Basic Research Needs for Advanced Energy Systems," Report of the Basic Energy Sciences Workshop on Basic Research Needs for Advanced Nuclear Energy Systems, Office of Basic Energy Sciences, U.S. Department of Energy (2006). 
A Basic Energy Sciences workshop ${ }^{y}$ on the broader topic of Materials in Extreme Environments identified the topic of Design of Materials with Revolutionary Tolerance to Extreme Photon and Particle Fluxes as a priority research direction, including the following three primary challenges:

1. Understanding the fundamental origins of the performance limits of materials under high flux environments

2. Understanding material response over the full range of time and length scales, from defect creation by atomic ionization or displacement in attoseconds or femtoseconds, to defect migration and assembly into large clusters over microseconds, and to macroscopic degradation of performance and eventual failure over years or millennia

3. Developing defect-free, defect-tolerant, or self-repairing materials for application in high flux environments.

In 2017, the DOE's Office of Basic Energy Sciences directly addressed nuclear research needs through a Basic Research Needs workshop on Future Nuclear Energy-Inspiring Science at the Extremes of Chemistry and Materials. ${ }^{\mathrm{z}}$
[Advanced Nuclear Reactors] demand the discovery and design of revolutionary new materials and fuels, coupled with innovative approaches to materials synthesis and processing and optimization of the performance and certification of the new components. Combining modeling and simulation with in situ characterization methods will reveal and predict processes that dictate performance and degradation under extreme operational conditions... New computational tools and data analytics will expedite the identification of chemical compositions and structures of materials with tailored properties required to withstand the harshest reactor environments, followed by innovative synthesis and processing capabilities for materials production.

This workshop identified five priority research needs directly applicable to nuclear energy:

1. Enable design of revolutionary molten salt coolants and liquid fuels

2. Master the hierarchy of materials design and synthesis for complex, reactor environments

3. Tailor interfaces to control the impact of nuclear environments

4. Reveal multiscale evolution of spatial and temporal processes for coupled extreme environments

5. Identify and control unexpected behaviors from rare events and cascading processes.

MFC capabilities and expertise extend to the areas that are highlighted above, primarily through the use of advanced microstructural characterization, property measurement tools, and radiochemistry.

Figure C-16 shows fuel areas at a fission density of $1.1 \times 10^{22} \mathrm{f} / \mathrm{cm}^{3}$. In low-enriched uranium fuel, all U-235 is consumed at $7.8 \times 10^{21} \mathrm{f} / \mathrm{cm}^{3}$. The fission gas bubble superlattice remains in some areas, along with a high concentration of small bubbles in the U-Mo matrix that remains at this burnup. The surprising stability of this fission gas structure spurred interest from Basic Energy Sciences, who requested a proposal to further investigate the formation and stability of this structure.

y. "Basic Research Needs for Materials under Extreme Environments," Report of the Basic Energy Sciences Workshop for Materials under Extreme Environments, Office of Basic Energy Sciences Department of Energy (February 2008).

z. "Basic Research Needs for Future Nuclear Energy," Report from the Basic Research Needs for Future Nuclear Energy Workshop, U.S. Department of Energy, Office of Science (2017). 


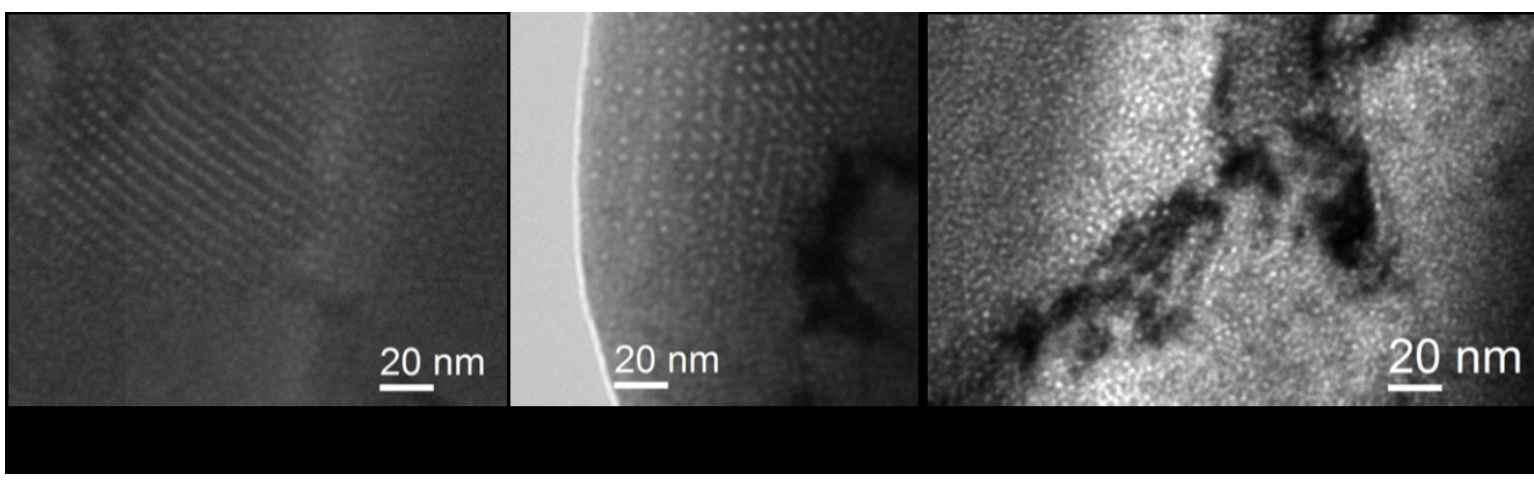

Figure C-16. Examination using transmission electron microscopy shows that the unusual fission gas bubble superlattice that forms in U-Mo fuel during irradiation and is retained to ultra-high burnup.

MFC's significant inventory of actinide materials and capability to handle and process significant quantities of these materials in research user facilities, along with a sizable inventory of the actinide materials required for research, will lead to expansion of capabilities for investigating the fundamental properties and underlying physics of $5 \mathrm{f}$ electron materials.

\section{C-9.2 Focused Basic Research Goals}

Basic research that supports longer-term goals for improved nuclear fuel is focused on understanding nuclear fuel degradation processes and the physical properties of actinide-bearing materials. This understanding enables the ability to design fuel materials with improved burnup potential.

\section{C-9.2.1 Fundamental Behavior of Nuclear Fuel Under Irradiation}

The in-service behavior of nuclear fuels is complex and unlike any other material system. Massive electronic energy deposition from fission fragments into the fuel matrix leads to material changes including initial in-pile densification followed by volumetric swelling; grain refinement and growth; composition (actinide) redistribution across the pellet diameter; restructuring into nanoscale grains at the fuel pellet periphery; and large compositional changes due to fission reactions that lead to dissolved metallic fission products, metallic and oxide fission products in the form of nanoscale precipitates, and bubbles of insoluble gas.

The damage mechanisms and microstructural evolution in fuels is very different and much more complex than for the neutron interactions with non-fissile materials. Although nuclear fuels have been in use for more than six decades, this complex behavior is not well understood, making the rational design of improved nuclear fuels nearly impossible. Achieving major increases in performance requires a more complete understanding of fission-induced phenomena from the initial energy deposition and defect production, long-term microstructural evolution, and fission gas behavior.

Achieving a mechanistic understanding of fission fragment energy deposition in fuel matrices is an important fundamental research field. One of the main unsolved questions is the spread of the deposited energy as a function of space and time and its conversion into atomic motion in the target material. An important research area is the understanding of the thresholds for persistent damage (fission tracks), a direct indicator of the radiation response of fuel materials. Fission fragment 'damage', in some cases, can be used to shape fuel response in a positive manner through changes in crystal structure and re-solution of second phase precipitates and fission gas bubbles. This research area requires careful irradiation in reactor or through the use of swift heavy ion sources to low fission densities. Characterization of the discrete fission tracks produced is used along with multiscale methods developed to simulate individual fission events to provide the information required to understand irradiation response. The TREAT reactor provides an ideal vehicle for this testing. 
The link between specific microstructure changes and the nature of fission-induced damage is complex and constantly evolving during irradiation. In some cases, rapid degradation of properties and behavior occurs; in others annealing of preexisting damage or formation of new structures leads to improved properties. These effects are dependent on numerous material-specific factors, including free electron density, electron-phonon coupling, and the starting microstructural state. Early experiments show that material response can be controlled using tailored electronic states, solid state chemistry, precipitate structure, crystal structure, and physical properties, allowing stabilization of non-equilibrium crystal structures, control of grain size and crystallinity, and development of fine precipitate structures that act as fission gas nucleation sites. Control of these microstructural features determines resilience to radiation damage. Effective research in this area requires the use of higher flux reactors such as ATR to expose a matrix of materials designed for radiation tolerance to the fission environment, followed by determination of macroscopic response and microstructural analysis; again, linked to modeling of microstructural evolution that includes the damage source term.

The behavior of the noble fission gases xenon and krypton in nuclear fuel is of critical importance, and ultimately limits the usable life of nuclear fuel. The diffusion, nucleation, growth, mobility, and resolution of noble gas bubbles influence both the amount of material swelling and the quantity of fission gas released. These behaviors are closely linked to microstructural evolution, but these relationships are not well defined. Fission gas evolution processes have a strong spatial dependence and occur across a range of time scales from the sub-picosecond fission fragment energy deposition process to the $>10^{8} \mathrm{~s}$ fuel operating lifetime. Progress in this area requires in-pile experiments specifically targeted at understanding noble gas behavior and coupling this experimentally derived knowledge to multiscale simulations.

\section{C-9.2.2 Fundamental Properties of Actinide Materials}

The availability of new scientific tools and specialized facilities (IMCL and SPL) at MFC dedicated to nanoscale characterization of fuels and materials and open to the science community lays the groundwork for research leading to resolution of the challenges listed above. At a more fundamental level, the actinides (i.e., $5 \mathrm{f}$ electron elements) defy efforts to understand their unusual properties. These elements are among the most complex and display some of the most unusual behaviors of any series on the periodic table.

At the core of achieving a full understanding of advanced fuel behavior, a solid fundamental understanding of the physical properties of actinide materials, including transport, thermodynamics, and magnetism is required. The unusual thermal behavior of $\mathrm{UO}_{2}$ is an example of the complexity of actinide materials. As a ceramic, thermal transport in $\mathrm{UO}_{2}$ is mainly controlled by phonons. It has recently been suggested $^{\text {aa }}$ that the unusually low thermal conductivity and its unique temperature dependence, which have been a mystery since the beginning of the nuclear era, is related to resonant spin-phonon interactions. These collective phenomena suppress the thermal conductivity and lead to many intriguing transport and thermal behaviors. The majority of the unique properties is related to strong electronic correlations and interplays with complex magneto-phonon interactions, the understanding of which is necessary to describe and predict the physical properties of this material and other actinides.

Exploring the fundamental nature of actinides, especially TRU elements and compounds at this level, requires specialized research tools installed in nuclear research facilities. Measurements performed at cryogenic and moderate $(\leq 800 \mathrm{~K})$ temperatures under extreme conditions such as pressure and magnetic fields provide the richest fundamental information on actinide material behavior because of larger variations in properties with small changes in temperature, less uncertainty, and larger differences in properties for different materials. Characterization of property variations measured with high fidelity allow development of the best predictive modelling capability and the best assurances for validation and

aa. K. Gofryk, S. Du, C. R. Stanek, J. C. Lashley, X.-Y. Liu, R. K. Schulze, J. L. Smith, D. J. Safarik, D. D. Byler, K. J. McClellan, B. P. Uberuaga, B. L. Scott, and D. A. Andersson, 2014, "Anisotropic thermal conductivity in uranium dioxide," Nature Communications 5: 4551. 
verification at all temperatures. On the other hand, changing distances between atoms by amplification of pressure affects the collective vibrational properties and the way phonons interact with other quasiparticles. Transport, thermodynamic, and spectroscopic measurements under pressure can be used to probe coupling between these states. By proving the dependence of thermal transport in actinide materials on the quasiparticle scattering and excitations and on coupling between lattice vibrations and magnetism, work in this area will shed unprecedented light on the physical, especially thermal, properties of these unique materials.

Because actinides are difficult to handle in normal laboratory environments, a Physical Property Measurement System (PPMS, Figure C-17) designed to make the measurements described above will be installed in IMCL. This measurement platform allows a variety of transport and thermodynamic measurements of nuclear materials in wide temperature (near $0 \mathrm{~K}$ ) and magnetic field ranges. A similar system able to perform measurements of minor actinide materials, in conjunction with microstructural characterization, will provide deep insight into the unique properties related to strong electronic correlations and their interplay with complex magneto-phonon interactions. The integration of this technology with microscopic samples produced by FIB will be a key enabling factor for the $5 \mathrm{f}$ physics and chemistry research communities. Efforts required to produce high purity actinide materials for research are also under way. The results obtained from research conducted using this capability will provide fundamental understanding of nuclear material properties tied to performance, and fill in missing parameters for advanced modeling and simulations crucial for model validation and development.

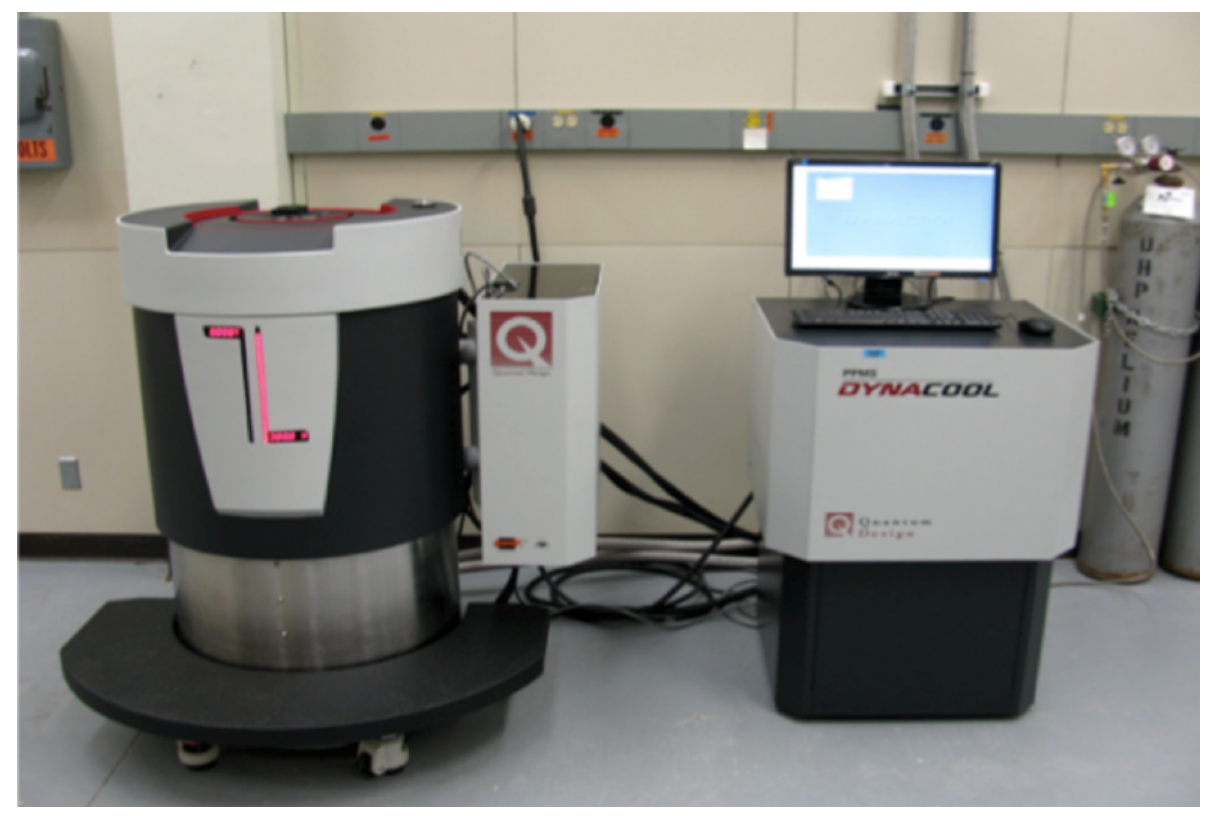

Figure C-17. Physical Property Measurement System (DynaCool-9, currently installed at the INL Idaho Research Center). Availability of this capability in IMCL will result in unique capability for understanding the fundamental properties of the actinides and actinide-bearing ceramics and alloys. 
MFC FIVE-YEAR MISSION STRATEGY

Appendix C

MFC Core Competencies

Page intentionally left blank 
MFC FIVE-YEAR MISSION STRATEGY

Appendix D

Flow Down of INL Strategic Objectives to MFC Critical Outcomes

\section{Appendix D}

\section{Flow Down of INL Strategic Objectives to MFC Critical Outcomes}


MFC FIVE-YEAR MISSION STRATEGY

Appendix D

Flow Down of INL Strategic Objectives to MFC Critical Outcomes

Page intentionally left blank 


\section{Appendix D}

\section{Flow Down of INL Strategic Objectives to MFC Critical Outcomes}

Of the four mission-enabling INL strategic objectives, three are directly applicable to MFC. Table D-1 provides the details of these three INL strategic objectives, and shows how they flow down to the MFC critical outcomes.

Table D-1. INL Strategic Objectives Supported by MFC and Flow down to MFC Critical Outcomes.

\begin{tabular}{|c|c|c|c|c|}
\hline & \multicolumn{3}{|c|}{ Science and Technical Excellence } & Operational Excellence \\
\hline $\begin{array}{l}\text { Strategic } \\
\text { Objectives } \\
\text { Supported by } \\
\text { MFC } \square\end{array}$ & $\begin{array}{l}\text { Sustained and ex } \\
\text { leadership to adv } \\
\text { energy future and } \\
\text { contribution of n } \\
\text { nation's energy } n\end{array}$ & $\begin{array}{l}\text { panded nuclear energy } \\
\text { ance a low-carbon } \\
\text { increase the } \\
\text { uclear energy to the } \\
\text { nix }\end{array}$ & $\begin{array}{l}\text { Increased performance and } \\
\text { economic competitiveness } \\
\text { of materials for extreme } \\
\text { environments, including } \\
\text { advanced energy-generation } \\
\text { and management systems, } \\
\text { and space and defense } \\
\text { systems }\end{array}$ & $\begin{array}{l}\text { Achieve excellence in } \\
\text { Laboratory operations } \\
\text { and enable modern } \\
\text { science by transforming } \\
\text { INL infrastructure, } \\
\text { capabilities, systems, } \\
\text { and processes }\end{array}$ \\
\hline $\begin{array}{l}\text { S\&T } \\
\text { Initiatives } \\
\text { Supported by } \\
\text { MFC } \square \\
\end{array}$ & $\begin{array}{l}\text { Nuclear reactor } \\
\text { sustainment and } \\
\text { expanded } \\
\text { deployment } \\
\end{array}$ & $\begin{array}{l}\text { Integrated fuel cycle } \\
\text { solutions }\end{array}$ & $\begin{array}{l}\text { Advanced materials and } \\
\text { manufacturing for extreme } \\
\text { environments }\end{array}$ & - \\
\hline $\begin{array}{l}\text { Pillars (S \& T } \\
\text { Initiatives)/ } \\
\text { Operations } \\
\text { Initiatives } \\
\text { (Operational } \\
\text { Excellence) }\end{array}$ & $\begin{array}{l}\text { 1.Strengthen the } \\
\text { domestic } \\
\text { commercial } \\
\text { nuclear energy } \\
\text { enterprise } \\
\text { Improve } \\
\text { economic } \\
\text { performance } \\
\text { Expand revenue } \\
\text { Improve } \\
\text { operations and } \\
\text { sustainability } \\
\text { 2.Enable U.S. } \\
\text { technological } \\
\text { leadership in } \\
\text { global nuclear } \\
\text { energy markets } \\
\text { Demonstration } \\
\text { and testing of } \\
\text { advanced } \\
\text { reactors } \\
\text { Innovative } \\
\text { nuclear reactor } \\
\text { and systems } \\
\text { design } \\
\text { Innovative } \\
\text { nuclear fuels } \\
\text { and materials }\end{array}$ & $\begin{array}{l}\text { 1.Availability of } \\
\text { special nuclear } \\
\text { material (SNM) } \\
\text { Support development } \\
\text { and deployment of the } \\
\text { U.S. high-assay, low- } \\
\text { enriched uranium } \\
\text { (HALEU) fuel cycle } \\
\text { infrastructure } \\
\text { Support development } \\
\text { of HALEU materials } \\
\text { transportation } \\
\text { infrastructure } \\
\text { Assessing alternatives } \\
\text { to uranium-235 } \\
\text { 2.Management of } \\
\text { radiological waste } \\
\text { materials } \\
\text { Deploy S\&T to } \\
\text { develop waste } \\
\text { management options } \\
\text { 3.Proliferation risk } \\
\text { reduction } \\
\text { Demonstrate direct } \\
\text { immobilization of } \\
\text { used nuclear fuel } \\
\text { (UNF) } \\
\text { Demonstrate } \\
\text { simplified UNF }\end{array}$ & $\begin{array}{l}\text { 1.Process discovery and } \\
\text { development } \\
\text { Develop process-informed, } \\
\text { multiscale, design-driven } \\
\text { manufacturing for extreme } \\
\text { environments including: } \\
\text { Nuclear-reactor components } \\
\text { and fuels with revolutionary } \\
\text { performance improvements } \\
\text { and cost competitiveness } \\
\text { Create next generation } \\
\text { survivability materials with } \\
\text { transformational } \\
\text { innovations in advance } \\
\text { material system designs for } \\
\text { defense and intelligence to } \\
\text { function in extreme } \\
\text { environments (dynamic } \\
\text { loading, dissipation of } \\
\text { thermal energies, } \\
\text { radioactive, shock wave } \\
\text { mitigation) } \\
\text { Expand fabrication process } \\
\text { science through the } \\
\text { development of innovative } \\
\text { capabilities, such as spark } \\
\text { plasma sintering (SPS) } \\
\text { 2.Secure digital design and } \\
\text { manufacturing }\end{array}$ & $\begin{array}{l}\text { Transform how we } \\
\text { perform and manage } \\
\text { work } \\
\text { Build INL's future } \\
\text { workforce } \\
\text { Modernize and mature } \\
\text { INL information systems } \\
\text { and services } \\
\text { Optimize cost } \\
\text { management } \\
\text { Sustain, modernize, and } \\
\text { establish new } \\
\text { infrastructure capability } \\
\text { Achieve leadership in } \\
\text { safety to enable cutting- } \\
\text { edge S\&T } \\
\text { Advance INL's } \\
\text { stewardship of its } \\
\text { environmental legacy } \\
\text { Advance INL's security }\end{array}$ \\
\hline
\end{tabular}




\begin{tabular}{|c|c|c|c|c|}
\hline & \multicolumn{3}{|c|}{ Science and Technical Excellence } & Operational Excellence \\
\hline & $\begin{array}{l}\text { International } \\
\text { leadership in } \\
\text { scientific } \\
\text { frontiers } \\
\text { 3. Expand and } \\
\text { deploy National } \\
\text { nuclear energy } \\
\text { strategic } \\
\text { infrastructures } \\
\text { Deliver world- } \\
\text { class research, } \\
\text { development, } \\
\text { and deployment } \\
\text { (RD\&D) assets } \\
\text { and irradiation } \\
\text { capabilities } \\
\text { Strengthen and } \\
\text { leverage } \\
\text { National } \\
\text { Reactor } \\
\text { Innovation } \\
\text { Center (NRIC) } \\
\text { Enable industry } \\
\text { and academic } \\
\text { innovation }\end{array}$ & $\begin{array}{l}\text { recycling processes } \\
\text { Develop and } \\
\text { demonstrate real-time } \\
\text { interrogation of UNF } \\
\text { treatment processes } \\
\text { 4.Management of } \\
\text { legacy fuels } \\
\text { Understand Al-clad } \\
\text { UNF chemical and } \\
\text { radiolytic behavior } \\
\text { during extended dry } \\
\text { storage } \\
\text { Develop treatment } \\
\text { technologies and } \\
\text { disposition options for } \\
\text { sodium-bonded fuels } \\
\text { Advance retrieval and } \\
\text { treatment technologies } \\
\text { for mixed low-level } \\
\text { waste } \\
\text { Develop ability to } \\
\text { load UNF in DOE } \\
\text { standard canister } \\
5 . R D \& D \text { test beds } \\
\text { Develop RD\&D } \\
\text { testbeds coupling } \\
\text { front-end and back- } \\
\text { ends systems with } \\
\text { advanced safeguards } \\
\text { and security } \\
\text { technologies }\end{array}$ & $\begin{array}{l}\text { Predict manufacturing } \\
\text { process parameters and } \\
\text { determine physical and } \\
\text { performance characteristics } \\
\text { using process-informed } \\
\text { digital design (modeling and } \\
\text { simulation [M\&S] and } \\
\text { artificial intelligence } \\
\text { [AI]/machine learning [ML] } \\
\text { capabilities) } \\
\text { Secure and protect } \\
\text { manufacturing processes } \\
\text { and end applications } \\
\text { through cyber-informed, } \\
\text { autonomous and adaptive } \\
\text { process control and } \\
\text { monitoring systems } \\
\text { architecture } \\
\text { 3.Intensification and scale- } \\
\text { up } \\
\text { Demonstrate traditional } \\
\text { process advancement } \\
\text { through pilot- and } \\
\text { production-scale advanced } \\
\text { materials and manufacturing } \\
\text { testing and through } \\
\text { advanced research in scaling } \\
\text { processes science } \\
\text { Perform testing and } \\
\text { characterization of nuclear } \\
\text { materials and extreme } \\
\text { environments survivability } \\
\text { systems }\end{array}$ & \\
\hline $\begin{array}{l}\text { MFC Critical } \\
\text { Outcome } \\
\end{array}$ & $\begin{array}{l}\text { Applicable } \\
\text { Pillars } \\
\downarrow\end{array}$ & $\begin{array}{l}\text { Applicable Pillars } \\
\downarrow\end{array}$ & $\begin{array}{l}\text { Applicable Pillars } \\
\downarrow\end{array}$ & $\begin{array}{l}\text { Applicable Operations } \\
\text { Initiative } \\
\downarrow\end{array}$ \\
\hline $\begin{array}{l}\text { 1.Enable and } \\
\text { accelerate the } \\
\text { demonstration, } \\
\text { testing... }\end{array}$ & $\begin{array}{l}2 \text { Enable U.S. } \\
\text { technological } \\
\text { leadership in } \\
\text { global nuclear } \\
\text { energy markets } \\
3 \text { Expand and } \\
\text { deploy National } \\
\text { nuclear energy } \\
\text { strategic } \\
\text { infrastructures }\end{array}$ & - & $\begin{array}{l}1 \text { Process discovery and } \\
\text { development }\end{array}$ & - \\
\hline $\begin{array}{l}\text { 2.Fabricate } \\
\text { and supply } \\
\text { innovative } \\
\text { nuclear fuels }\end{array}$ & $\begin{array}{l}2 \text { Enable U.S. } \\
\text { technological } \\
\text { leadership in } \\
\text { global nuclear }\end{array}$ & $\begin{array}{l}1 \text { Availability of } \\
\text { special nuclear } \\
\text { material (SNM) }\end{array}$ & - & - \\
\hline
\end{tabular}


MFC FIVE-YEAR MISSION STRATEGY

Appendix D

Flow Down of INL Strategic Objectives to MFC Critical Outcomes

\begin{tabular}{|l|l|l|l|l|}
\hline & \multicolumn{2}{|c|}{ Science and Technical Excellence } & Operational Excellence \\
\hline$\ldots$ & energy markets & $\begin{array}{l}3 \text { Proliferation risk } \\
\text { reduction } \\
5 \text { RD\&D test beds }\end{array}$ & & \\
\hline
\end{tabular}


MFC FIVE-YEAR MISSION STRATEGY

Appendix D

Flow Down of INL Strategic Objectives to MFC Critical Outcomes

\begin{tabular}{|l|l|l|l|l|}
\hline & \multicolumn{2}{|c|}{ Science and Technical Excellence } & Operational Excellence \\
\hline & & & & \\
& & & & \\
\hline
\end{tabular}


MFC FIVE-YEAR MISSION STRATEGY

Appendix D

Flow Down of INL Strategic Objectives to MFC Critical Outcomes

\begin{tabular}{|c|c|c|c|c|}
\hline & \multicolumn{3}{|c|}{ Science and Technical Excellence } & Operational Excellence \\
\hline $\begin{array}{l}\text { 2.Fabricate } \\
\text { and supply } \\
\text { innovative } \\
\text { nuclear fuels } \\
\text {... }\end{array}$ & $\begin{array}{l}2 \text { Enable U.S. } \\
\text { technological } \\
\text { leadership in } \\
\text { global nuclear } \\
\text { energy markets }\end{array}$ & & & \\
\hline $\begin{array}{l}\text { 3.Perform } \\
\text { irradiation, } \\
\text { analysis and } \\
\text { testing ... }\end{array}$ & $\begin{array}{l}\text { 1Strengthen the } \\
\text { domestic } \\
\text { commercial } \\
\text { nuclear energy } \\
\text { enterprise } \\
2 \text { Enable U.S. } \\
\text { technological } \\
\text { leadership in } \\
\text { global nuclear } \\
\text { energy markets } \\
3 \text { Expand and } \\
\text { deploy National } \\
\text { nuclear energy } \\
\text { strategic } \\
\text { infrastructures }\end{array}$ & - & $\begin{array}{l}1 \text { Process discovery and } \\
\text { development } \\
3 \text { Intensification and scale- } \\
\text { up }\end{array}$ & - \\
\hline $\begin{array}{l}\text { 4.Provide } \\
\text { components } \\
\text { and/or } \\
\text { technology to } \\
\text { meet NASA } \\
\text { objectives... }\end{array}$ & $\begin{array}{l}3 \text { Expand and } \\
\text { deploy National } \\
\text { nuclear energy } \\
\text { strategic } \\
\text { infrastructures }\end{array}$ & - & $\begin{array}{l}3 \text { Intensification and scale- } \\
\text { up }\end{array}$ & - \\
\hline $\begin{array}{l}\text { 5.Fulfill } \\
\text { environmental } \\
\text { stewardship } \\
\text { commitments }\end{array}$ & - & $\begin{array}{l}2 \text { Management of } \\
\text { radiological waste } \\
\text { materials } \\
3 \text { Proliferation risk } \\
\text { reduction } \\
4 \text { Management of } \\
\text { legacy fuels } \\
5 \text { RD\&D test beds }\end{array}$ & - & $\begin{array}{l}7 \text { Advance INL's } \\
\text { stewardship of its } \\
\text { environmental legacy }\end{array}$ \\
\hline
\end{tabular}


MFC FIVE-YEAR MISSION STRATEGY

Appendix D

Flow Down of INL Strategic Objectives to MFC Critical Outcomes

Page intentionally left blank 
MFC FIVE-YEAR MISSION STRATEGY

Appendix $\mathrm{E}$

Acronyms

\section{Appendix E}

\section{Acronyms}


MFC FIVE-YEAR MISSION STRATEGY

Appendix $E$

Acronyms

Page intentionally left blank 


\section{Appendix E}

\section{Acronyms}

ARL MFC Analytical Research Laboratories

ARDP Advanced Reactor Development Program

ATR Advanced Test Reactor

CAES Center for Advanced Energy Studies

DOD Department of Defense

DOE Department of Energy

DOE-EM DOE Office of Environmental Management

DOE-NE DOE Office of Nuclear Energy

DOE-SC DOE Office of Science

EBR-II Experimental Breeder Reactor-II

EES\&T Energy \& Environment Science and Technology (directorate within INL)

EFF Experimental Fuels Facility

EML Electron Microscopy Laboratory

FASB Fuels and Applied Science Building

FAST Fission Accelerated Steady-state Test

FCF Fuel Conditioning Facility

FMF Fuel Manufacturing Facility

FY fiscal year

GAIN Gateway for Accelerated Innovation in Nuclear

HALEU High-Assay Low-Enriched Uranium

HFEF Hot Fuel Examination Facility

IFM Idaho Facilities Management

IMCL Irradiated Materials Characterization Laboratory

INL Idaho National Laboratory

INTEC Idaho Nuclear Technology and Engineering Center

LWR light water reactor

MFC Materials and Fuels Complex (location and directorate within INL) 
MMRTG Multi Mission Radioisotope Thermoelectric Generator

NASA National Aeronautics and Space Administration

NEUP Nuclear Energy University Program

N\&HS National \& Homeland Security (directorate within INL)

NNSA National Nuclear Security Administration

NRIC National Reactor Innovation Center

NS\&T Nuclear Science and Technology (directorate within INL)

NSUF Nuclear Science User Facilities

OMI Operations Management Improvement

ORNL Oak Ridge National Laboratory

PEMP Performance Evaluation and Measurement Plan

PIE Post-Irradiation Examination

R\&D Research and Development

RD\&D Research, Development, and Demonstration

RPS Radioisotope Power System

SCO Strategic Capabilities Office (Department of Defense)

SNF Spent Nuclear Fuel

SPL Sample Preparation Laboratory

S\&T Science and Technology

TREAT Transient Reactor Test Facility

TRIGA Training, Research, Isotope, General Atomics

TRISO TRistructural ISOtropic

TRU TRansUranic

VTR Versatile Test Reactor

ZPPR Zero Power Physics Reactor Facility 